\title{
El consumo de
}

Lycopersicum esculentum podría aumentar lipoproteínas de alta densidad (HDL) y disminuir el estrés oxidativo a corto plazo

\author{
Eva Madrid $A^{1}$, D arío Vásquez $Z^{a}$, Fanny Leyton $A^{a}$, \\ Christian Mandiola ${ }^{2 b}$, Jorge A Escobar $F^{2 c}$. \\ Short-term Lycopersicum esculentum \\ consumption may increase plasma \\ high density lipoproteins and \\ decrease oxidative stress
}

Background: Tomato has a high antioxidant capacity due to its high content of vitamin $\mathrm{C}$, vitamin $\mathrm{E}$ and lycopene that is a powerful free radical scavenger. However, the effects of tomato on plasma lipoproteins is not well known, and there is little evidence about the relationship between tomato consumption and oxidative state changes in humans. Aim: To assess in vivo the effects of dietary supplementation with pure concentrated tomato juice on short term changes in oxidative state and plasma lipoproteins in healthy volunteers. Subjects and methods: Seventeen healthy volunteers were studied. They received a supplement of pure tomato juice during 7 days. At baseline, at the end of the supplementarion period and eight days after the end of the supplementation, a blood sample was drawn to measure total antioxidant capacity (TRAP), enzymatic antioxidants (catalase and superoxide dismutase), non-enzimatic antioxidants (lycopene and $\alpha$-tocopherol) and plasma lipoproteins. Results: Lycopene level increased early and significantly in comparison with basal levels (48\%; $\mathrm{p} \varangle 0.05$ ). TRAP, catalase and superoxide dismutase did not change significantly. HDL cholesterol increased significantly in $5.6 \pm 4.3 \mathrm{mg} / \mathrm{dL}$ ( $\mathrm{p} \varangle 0.002$ ) on the second sampling period, improving the ratio cholesterol/HDL It returned to baseline in the third period. Conclusions: Dietary supplementation of concentrated tomato juice significantly increases lycopene levels and HDL cholesterol. Non significant changes observed in TRAP, catalase and superoxide dismutase were observed during the supplementation period (Rev Méd Chile 2006; 134: 855-62).

(Key words: Free radical scavengers; Lycopersicon esculentum; Lipoproteins)

\begin{abstract}
Recibido el 30 de junio, 2005. Aceptado el 28 de diciembre, 2005.
Declaración de ayuda financiera: Proyecto financiado por Dirección de Proyectos de la Universidad de Valparaíso (DIPUV). Esta institución no tuvo influencia en el diseño del estudio, recolección, análisis o interpretación de los datos, ni en la preparación, revisión o aprobación del manuscrito.

${ }^{1}$ Laboratorio de Morfología, Escuela de Medicina Universidad de Valparaíso. ${ }^{2}$ Instituto de Química, Facultad de Ciencias Básicas y Matemáticas, Pontificia Universidad Católica de Valparaíso.

aEstudiante de Medicina. Escuela de Medicina, Universidad de Valparaíso.

bioquímico

${ }^{\mathrm{c} D}$ Doctor en Ciencias mención en Bioquímica
\end{abstract}

Correspondencia a: Dra. Eva Madrid Arís. Escuela de Medicina, Universidad de Valparaíso. Hontaneda 2653, Valparaíso, Chile. Teléfono: 5632 507356. Fax: 5632 507321. E mail: eva.madrid@uv.cl 
$E^{1}$ estrés oxidativo se define como la pérdida del equilibrio entre la producción de radicales libres y la acción de los sistemas antioxidantes, a favor de los primeros ${ }^{1}$.

Los radicales libres o especies reactivas del oxígeno (ROS) y el daño oxidativo inducido por ellas, han sido implicados en la patogenia de varias enfermedades humanas ${ }^{2,3}$, incluyendo diabetes, formación de placas ateromatosas por oxidación y depósito de lipoproteínas de baja densidad (LDL) y carcinogénesis por genotoxici$\operatorname{dad}^{4-6}$.

Los sistemas antioxidantes que inactivan a radicales libres pueden clasificarse en sistemas enzimáticos de acción intracelular como catalasa (CAT), superóxido dismutasa (SOD) y glutatión peroxidasa $^{7}$ y sistemas no enzimáticos, que son sustancias eliminadoras o secuestradoras de ROS como el $\alpha$-tocoferol (vitamina E), ácido ascórbico, carotenos aportados por la dieta, glutatión y licopeno ${ }^{8-10}$.

Dentro de los agentes antioxidantes no enzimáticos, el licopeno es uno de los antioxidantes más potentes conocido hasta ahora, propiedad dada por su gran capacidad in vitro de secuestrar $\operatorname{ROS}^{11} \mathrm{y}$, en especial, por eliminar el oxígeno singlete ${ }^{5,12,13}$. Es posible encontrarlo en el plasma humano y sus propiedades químicas le confieren una potencial acción preventiva sobre enfermedades cardiovasculares, protegiendo las biomoléculas críticas como los lípidos y las lipoproteínas de baja densidad (LDL). El licopeno también tiene efecto anticarcinogénico, protegiendo las proteínas y el $\mathrm{ADN}^{13,14}$.

La mayor fuente de licopeno de la dieta occidental lo constituye el tomate (lycopersicum esculentum), que incorpora, además del licopeno, otras sustancias antioxidantes como vitamina $C$, $\beta$ caroteno y $\alpha$-tocoferol ${ }^{13}$.

Se han establecido claramente los niveles séricos de licopeno y cómo éstos varían con el consumo de un derivado de tomate. Sin embargo, sus efectos beneficiosos son significativos sólo cuando se incorpora a través del tomate y no aisladamente $^{4,5}$. Esto, debido a que el tomate, además de licopeno, presenta múltiples componentes que, supuestamente, pueden actuar de manera sinérgica como antioxidantes a través de interacciones complejas ${ }^{15,16}$. Estudios observacionales han reportado recientemente la asociación positiva entre consumo de tomate y sus derivados y las concentraciones totales plasmáticas de licopenos y de $\mathrm{HDL}^{17}$.

La mayor parte de la evidencia acumulada se ha hecho en base a estudios efectuados in vitro o retrospectivos, siendo escasos y controversiales los estudios hasta ahora realizados con seres humanos. Toda esta evidencia, y la falta de estudios locales con productos nacionales, nos han llevado a estudiar el potencial antioxidante de tomates provenientes de la zona de Quillota en la Quinta Región de Chile, a través de un análisis de elementos relacionados con las defensas antioxidantes, la producción de radicales libres y lipoproteínas plasmáticas.

\section{Material y MÉTOdo}

Sujetos. Se realizó un estudio experimental longitudinal de medidas repetidas con 20 estudiantes universitarios de Valparaíso, sanos, elegidos al azar, de ambos sexos y de edades que fluctuaron entre los 20 y 25 años. Se aplicó un cuestionario referido a dieta, patologías actuales y previas, consumo de medicamentos, vitaminas, tabaco, alcohol y drogas. Se midieron niveles de presión arterial e índice de masa corporal (IMC). Se excluyeron aquellos individuos que presentaran una o más de las siguientes condiciones: patologías crónicas o agudas, consumo de fármacos o drogas, presión arterial sistólica mayor o igual a $140 \mathrm{mmHg}$ o diastólica mayor o igual a $90 \mathrm{mmHg}$, IMC mayor a 25 ó menor a 20. El protocolo fue aprobado por el Comité de Ética de la Facultad de Medicina de la Universidad de Valparaíso.

Fueron seleccionados 17 voluntarios (9 hombres y 8 mujeres), los que no presentaron diferencias significativas en edad ni en IMC. Luego de ser instruidos respecto al desarrollo del ensayo, ingresaron al protocolo de investigación dando su consentimiento informado. La experiencia duró 16 días seguidos, el primer día se procedió a tomar una primera muestra de sangre venosa, en ayuno, a cada voluntario (que denominamos muestra A), a fin de establecer sus niveles plasmáticos basales de la actividad superóxido dismutasa (SOD) y catalasa sérica (CAT), medir el potencial antioxidante total (TRAP), los niveles de licopeno y alfa tocoferol plasmáticos, y perfil lipídico. Se suminis- 
tró durante 7 días a cada voluntario una dosis de jugo concentrado de tomates (Lycopersicum esculentum solanum), de $4 \mathrm{cc} / \mathrm{kg}$ peso/día a una concentración de 119,9 $\mu \mathrm{M}$ de licopeno, preparados por una industria regional sin aditivos químicos.

Entre el segundo y octavo día, cada voluntario ingirió diariamente el jugo concentrado de tomates, junto con su dieta habitual, con una preparación y un horario aleatorio. Al noveno día, se tomó una segunda muestra de sangre venosa en ayuno (muestra B), para consignar variaciones de niveles plasmáticos de TRAP, licopeno, actividad de SOD, CAT y variaciones en el perfil lipídico. Al decimosexto día, se tomó una tercera muestra de sangre venosa en ayuno (muestra $\mathrm{C}$ ), y se realizaron las mismas mediciones.

Obtención de muestra de sangre. Se obtuvo $10 \mathrm{~mL}$ de sangre venosa periférica; $5 \mathrm{~mL}$ en tubo seco para el análisis lipídico, $5 \mathrm{~mL}$ en tubos con citrato para el análisis de los otros marcadores. Los tubos citratados fueron centrifugados a $2.000 \mathrm{rpm}$, separando plasma de elementos figurados. El plasma fue puesto en un nuevo tubo para una segunda centrifugación. Luego fue fraccionado en muestras de $1 \mathrm{~mL}$ y congeladas a $-80^{\circ} \mathrm{C}$ para su análisis posterior.

Análisis enzimático. CAT: se midió con el método descrito por Aebi ${ }^{18}$.

SOD: se ocupó el método de epinefrinaadenocromo ${ }^{19}$.

TRAP: Corresponde a la cantidad de radicales libres que pueden ser "atrapados" por una muestra con propiedades antioxidantes. Se expresan en equivalentes de TROLOX ${ }^{20}$.

Licopeno y $\alpha$-tocoferol: Se determinaron mediante Cromatografía Líquida de Alta Presión (HPLC). El equipo; una bomba isocrática M 45 (Waters), un detector UV-Visible LaChrom L-7420 (Merck Hitachi), asociado al software CSW 1.7 (DataApex Ltda. 1998). La columna de fase reversa de $(250$ x 4,6 mm, $5 \mathrm{~mm}$, C 18) LiChrospher 100 RP-18 (Merck). La fase móvil, fue una mezcla de metanol y tetrahidrofurano estabilizado con BHT 0,1\% en una proporción de 85:15. Se trabajó a temperatura ambiente con un flujo de $1 \mathrm{~mL} / \mathrm{min}$. Se detectó a una longitud de onda $290 \mathrm{~nm}$.
Licopeno estándar de tomate $90 \%$ a 95\% (Sigma-Aldrich, St. Louis, MO, USA), se preparó en tetrahidrofurano con BHT al 0,1\% en atmósfera de nitrógeno, protegido de la luz y almacenado a -80ํㅡ. El estándar de $\alpha$-tocoferol (Sigma-Aldrich, St. Louis, MO, USA) se almacenó en oscuridad a $80^{\circ} \mathrm{C}$. De la muestra, se tomaron $250 \mathrm{~mL}$ de plasma, se agregaron $500 \mathrm{~mL}$ de metanol, se agitó y agregó $3 \mathrm{~mL}$ de hexano, se agitó vigorosamente y se centrifugó a $1.800 \mathrm{rpm}$ por 8 min. Se separó el hexano, evaporando por sequedad con $\mathrm{N}_{2}$. El producto obtenido se resuspendió en $250 \mathrm{~mL}$ de fase móvil. Las muestras se mantuvieron protegidas de la luz durante todo el proceso de extracción. La detección se realizó mediante kit de detección de licopeno (Sigma-Aldrich, St. Louis, MO, USA).

Análisis de perfil lipídico. El perfil lipídico se determinó en suero con el método CHOD/PAP (Fenol) -GPO/PAP (4 -Clorofenol).

Estadística: Debido al tamaño muestral obtenido y a que los datos no presentaron una distribución normal, se utilizaron pruebas de hipótesis para variables no paramétricas. Análisis de varianza fue usado para enzimas, $\alpha$-tocoferol y licopeno. Wilcoxon Aldrich para análisis de los valores de lipoproteínas. Se usó el software Stata 8.0 (Stata company, USA). Se consideró significativo un valor de $\mathrm{p}$ menor de 0,05 .

\section{RESULTADOS}

Durante la experiencia dos voluntarios abandonaron el protocolo, ambos por intolerancia al jugo concentrado de tomates (dispepsia). Del total de individuos que completaron el protocolo, a tres no se les tomó sangre el día 16 (muestra C) debido al incumplimiento del ayuno.

Los valores promedio de las siete variables de estudio en las tres mediciones temporales (A, B y C) se muestran en la Tablas 1 y 2. Luego de 7 días de suplementación dietaria con jugo concentrado de tomates, el nivel de HDL y de licopeno aumentaron 9,47\% [5,6 mg/dL $(\mathrm{p}=0,002)] \mathrm{y}$ $48,27 \%[0,014 \mu \mathrm{g} / \mathrm{mL}(\mathrm{p}=0,023)]$, respectivamente. Este rápido y significativo efecto se revirtió 
Tabla 1. Promedios de H D L, índice colesterol total/H D L, licopeno y $\alpha$-tocoferol plasmático basal (A) a los siete días de suplementación (B) y siete días después de suspendida la suplementación (C)

\begin{tabular}{|lccc|}
\hline Muestra & A $(\mathrm{n}=15)$ & $\mathrm{B}(\mathrm{n}=15)$ & $\mathrm{C}(\mathrm{n}=12)$ \\
\hline HDL $[\mathrm{mg} / \mathrm{dL}]$ & $59,13 \pm 4,2$ & $64,76 \pm 4,6^{\#}$ & $61,73 \pm 3,5$ \\
CoL/HDL & $3.494 \pm 0,8$ & $3.320 \pm 0,5^{ø}$ & $3.370 \pm 0,4$ \\
Licopeno $[\mu \mathrm{g} / \mathrm{ml}]$ & $0,029 \pm 0,002$ & $0,043 \pm 0,005^{*}$ & $0,021 \pm 0,004$ \\
$\alpha$-tocoferol $[\mu \mathrm{g} / \mathrm{ml}]$ & $418 \pm 56,5$ & $155,4 \pm 59,8^{\circ}$ & $448,4 \pm 64,5$ \\
\hline
\end{tabular}

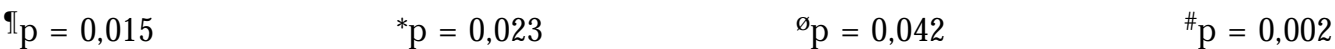

Tabla 2. Actividad promedio (en unidades por miligramo de proteína) de las enzimas superóxido dismutasa (SO D ) catalasa (CAT ) y niveles de capacidad antioxidante total (T RAPS) en plasma basal (A), post siete días de suplementación (B) y post siete días finalizada la suplementación (C). (Valor de $p>0,05$ )

\begin{tabular}{|lccc|}
\hline Muestra & A $(\mathrm{n}=15)$ & $\mathrm{B}(\mathrm{n}=15)$ & $\mathrm{C}(\mathrm{n}=12)$ \\
\hline SOD [UA/mgp] & $0,341 \pm 0,085$ & $0,298 \pm 0,033$ & $0,568 \pm 0,172$ \\
CAT [UA/mgp] & $0,461 \pm 0,06$ & $0,345 \pm 0,092$ & $0,445 \pm 0,27$ \\
TRAPS [equivalente Trolox] & $0,612 \pm 0,17$ & $0,605 \pm 0,08$ & $0,653 \pm 0,22$ \\
\hline
\end{tabular}

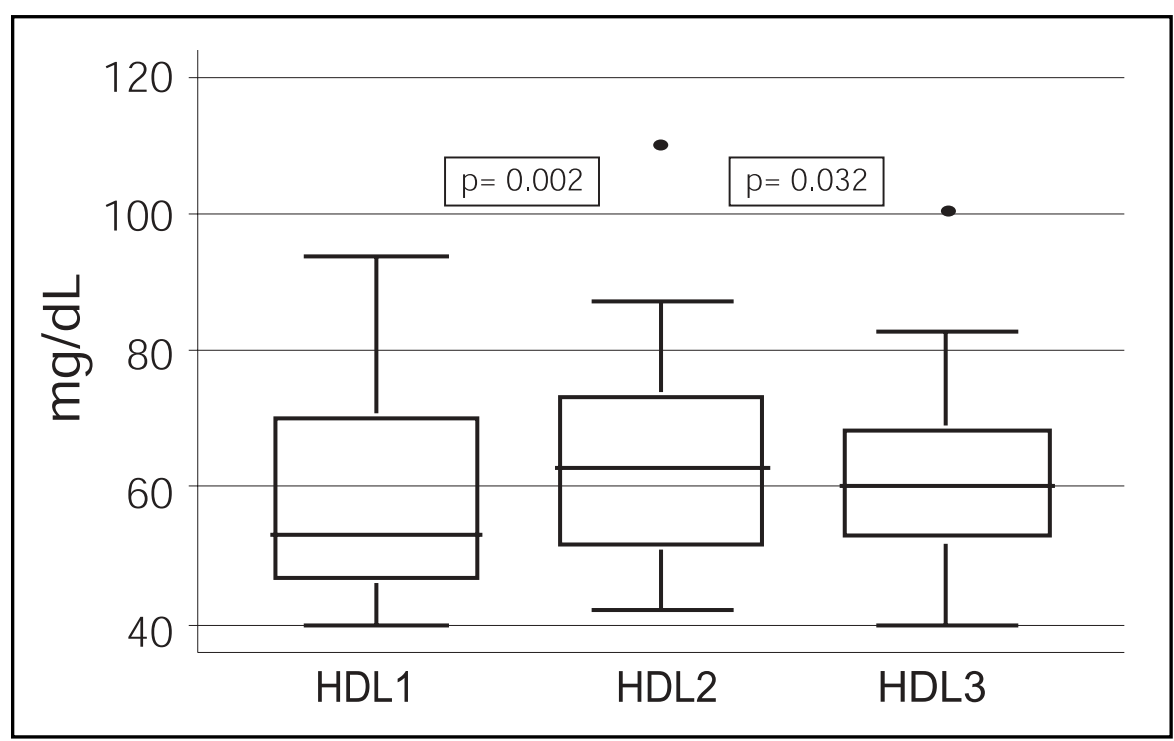

Figura 1. Concentración de HDL plasmática en $\mathrm{mg} / \mathrm{dL}$. HDL1= muestra A (día 0), HDL2 = muestra B (día 7), HLD3= muestra C (día 14). 


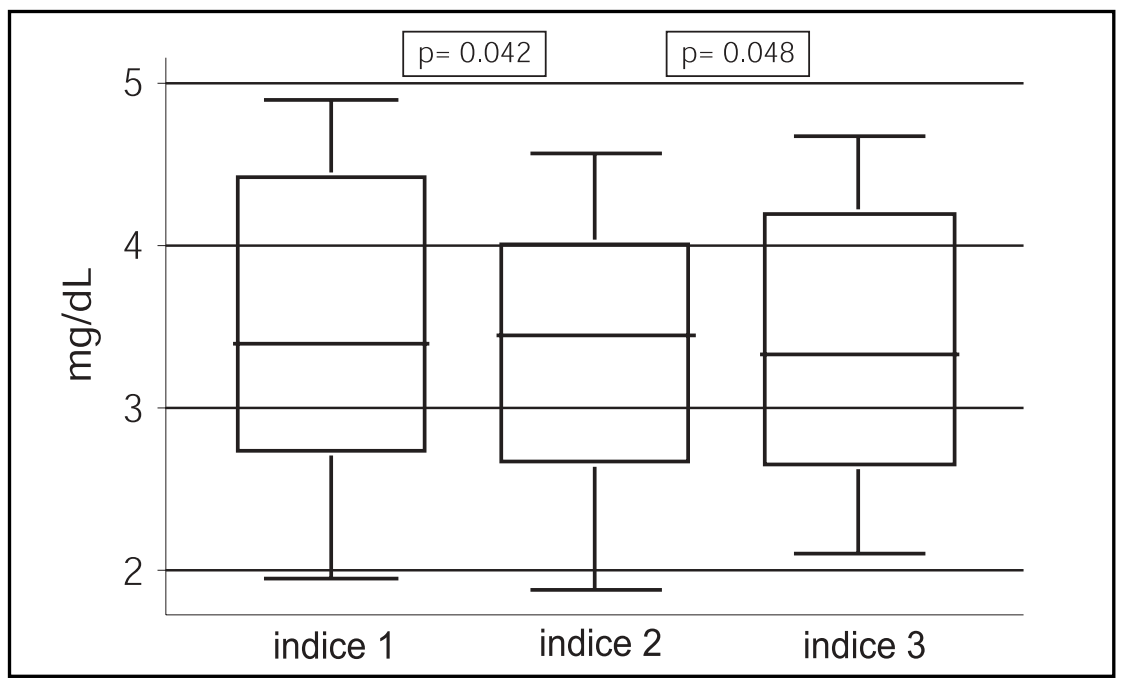

Figura 2. Índice Colesterol total/ HDL. Indice 1= muestra A (día 0); indice $2=$ muestra B (día 7); indice $3=$ muestra C (día 14).

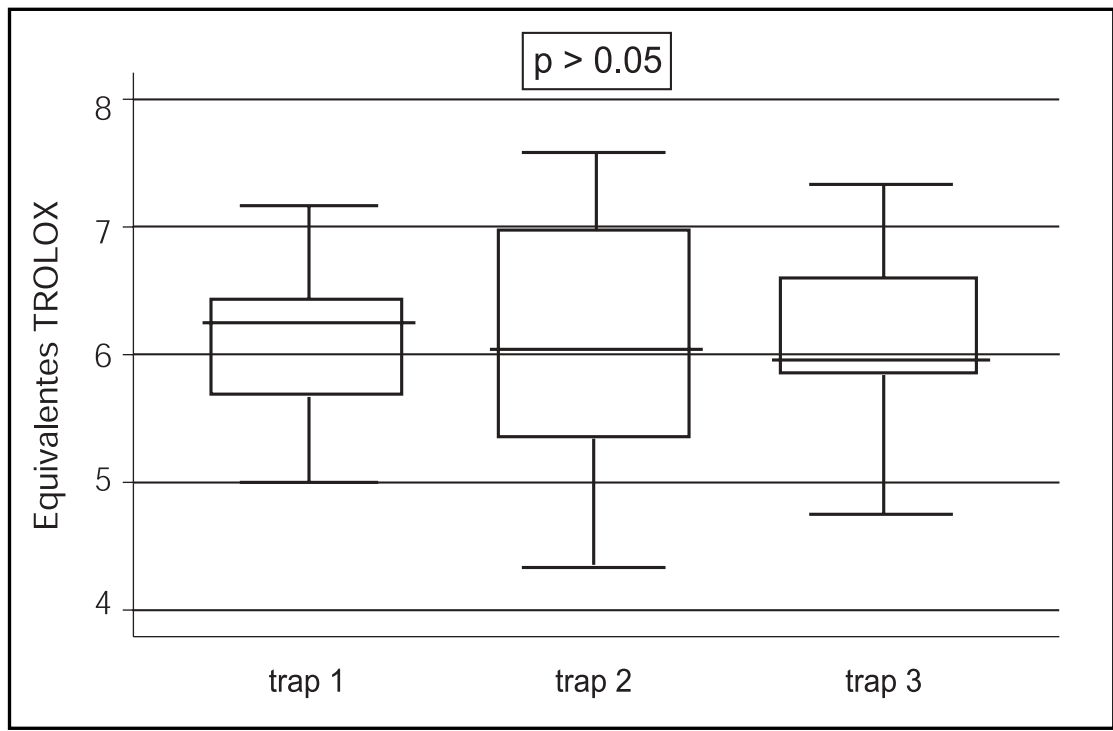

Figura 3. Capacidad antioxidante total en plasma (TRAP) en equivalentes Trolox. Trap 1= muestra A (día 0); Trap 2= muestra B (día 7); Trap 3= muestra C (día 14).

luego de 7 días de dieta habitual no suplementada, retornando a valores comparables al basal.

Luego de 7 días de suplementación dietaria, la relación colesterol total/HDL y la concentración plasmática de $\alpha$-tocoferol disminuyeron $4,97 \%$ $[0,174(\mathrm{p}=0,042)]$ y $62,9 \%[262,6 \mu \mathrm{g} / \mathrm{mL}(\mathrm{p}=$
0,015)], respectivamente, presentando un curso reversible, al igual que HDL y licopeno, luego de siete días de dieta habitual no suplementada.

No se observaron variaciones significativas de colesterol total, triglicéridos, LDL o VLDL Así mismo, los niveles de TRAP, actividad SOD y 
actividad CAT en el total de individuos no varió significativamente en ninguna de las mediciones respecto al basal grupal e individual (Tabla $1 \mathrm{y}$ Tabla 2).

\section{DisCUSIÓN}

El estrés oxidativo ha sido involucrado en múltiples estudios, tanto en la génesis, como en el transcurso de diversas enfermedades humanas ${ }^{9}$, además, ha logrado ser medido a través de distintas técnicas, una de ellas es el análisis de la actividad de ciertas enzimas en sangre y de la capacidad antioxidante total del plasma ${ }^{21}$. Hay evidencia publicada que este estrés oxidativo puede ser modificado a través de la ingesta de ciertos alimentos ${ }^{25,26}$. Dentro de ellos, el tomate y sus derivados tienen gran importancia ${ }^{27}$. Al respecto, y contrario a lo reportado en estudios in vitro, la actividad de antioxidantes plasmáticos enzimáticos en este estudio no sufren modificaciones significativas con el suministro de jugo concentrado de tomates. Esta situación puede deberse a que el tiempo de exposición al jugo de tomates fue corto y los efectos en la capacidad antioxidante total y en la actividad enzimática final no alcanzan a verificarse, debido a que estas enzimas pueden requerir un mayor tiempo para su inducción a nivel intracelular.

Los antioxidantes no enzimáticos (licopeno y $\alpha$-tocoferol) sí sufren una modificación manifiesta con el suministro de jugo de tomate. Esto, junto con la mantención de la capacidad antioxidante total del plasma, parece ser expresión de un equilibrio oxidativo compensatorio fisiológico, debido a que la homeostasis de las sustancias oxidantes del organismo se obtiene mediante un control enzimático y la participación de los antioxidantes de los alimentos ${ }^{22}$.

Las variaciones de antioxidantes no enzimáticos se producen de manera rápida y significativa durante el período de suplementación, retornando a los valores iniciales una semana después. Estas modificaciones resultan altamente sensibles, pero poco permanentes. Estos hallazgos presentan similitudes a lo reportado por Porrini et al, encontrándose aumento de niveles de licopeno posterior a la suplementación con jugo de tomates, sin un aumento concomitante de $\alpha$-tocoferol. Sin embargo, en ese estudio, la concentración plasmática de $\alpha$-tocoferol se mantiene en niveles cercanos al basal ${ }^{23}$. Los niveles de $\alpha$-tocoferol disminuyen, probablemente, como consecuencia de su acción antioxidante precoz, sin embargo, hay que considerar que ambos antioxidantes no enzimáticos son liposolubles, por lo que el contenido plasmático medido representa solo una pequeña fracción del $\alpha$-tocoferol y licopeno total inserto en las membranas lipídicas. Además, la diferencia verificada entre los estudios puede tener explicación en la distinta biodisponibilidad de carotenoides en los derivados del tomate que se utilizan en ellos.

La variación del valor de $\alpha$-tocoferol plasmático, que disminuye en $62,9 \%$, se puede atribuir a las propiedades farmacocinéticas en la absorción y transporte del licopeno, ya que éste estaría utilizando parte de la misma maquinaria de absorción y distribución de carotenoides y vitaminas esenciales que el tocoferol. El licopeno, al presentar una mejor afinidad para asociarse a quilomicrones y algunas otras lipoproteínas, competiría con el $\alpha$-tocoferol por estos sitios de unión, haciendo que baje su concentración plasmática ${ }^{24}$. Dado que ambos carotenoides son liposolubles, a partir de estos valores plasmáticos de $\alpha$-tocoferol no podemos hacer deducciones respecto de la concentración tisular.

La elevación de los valores plasmáticos de HDL resulta rápida y significativa, siendo uno de los aspectos de mayor relevancia en este estudio, ya que presenta una potencial capacidad terapéutica en pacientes con dislipidemias. Estos hallazgos contrastan con lo reportado por Böhm en un estudio de biodisponibilidad de licopeno con 22 mujeres adultas. Sin embargo, son compatibles con reportes recientes de un estudio de tipo observacional en 1.687 adultos mayores del Reino Unido que presenta una asociación positiva entre concentración de licopenos y de $\mathrm{HDL}^{17}$. Parece ser que estos hallazgos resultan sensibles respecto al tamaño muestral del estudio y a la posible interacción de variables confundentes no controladas que modifican el perfil lipídico. En este sentido, el número limitado de individuos de este ensayo podría generar datos que subestimen el efecto de la suplementacion de jugo de tomates en las lipoproteínas plasmáticas. Junto con esto, la importancia del tema nos lleva a postular la necesidad de mayor investigación en este campo. 
Futuros estudios han de buscar determinar el grado de óxido reducción de lipoproteínas in vivo, elemento demostrado como precursor de

\section{REFERENCIAS}

1. Hawiwell B, Gutteridge J. Oxigen free radicals and iron in relation to biology and medicine: some problems and concepts. Arch Biochem Biophys 1986; 246: 501-14.

2. Cadet J, Kalyanaraman B, Fontecave M, Pierre J. Analysis of free radicals in biological systems. Basel, Switzerland; Birkhäuser Verlag, pp 83-98, 1995.

3. Haшwiel B. Free radicals, antioxidants and human disease: curiosity, cause or consequence? Lancet 1994; 344: 721-4.

4. UpRItChaRd J, SutherLand W, ManN J. Effect of Supplementation with tomato juice, vitamin E, and vitamin $\mathrm{C}$ on LDL oxidation and products of inflammatory activity in type 2 diabetes. Diabetes Care 2000; 23: 733-8.

5. Hadiey CW, Clinton SK, Schwartz SJ. The consumption of processed tomato products enhances plasma lycopene concentrations in association with a reduced lipoprotein sensitivity to oxidative damage. J Nutr 2003; 133: 727-32.

6. Giovannucci E. Tomatoes, tomato-based products, lycopene, and cancer: Review of the epidemiologic literature. J Natl Cancer Inst 1999; 17; 91: 31731.

7. Mahaney MC, CZerwinski SA, Adachi T, Wilcken DE, WANG XL. Plasma levels of extracellular superoxide dismutasa in an Australian population: genetic contribution to normal variation and correlations with plasma nitric oxide and apoliprotein A-I levels. Arterioscler Thromb Vasc Biol 2000; 20: 683-8.

8. Fridovich I. Superoxide radical and superoxide dismutases. Annu Rev Biochem 1995; 64: 97-112.

9. CheEseman KH, Stater TF. En: British Medical Bulletin: Free radicals in medicine. Londres: Editorial Churchill-Livingstone, 1993; 49: 479-724.

10. Mao GD, Thomas PD, Lopaschuk GD, Poznansky MJ. Superoxide dismutase (SOD)-catalase conju- enfermedades cardiovasculares y, probablemente, algunos tipos de cáncer.

gates role of hydrogen peroxide and the fenton reaction in SOD Toxicity. J Biol Chem 1993; 268: 416-20.

11. Dimascio P, Kaiser S, Sies H. Lycopene is the most efficient biological carotenoid singlet oxygen quencher. Arch Biochem Biophys 1989; 274: 532-8.

12. Gann PH, Ma J, Giovannucci E, WiLett W, Sacks FM. HenNeKens CH ET AL. Lower prostate cancer risk in men with elevated plasma lycopene levels: results of a prospective analysis. Cancer Research 1999; 59: 1225-30.

13. Sies H, Stahl W. Lycopene: Antioxidant and biological effects and its bioavailability in the human. Proc Soc Exp Biol Med 1998; 218: 121-4.

14. Agarwal S, Rao V. Tomato lycopene and low density lipoprotein oxidation: A human dietary intervention study. Lipids 1998; 33: 981-4.

15. Carroll YL, Corridan BM, Morrissey PA. Lipoprotein carotenoid profiles and the susceptibility of low density lipoprotein to oxidative modification in healthy elderly volunteers. Eur J Clin Nutr 2000; 54: 500-7.

16. WeIsBuRger JH. Evaluation of the evidence on the role of tomato products in disease prevention. Proc Soc Exp Biol Med 1998; 218: 140-3.

17. Re R, Mishra GD, Thane CW, Bates CJ. Tomato consumption and plasma lycopene concentration in people aged 65 and over in a British National Survey. Eur J Clin Nutr 2003; 57: 1545-54.

18. Aвві H. Enzymatischen analyse. En: Methoden der Enzymatischen Analyse. Weinheim: Editorial Bergmeyer, 2000; 636-47.

19. MisRa HP, FRIDOvich I. The role of superoxide anion in the autoxidation of epinephrine and a simple assay for superoxide dismutase. J Biol Chem 1972; 247: 3170-5.

20. Lusi Ea, Salm-Hanna M, Pascual C, Del Castillo MD. Evaluation of total antioxidant potential (TRAP) and total antioxidant reactivity from luminol-enhanced chemiluminescence measurements. Free Radic Biol Med 1995; 18: 153-8. 
21. Вӧнм V, Biтsch R. Intestinal absortion of lycopene from different matrices and interactions to other carotenoids, the lipid status, and the antioxidant capacity of human plasma. Eur J Nut 1999; 38: $118-25$.

22. Ortiz HN, Giacopini MI, Alfonso P, Bosch V. Efecto antioxidante del tomate (Lycopersicum Esculentum Mill) en la lipoproteína de alta densidad (HDL) y en los microsomas hepáticos de la rata. AVFT 2003; 22: 10-5.

23. Porrini M, Riso P, Brusamolno A, Berti C, Guarnieri $\mathrm{S}$, VISIOL F. Daily intake of a formulated tomato drink affects carotenoid plasma and lymphocyte concentrations and improves cellular antioxidant protection. Br J Nutr 2005; 93: 93-9.

24. Dimadkar-Navsariwla V, Noyoyny J, Gustin D, Sosman J, Rodvold K, Crowel J et al. A physiological pharmacokinetic model describing the disposi- tion of lycopene in healthy men. J Lipid Res 2003; 44: 1927-39.

25. Campbell CG, Brown BD, Dufner D, Thorland WG. Effects of soy or milk protein during a high-fat feeding challenge on oxidative stress, inflammation, and lipids in healthy men. Lipids 2006; 41: 257-65.

26. KinNiRy P, Amrani Y, Vachani A, Solomides CC, ARguiri E, Workman A ET AL. Dietary flaxseed supplementation ameliorates inflammation and oxidative tissue damage in experimental models of acute lung injury in mice. J Nutr 2006; 136: 1545-51.

27. Riso P, Visioli F, Grande S, Guarnieri S, Gardana C, SimonETti $\mathrm{P}$ ET aL. Effect of a tomato-based drink on markers of inflammation, immunomodulation, and oxidative stress. J Agric Food Chem 2006; 54: 2563-6.

Agradecimientos

Al Instituto de Bioquímica de la Pontificia Universidad Católica de Valparaíso, Chile, por la participación en el procesamiento de muestras y uso de equipamientos.

A Conservas Centauro por la preparación de concentrados de tomates de producción limpia. 


\title{
Prevalencia de anticuerpos contra Bartonella henselae en niños, en adolescentes y en una población de riesgo ocupacional en Chile
}

\author{
Marcela Ferrés G ${ }^{1}$, Katia Abarca V 1 , Priscilla Prado $D^{2}$, \\ Luisa Montecinos Pla, Maritza Navarrete $C^{3}$, Pablo A Vial $C^{4}$. \\ Prevalence of Bartonella henselae \\ antibodies in Chilean children, \\ adolescents and veterinary workers
}

Background: Bartonella henselae is the causative agent of catscratch disease. Aim: To study the seroepidemiology of Bartonella henselae in healthy Chilean children and in a population with occupational risk. Material and methods: Serum IgG antibodies were determined by indirect fluorescence technique in 181 children and adolescents and in 107 technical and professional workers involved in the care of cats. Samples with titers equal to or greater than 64 were considered positive. Results: Twenty four (13.3\%) children and $11(10.3 \%)$ occupational risk subjects were seropositive. No significant differences by age and gender were observed. Conclusions: Assuming that seroprevalence indicates level of exposure to Bartonella henselae, these results suggest that this infection is endemic in Chile and, for this reason, the best antibody titer to diagnose acute cat-scratch disease should be higher than the figure recommended by the Centers for Disease Control in the in United States (Rev Méd Chile 2006; 134: 863-7).

(Key w ords: Antibodies, bacterial; Bartonella henselae; Cat-scratch disease)

Recibido el 8 de junio, 2005. Aceptado el 26 de diciembre, 2005.

Proyecto financiado por Fondecyt №1990124.

${ }^{1}$ Laboratorio de Infectología y Virología Molecular, Pontificia Universidad Católica de Chile, Santiago de Chile. ${ }^{2}$ Servicio de Pediatría, Hospital Padre Hurtado, ${ }^{3}$ Instituto de Microbiología Clínica, Universidad Austral de Chile, Valdivia, Chile. ${ }^{4}$ Facultad de Medicina Clínica Alemana y Universidad del Desarrollo de Chile.

aBioquímico

$\mathrm{B}$ artonella henselae es reconocida como el agente etiológico de la enfermedad por arañazo de gato (EAG) desde 1994. Desde entonces, este agente se ha asociado a un creciente espectro

Correspondencia a: Dra. Marcela Ferrés G. Laboratorio de Infectología y Virología Molecular, Pontificia Universidad Católica de Chile. Marcoleta 391, 4⿳0 piso, Santiago, Chile. Fono: 56-2-354 6823. Fax: 56-2-638 7457. E mail: mferres@med.puc.cl de manifestaciones clínicas. La infección se ha descrito a nivel mundial y existen algunas encuestas serólogicas que informan su prevalencia en diversas poblaciones. Estudios realizados en niños, han encontrado prevalencias de $15 \%$ en Grecia y 18,5\% en Canadá1,2; en adultos, las cifras varían entre 3 y $6 \%$ en Estados Unidos de Norteamérica (EE.UU) continental, Hawai, España, Tailandia y Japón ${ }^{3-7}$ hasta $37 \%$ en Canadá ${ }^{8}$. 
Estudios en poblaciones de riesgo ocupacional en EE.UU y Japón informan cifras entre 7 y $15 \% 9,10$. En dueños de gatos, se han encontrado prevalencias de $29 \%$ en España ${ }^{5}$ y de $18 \%$ en un pequeño grupo en Chile ${ }^{11}$.

Estudios realizados por investigadores del Centro de Control de Enfermedades de Atlanta (CDC), EE.UU, han estimado que títulos de IgG específica anti-Bartonella henselae iguales o mayores a 64 (los títulos se reportan como el inverso de la dilución del suero), se correlacionan bien con enfermedad aguda, ya que se encuentran en más de $85 \%$ de los casos clínicos sintomáticos de EAG y sólo en 3\% de los controles sanos ${ }^{3}$. Por ello, en ese país, se considera que la presencia de IgG anti- Bartonella henselae en título de 64 en un sujeto sin manifestaciones clínicas de EAG es indicativo de exposición previa a la bacteria y es por tanto, el nivel de corte usado para estudios de seroprevalencia.

En Chile, la EAG no es una enfermedad de notificación obligatoria, por lo que su relevancia a nivel de salud pública nacional no ha sido determinada. Hasta la fecha, sólo se han publicado en nuestro medio pequeñas series clínicas de infecciones por Bartonella hensela $e^{12-14}$. En consideración a que el diagnóstico de EAG, tanto en sus manifestaciones clásicas como atípicas, ha ido en aumento en nuestro medio, es necesario mejorar el conocimiento epidemiológico de esta infección en Chile.

El objetivo primario de este estudio fue determinar la prevalencia de anticuerpos IgG antiBartonella henselae en dos poblaciones chilenas: niños y adolescentes sanos y sujetos con exposición ocupacional a gatos. Los objetivos secundarios fueron identificar posibles diferencias por edad y género; comparar las prevalencias obtenidas en ambas poblaciones; e investigar posibles factores asociados a la infección en los sujetos con riesgo laboral.

\section{PoBLACIÓN Y MÉTODO}

Niños y adolescentes. Se analizaron sueros de 181 niños sanos residentes en Santiago. Los sueros pertenecían a una colección tomada durante 19881990 para un estudio seroepidemiológico de hepatitis $\mathrm{A}^{15}$. Se obtuvo autorización de la Unidad de Bioética del Ministerio de Salud para utilizar estos sueros. Las muestras fueron seleccionadas al azar, de un total de 681 sueros de sujetos entre $1 \mathrm{a}$ 19 años y procesadas en forma ciega, utilizando un código que informaba edad y género de cada caso estudiado. No se contó con información epidemiológica relevante para EAG como el antecedente de contacto con gatos.

Población de riesgo ocupacional. Se invitó a participar a médicos veterinarios y técnicos veterinarios que trabajan en tres bioterios universitarios y diez clínicas veterinarias que atienden animales pequeños, de las ciudades de Santiago y Valdivia. Ciento siete sujetos aceptaron participar (95\% de los contactados). Se les entrevistó mediante un cuestionario y se les extrajo $5 \mathrm{~mL}$ de sangre venosa para la detección de anticuerpos.

Métodos diagnósticos. Serología: Se determinó la presencia de anticuerpos séricos IgG específicos anti-Bartonella henselae por técnica de inmunofluorescencia indirecta (IFI), utilizando un kit comercial (Focus ${ }^{\mathrm{TM}}$ ). Esta prueba utiliza células Vero E6 infectadas con Bartonella henselae, las que fijadas sobre un portaobjeto son incubadas con el suero a analizar. La unión del anticuerpo del paciente con el antígeno bacteriano se visualiza bajo microscopio de fluorescencia, mediante observación de fluorescencia verde manzana brillante sobre los bacilos fijados en el portaobjeto. La sensibilidad esperada del ensayo es de 88$95 \% 16$. Las muestras fueron procesadas en el Laboratorio de Infectología y Virología Molecular de la Pontificia Universidad Católica de Chile, siguiendo las instrucciones del fabricante. Los sueros se procesaron en dilución basal de 1:64 y aquellos que resultaron positivos se diluyeron hasta determinar sus títulos. En cada procedimiento se usó un control negativo y uno positivo ${ }^{17}$.

Entrevista ocupacional. Se aplicó un cuestionario a la población de riesgo laboral solicitando información demográfica, actividad ocupacional y antecedentes epidemiológicos de exposición a gatos. Se incluyeron las siguientes variables como posibles factores asociados a infección: tipo de trabajo (veterinarios $\mathrm{v} / \mathrm{s}$ auxiliares técnicos) y antecedente de accidentes con gatos (arañazo, mordedura, herida infectada, linfadenopatía regional). 
Estadística. Se utilizó programa Epi 6 y prueba estadística Fisher de 2 colas para comparar las variables en estudio para cada uno de los subgrupos (positivos y negativos para anticuerpos antiBartonella henselae).

\section{RESULTADOS}

Niños y adolescentes. Se analizaron un total de 181 muestras de individuos, cuya edad fluctuó entre 2 y 17 años (promedio 6,5), 49,7\% sexo masculino. Se encontró anticuerpos IgG anti-Bartonella henselae en 24 sujetos (13,3\%). En 21 de ellos (11,6\% del total), el título de anticuerpos fue de 64 y en 3 $(1,7 \%)$ fue de 256 . No hubo diferencias por género: $14 / 90(15,5 \%)$ de los hombres y 10/91 (11\%) de las mujeres resultaron seropositivos ( $p$ $>0,1)$. La prevalencia por grupo etario se presenta en la Figura 1. Se observa tendencia al aumento de la seroprevalencia con la edad, aunque esta variación no fue significativa al comparar cada uno de los grupos de edad analizados $(p>0,1)$.
Población de riesgo ocupacional. Se analizaron un total de 107 muestras, 58,8\% hombres, edad promedio 29 años (rango 18 a 63). Se encontró anticuerpos IgG anti-Bartonella henselae en 11 (10,3\%), todos con títulos de 64 . La prevalencia por género mostró tendencia a mayor positividad en mujeres, sin alcanzar valor estadístico: 4/63 (6,3\%) de los hombres y $7 / 44(15,9 \%)$ de las mujeres resultaron positivos $(p=0,1)$. La Tabla 1 resume la relación entre prevalencia y las variables estudiadas. Los datos sugieren una mayor prevalencia en auxiliares técnicos que en veterinarios y en individuos que habían sufrido arañazo y mordedura por gatos. Sin embargo, las diferencias no resultaron estadísticamente significativas. Finalmente, la presencia de anticuerpos anti-Bartonella henselae fue significativamente mayor en individuos con historia de herida (arañazo o mordedura) con signos de infección. Las otras variables estudiadas no fueron estadísticamente significativas.

Comparación entre ambas poblaciones. La prevalencia de anticuerpos anti-Bartonella henselae no

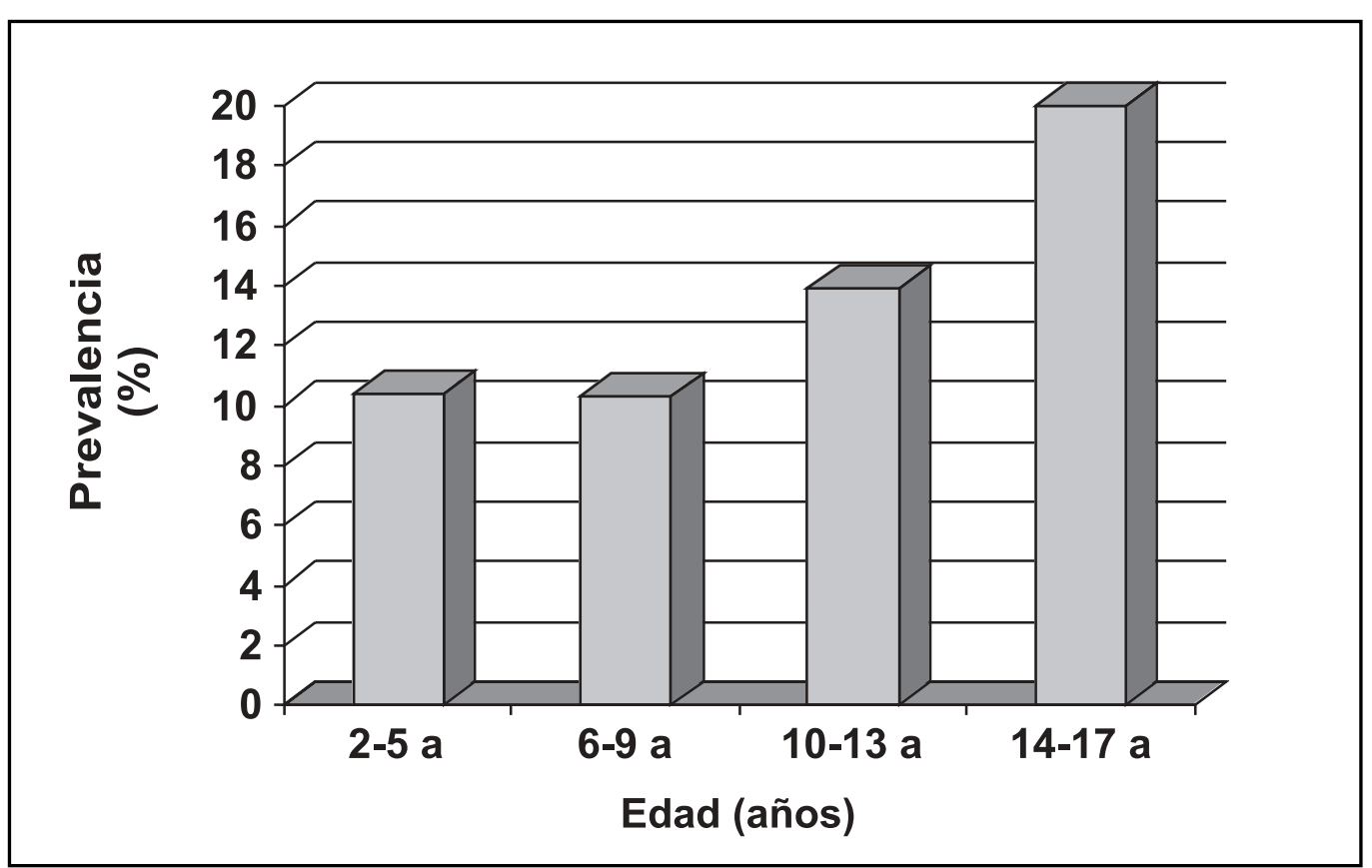

Figura 1. Distribución por edad de la seroprevalencia de Bartonella henselae en población pediátrica, Santiago, Chile $(\mathrm{n}=181)$. 
Table 1. Seroprevalencia de Bartonella henselae según factores de riesgo, en 107 sujetos con riesgo ocupacional

\begin{tabular}{|lccc|}
\hline Características de los sujetos & Positivos/total & $\%$ & $\mathrm{p}^{* *}$ \\
\hline Veterinarios & $5 / 76$ & 6,6 & 0,056 \\
Auxiliares técnicos & $6 / 31$ & 19,4 & $>0,1$ \\
Antecedente de accidente con gatos* & $11 / 98$ & 11,2 & $>0,1$ \\
Antecedente de arañazo de gato & $2 / 39$ & 5,1 & 0,060 \\
Antecedente de arañazo y mordedura de gato & $9 / 58$ & 15,5 & 0,038 \\
Antecedente de herida infectada & $5 / 21$ & 23,8 & $>0,1$ \\
Antecedente de linfadenopatía sugerente de EAG & $2 / 7$ & 28,6 & \\
\hline
\end{tabular}

*Rasguño o mordedura. **Test de Fisher 2 colas.

difiere en forma estadísticamente significativa entre la población pediátrica estudiada y los sujetos con riesgo ocupacional $(p=0,45)$.

\section{DisCUSIÓN}

Bartonella henselae ha sido reconocida como el agente causal de la EAG, angiomatosis bacilar y peliosis hepática. En este estudio se investigó la prevalencia de exposición a Bartonella henselae, a través de la detección de anticuerpos IgG específicos contra este agente. Los resultados obtenidos en población pediátrica muestran una prevalencia de 13,3\%. Esta cifra es similar a las encontradas en otros estudios realizados en niños en Grecia y Canadá1,2. En forma similar, la prevalencia obtenida en los sujetos con riesgo ocupacional $(10,3 \%)$, se asemeja a otros informes que señalan cifras que oscilan entre 7 y $15 \% 9,10$.

Estos resultados sugieren que la infección por Bartonella henselae es endémica en Chile. Esta observación es concordante con la alta prevalencia de anticuerpos encontrados en gatos (75-95\%) de tres regiones de Chile ${ }^{18}$ y a la apreciación de los pediatras chilenos de un elevado número de casos de EAG en nuestro medio.

La EAG es considerada la primera causa de adenopatía crónica regional en niños en EE.UU, con una incidencia estimada en 22.000 casos anuales ${ }^{19}$, lo que la sitúa como una de las enfermedades zoonóticas más comunes en ese país. Si bien en Chile no se dispone de datos de incidencia de esta infección, la prevalencia encontrada en este estudio sugiere que, muy probablemente, en nuestro país también es una zoonosis de gran importancia.

La mayoría de los estudios realizados en adultos sanos han encontrado anticuerpos anti-Bartonella henselae en alrededor de $5 \%{ }^{3-7}$, en Chile no existen estudios de este tipo. La mayor prevalencia encontrada en las dos poblaciones estudiadas en relación a lo informado en adultos en otros países, sugiere que los niños y el personal de salud veterinaria podrían constituir grupos de riesgo para adquirir esta infección por tener mayor exposición a gatos y mayor niesgo de sufrir accidentes (arañazos o mordeduras) que faciliten la transmisión. Son necesarios nuevos estudios de prevalencia que incluyan adultos chilenos sin contacto ocupacional con gatos para confirmar esta hipótesis.

En los sujetos con riesgo ocupacional, se pudo identificar una asociación estadística entre el antecedente de herida infectada e infección por Bartonella henselae. Otros dos factores, la condición de auxiliares de veterinaria y el antecedente de haber sufrido arañazo y mordedura por gatos, mostraron una tendencia sin alcanzar significancia estadística, probablemente por el pequeño tamaño muestral. Una identificación más completa de los factores de riesgo asociados a infección requerirá de la realización de nuevos estudios con mayor tamaño muestral e idealmente con diseño de cohorte o caso control.

En EE.UU, el diagnóstico de EAG se sustenta en la presencia de anticuerpos IgG anti-Bartonella henselae en títulos de 64 o mayores en una persona con síntomas compatibles; títulos de 64 en población sana son considerados indicativos de infección pasada. El hallazgo de un elevado 
porcentaje $(13,3 \%)$ de niños chilenos asintomáticos con títulos de IgG anti-Bartonella henselae de 64 , sugiere que en nuestro medio, este título no

\section{REFERENCIAS}

1. Antoniou M, Economou I, Wang X, Psaroulaki I, Papadopoulos B, Christidou A et al. Fourteen-year seroepidemiological study of zoonoses in a Greek village. Am J Trop Med Hyg 2002; 66: 80-5.

2. Cimolai N, Benoit L, HiLl A, Lyons C. Bartonella henselae infection in British Columbia: evidence for an endemic disease among humans. Can J Microbiol 2000; 46: 908-12.

3. Regnery R, Olson J, Perkins B, Bibb W. Serological response to Rochalimaea henselae antigen in suspected cat-scratch disease. Lancet 1992; 339: 1443-5.

4. Demers DM, Bass JW, Vincent JM, Person DA, Noyes DK, Staege CM et al. Cat scratch disease in Hawaii: etiology and seroepidemiology. J Pediatric 1995; 127: 23-6.

5. Blanco JR, Oteo Ja, Martínez V, Ramale E, García A, IBARRA V. Seroepidemiology of Bartonella henselae infection in a risk group. Rev Clin Esp 1998; 198: 805-9.

6. Maruyama S, Boonmar S, Morita Y, Sakai T, Tanaka S, YAMAGUCHI F ET AL Seroprevalence of Bartonella henselae and Toxoplasma gondii among healthy individuals in Thailand. J Vet Med Sci 2000; 62: 635-7.

7. Kikuchi E, Maruyama S, Sakai T, Tanaka S, Yamaguchi F, Hagiwara T ET al Serological investigation of Bartonella henselae infections in clinically cat-scratch disease-suspected patients, patients with cardiovascular diseases, and healthy veterinary students in Japan. Microbiol Immunol 2002; 46: 313-6.

8. Sander A, Posselt M, Oberie K, Bredt W. Seroprevalence of antibodies to Bartonella henselae in patients with cat scratch disease and in healthy controls: evaluation and comparison of two commercial serological tests. Clin Diag Lab Immunol 1998; 5: 486-90.

9. Noah DL, Kramer CM, Verbsky MP, Rooney JA, Smith KA, CHILDS JE. Survey of veterinary professionals and other veterinary conference attendees for antibodies to Bartonella henselae and Bartonella quintana. J Am Vet Med Assoc 1997; 210: 342-4.

10. Kumasaka K, ARashima Y, Yanai M, Hosokawa N, Kawano K. Survey of veterinary professionals for antibodies to Bartonella henselae in Japan. Rinsho Byori 2001; 49: 906-10. sería adecuado para diagnosticar infección aguda y que para estos fines debiera usarse un punto de corte mayor.

11. Zaror L, Ernst S, Navarrete M, Baliesteros A, BoroscheCK D, FerRés M ET AL. Detección serológica de Bartonella henselae en gatos en la ciudad de Valdivia, Chile. Arch Med Vet 2002; 34: 103-9.

12. Abarca K, Vial P, Rivera M, García C, Oddó D, Prado P ET AL. Infección por Bartonella henselae en pacientes inmunocompetentes: Enfermedad por arañazo de gato. Rev Méd Chile 1996; 124: 1341-9.

13. Wolff E, Muñoz MP, Zapata C, Ledermann W. Enfermedad por arañazo de gato complicada con compromiso sistémico, osteomielitis vertebral y absceso paravertebral. Rev Chil Infect 2000; 17: 332-9.

14. TÄger M, Zamorano J. Osteomielitis, una manifestación inusual de la enfermedad por arañazo de gato. Rev Chil Infect 2000; 17: 326-31.

15. Fix A, San Martín O, Gauichio L, Vial P, Lagos R. Age-specific prevalence of antibodies to hepatitis A in Santiago, Chile: Risk factors and shift in age of infection among children and young adults. Am J Trop Med Hyg 2002; 66: 628-32.

16. Peter JB, Boyle M, Patnaik M, Hadfield TL, Barka NE, Schwartzman WA et al. Persistent generalized lymphadenopathy and non-Hodgkin's lymphoma in AIDS: association with Rochalimaea henselae infection. Clin Diagn Lab Immunol 1994; 1: 115-6.

17. Viral and Rickettsial Zoonoses Branch, Centers for Disease Control and Prevention. Serodiagnosis of Emerging Infectious Diseases: Bartonella and Ehrlichia Infections. Workshop, February 1-4, 1999.

18. Ferrés M, Abarca K, Godoy P, García P, Palavecino E, MÉndez G et al. Presencia de Bartonella henselae en gatos: cuantificación del reservorio natural y riesgo de exposición humana de esta zoonosis en Chile. Rev Méd Chile 2005; 133: 1465-71.

19. Bass J, Vincent J, Person D. Expanding spectrum of Bartonella infections: Cat Scratch Disease. Pediatric Infect Dis J 1997; 16: 163-9.

\section{Agradecimientos}

Agradecemos a la Dra. Rosanna Lagos, del Centro de Vacunas para el Desarrollo de Santiago, quien nos proporcionó los sueros de la población pediátrica. 


\title{
Identificación rápida de micobacterias no tuberculosas mediante análisis de patrones de restricción
}

\author{
Pamela Araya $\mathbf{R}^{1 \mathrm{la}}$, Maritza Velasco $\mathbf{R}^{2 \mathrm{~b}}$, Jorge Fernández $0^{\mathbf{l c}}$. \\ Rapid identification \\ of non tuberculous mycobacteria \\ by restriction pattern analysis
}

Background: The frequency of diseases caused by non tuberculous mycobacteria has increased in the last years. Their clinical diagnosis is difficult, mainly in immunocompromised patients. The identification of these mycobacteria by traditional methods is based on phenotypic characteristics and the results are obtained two to four weeks after their isolation in primary cultures. Aim: To report a new identification method for non tuberculous mycobacteria. Material and methods: The restriction pattern analysis method was implemented. It is based on the amplification, using polymerase chain reaction (PCR), of a polymorphic region of 440 base pairs that codifies Hsp65 protein, followed by a digestion with BstE II and Hae III restriction enzymes. The results were compared with patterns established for each strain. Results: Sixty four strains of mycobacteria obtained from clinical samples and seven reference mycobacteria, were identified using the traditional methods and restriction pattern analysis. The latter method identified the same strain as the former in $87.5 \%$ of cases. In the remainder $12.5 \%$ of cases there was no agreement between both methods. In these, the sequencing of a fragment of a gene that codifies $16 \mathrm{~S}$ ribosomal RNA, confirmed the correct identification by restriction patterns. Conclusions: Restriction pattern analysis is a rapid identification method for non tuberculous mycobaterial strains (Rev Méd Chile 2006; 134: 868-73).

(Key words: Mycobacteria, atypical; Restriction enzyme analysis; RNA, ribosomal)

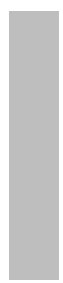

Recibido el 12 de julio, 2005. Aceptado el 5 de diciembre, 2005.

Trabajo financiado con fondos INCO-CA № ICA4-CT-2001-10087 y del Instituto de Salud Pública.

${ }^{1}$ Unidad de Desarrollo y ${ }^{2}$ Sección Micobacterias, Instituto de Salud Pública de Chile. Santiago de Chile.

aBioquímico

bTecnólogo Médico

${ }^{\mathrm{c}} \mathrm{PhD}$ y Licenciado en biología

Correspondencia a: Jorge Fernández Ordenes. Unidad de

Desarrollo, Departamento Laboratorios de Salud, Instituto de Salud Pública de Chile. Maratón 1.000, Ñunoa, Santiago de Chile. Fax: 3507573. E mail: jfernand@ispch.cl 
L as enfermedades producidas por micobacterias no tuberculosas, han tenido un importante incremento en los últimos años, debido particularmente a su asociación con el síndrome de inmunodeficiencia adquirida (SIDA) y con terapias immunosupresoras en pacientes trasplantados ${ }^{1-4}$. El aumento de los aislamientos de micobacterias no tuberculosas, también ha sido observado en nuestro país. Es así como el Laboratorio Nacional y de Referencia del Instituto de Salud Pública de Chile diagnosticó 15,8\% de micobacterias no tuberculosas en 2002, 25,6\% durante 2003, para alcanzar, durante el año 2004, 35\% del total de cepas de micobacterias recibidas.

La identificación clásica de micobacteria, basada en morfología, cultivos y pruebas bioquímicas, puede demorar varias semanas después de la recepción de las muestras y, en algunos casos, no se logra identificar correctamente los microorganismos con los protocolos disponibles ${ }^{5}$. Métodos alternativos como cromatografía en capa fina, cromatografía gas-líquido, cromatografía líquida de alta resolución y secuenciamiento del gen $16 \mathrm{~S}$ ARN, han sido utilizados en la identificación de las micobacterias. Sin embargo, su uso está limitado a los laboratorios de referencia, ya que requieren equipos muy sofisticados $^{6,7}$. También se han desarrollado sistemas comerciales de identificación como AccuProbe (GenProbe, USA), INNO-LipA micobacterias (Innogenetics, Bélgica) y Genotype Mycobacterias (Hain Lifescience, Alemania), que tienen un alto costo para los países de pocos recursos económicos ${ }^{7}$.

Un método rápido, que reduce el tiempo para la identificación de micobacterias no tuberculosas, fue desarrollado por Telenti ${ }^{8}$. Este método molecular se basa en la amplificación mediante la reacción en cadena de la polimerasa (PCR) de un fragmento polimórfico de $440 \mathrm{pb}$ que codifica para la proteína del shock térmico Hsp65. El producto amplificado es digerido con las enzimas de restricción BstE II y Hae III y la interpretación de los patrones de restricción se realizan por la simple observación de los patrones y por algoritmos disponibles en la página de Internet (http:app.chuv.ch/prasite) ${ }^{9,10}$.

En este estudio se analizaron aislados primarios y cepas de referencia de micobacterias, para determinar si la identificación a nivel de especies de micobacterias no tuberculosas con los métodos tradicionales son concordantes con el análisis de los patrones de restricción (APR). Para confirmar la identificación de las muestras discordantes, se secuenció un fragmento del gen 16S ARN.

\section{MATERIALES Y MÉTODOS}

Cepas. Se analizaron 64 aislados primarios que fueron enviados desde los Laboratorios de Bacteriología de la Tuberculosis del país, al Laboratorio Nacional y de Referencia de Micobacterias del Instituto de Salud Pública de Chile entre los años 2002 y 2004. Se incluyeron, 7 cepas de referencia ATCC y CIPT (American Type Culture Collection USA y Collection Institute Pasteur Tuberculosis) como controles. Los aislados primarios fueron identificados a especies por métodos tradicionales ${ }^{11}$.

Extracción de ADN genómico. Se centrifugó una alícuota de $500 \mu \mathrm{l}$ del cultivo de micobacteria a $9,500 \mathrm{~g}$ por $15 \mathrm{~min}$, suspendiéndose el pellet resultante en tampón de lisis (Tris- $\mathrm{HCl} 10 \mathrm{mM} \mathrm{pH}$ 7,5, EDTA 1,0 mM y 1\% Tritón X-100). Las células fueron inactivadas por calentamiento a $80^{\circ} \mathrm{C}$ por 10 min y mediante tres ciclos de ebullicióncongelación por 10 min cada uno.

Amplificación del ADN mediante reacción en cadena de la polimerasa (PCR). Se amplificó un segmento de $440 \mathrm{pb}$ del gen hsp $65^{12}$. La reacción de PCR fue efectuada en un volumen final de $50 \mu \mathrm{l}$ consistente en 1,5 mM de $\mathrm{MgCl}_{2}, 20 \mathrm{mM}$ Tris, $\mathrm{pH}$ 8,4, $50 \mathrm{mM} \mathrm{KCl}, 10 \%$ glicerol, 2 pmoles de los partidores TB11 (5'ACCAACGATGGTGTGTCCAT3') y TB12 (5'CTTGTCGAACCGCATACCCT3'), $200 \mu \mathrm{M}$ dNTP, $1 \mathrm{U}$ de Taq polimerasa y $5 \mu \mathrm{l}$ de lisado celular como templado. El proceso de amplificación del ADN consistió en una etapa de denaturación inicial de $95^{\circ} \mathrm{C}$ por $5 \mathrm{~min}$, seguida por 35 ciclos de amplificación que incluyeron 1 min de denaturación a $94^{\circ} \mathrm{C}, 1$ min de hibridación a $60^{\circ} \mathrm{C}$ y 1 min de extensión a $72^{\circ} \mathrm{C}$, para terminar con una etapa de extensión final de 5 min a $72^{\circ} \mathrm{C}$. Los productos de la PCR fueron analizados por electroforesis en geles de agarosa al $2 \%$ y visualizados en transiluminador de luz UV.

Análisis de fragmentos de restricción. Los productos de la amplificación fueron digeridos separadamente con las enzimas de restricción BstE II y Hae III. Con posterioridad, los productos de la diges- 
tión fueron separados en geles de agarosa $4 \%$, teñidos con bromuro de etidio $(4 \mu \mathrm{g} / \mathrm{ml})$ y visualizados en transiluminador UV. Los patrones de restricción obtenidos, fueron analizados en el programa computacional Quantity One de BIORAD e interpretados por patrones disponibles en el banco de datos. http:app.chuv.ch/prasite ${ }^{11,12}$.

Análisis de secuencia ARN ribosomal 16S. Un fragmento de $350 \mathrm{pb}$ del gen que codifica para el 16S ARN fue amplificado de acuerdo a los procedimientos descritos en la literatura ${ }^{13}$. El secuenciamiento de los amplicones fue realizado en un secuenciador automático ABI PRISM 310 Applied Biosystem $^{\mathrm{MR}}$, de acuerdo a las instrucciones del fabricante. La secuencia nucleotídica generada fue comparada con las descritas en la base de datos de GenBank, utilizando la herramienta BLAST disponible en el National Center for Biotechnology (http://www.ncbi.nlm.nih.gov).

\section{ResUlTADOS}

Un fragmento de $440 \mathrm{pb}$ del gen que codificaba para la proteína Hsp65 fue amplificado en todas las cepas estudiadas. Los fragmentos generados por la digestión con las enzimas Hae III y BstE II tuvieron un tamaño entre 50 a 440 pb (Figura 1). Los patrones de digestión obtenidos fueron comparados con las Tablas publicadas en el sitio de Internet http://www.app.chuv.ch/prasite.

En la Tabla 1, se muestran los resultados de la comparación de los métodos APR con los métodos tradicionales para la identificación de las cepas clínicas y cepas de referencia de Mycobacterium spp. El análisis de las cepas ATCC y CIPT mediante las pruebas clásicas, permitió la identificación de 5 de las 7 cepas de referencia. Las micobacterias M triviale y $\mathrm{M}$ chitae fueron identificadas en ambos casos como M fortuitum por las pruebas tradicionales, en cambio, todas las cepas de referencia fueron identificadas correctamente por APR.

En $56(87,5 \%)$ de las cepas obtenidas desde muestras clínicas, se identificó la misma especie con ambos métodos (Tabla 2). La identificación mediante APR, permitió identificar en 12 especies los subtipos. M intracellulare fue identificado en 8 muestras, correspondiendo seis al subtipo 1 , una al subtipo 2 y una al subtipo 4. Siete diferentes variantes de $\mathrm{M}$ avium fueron observadas mediante APR, correspondiendo 6 de ellas al subtipo 2 y una al subtipo 1. La especie M fortuitum fue identificada en 9 de las cepas, de las cuales 7 correspondie-

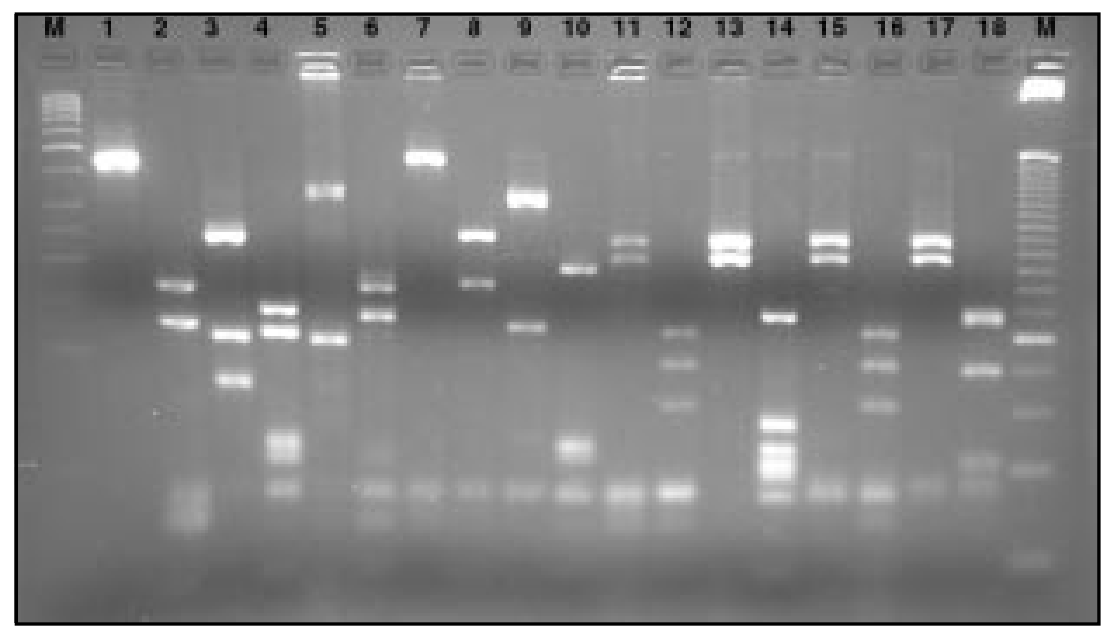

Figura 1. Patrones de restricción de cepas de micobacterias en gel de agarosa al 4\%, teñido con bromuro de etidio. Líneas 1, 3, 5, 7, 9, 11, 13, 15, 17 digestión con la enzima BstE II. Líneas 2, 4, 6, 8, 10, 12, 14, 16, 18 digestión con la enzima Hae III. Líneas 1 y 2 M triviale tipo 1, líneas 3 y 4 M fortuitum tipo 1, líneas 5 y $6 \mathrm{M}$ terrae tipo 1, líneas 7 y 8 M chitae tipo 1 líneas 9 y 10 M chelonae, líneas 11 y 12 M kansasii tipo 1, líneas 13 y 14 Mabscessus tipo 1, líneas 15 y 16 M kansasii tipo 1, líneas 17 y 18 M peregrinum tipo 1. Líneas M estándar de peso molecular 100 pb y 50 pb ADN ladder. 
Tabla 1. Identificación por APR y métodos tradicionales de cepas de referencia de micobacterias no tuberculosas

\begin{tabular}{|lllll|}
\hline Especies & ATCC & $\begin{array}{l}\text { Identificación } \\
\text { APR }\end{array}$ & $\begin{array}{l}\text { Identificación } \\
\text { métodos tradicionales }\end{array}$ & Resultados \\
\hline M terrae & CIPT 140320001 & M terrea & M terrea & Concordante \\
M scrofulaceum & CIPT 140220031 & M scrofulaceum & M scrofulaceum & Concordante \\
M flavescens & ATCC 14474 & M flavescens & M flavescens & Concordante \\
M kansasii & ATCC 12478 & M kansasii & M kansasii & Concordante \\
M abscessus & ATCC 19977 & M abscessus & M abscessus & Concordante \\
M chitae & ATCC 19627 & M chitae & M fortuitum & Discordante \\
M triviale & ATCC 23292 & M triviale & M fortuitum & Discordante \\
\hline
\end{tabular}

Tabla 2. C orrelación entre los procedimientos bioquímicos y tradicionales y la técnica de APR para la identificación de cepas de micobacterias no tuberculosa aisladas en Chile entre 2002 y 2004

\begin{tabular}{|c|c|c|c|}
\hline $\mathrm{N}^{\circ}$ de cepas & & APR & Identificación bioquímica \\
\hline \multirow[t]{4}{*}{8} & M intracellulare & & Complejo MAI \\
\hline & & 6 subtipo 1 & \\
\hline & & 1 subtipo 2 & \\
\hline & & 1 subtipo 4 & \\
\hline \multirow[t]{2}{*}{7} & M avium & & Complejo MAI \\
\hline & & 1 subtipo 1 & \\
\hline \multirow[t]{3}{*}{9} & M fortuitum & b subtipo 2 & M fortuitum \\
\hline & & 7 subtipo 1 & \\
\hline & & 2 subtipo 2 & \\
\hline \multirow[t]{4}{*}{9} & M gordonae & & M gordonae \\
\hline & & 2 subtipo 1 & \\
\hline & & 6 subtipo 4 & \\
\hline & & 1 subtipo 8 & \\
\hline \multirow[t]{2}{*}{4} & M abscessus & & M abscessus \\
\hline & & $\begin{array}{l}2 \text { subtipo } 1 \\
2 \text { subtipo } 2\end{array}$ & \\
\hline 9 & M kansasii & subtipo 1 & M kansasii \\
\hline 1 & M chelonae & subtipo 1 & M chelonae \\
\hline 1 & M marinum & subtipo 1 & M marimun \\
\hline 1 & M smegmatis & subtipo 1 & M smegmatis \\
\hline 1 & M peregrinum & subtipo 1 & M peregrimun \\
\hline 1 & M triviale & subtipo 1 & M triviale \\
\hline 1 & M scrofulaceum & subtipo 1 & M scrofulaceum \\
\hline 2 & Complejo fortuitum chelonae & subtipo 1 & M chelonae \\
\hline 2 & TBC & & Complejo tuberculosis \\
\hline
\end{tabular}

ron al subtipo 1 y 2 al subtipo 2. Nueve de las cepas estudiadas fueron identificadas como $\mathrm{M}$ gordonae, correspondiendo 6 de ellas al subtipo 4, 2 al subtipo 1 y una al subtipo 8. Los subtipos 1 y 2 fueron identificados en Mabscessus. Las micobacterias $\mathrm{M}$ kansasii, $\mathrm{M}$ chelonae, $\mathrm{M}$ marinum, $\mathrm{M}$ smegmatis, $\mathrm{M}$ peregrinum, $\mathrm{M}$ triviale, $\mathrm{M}$ scrofulaceum correspondieron al subtipo 1 . 
En 8 (12,5\%) de las muestras clínicas no hubo concordancia entre los resultados obtenidos por las pruebas clásicas y el análisis de los patrones de restricción (Tabla 3). Para resolver esta discrepancia entre ambos métodos, se secuenció en las 8 cepas una región específica del gen 16S ARN, confirmándose la identificación obtenida mediante APR en las 8 cepas.

Las especies clínicas $M$ terrae, M simiae y $M$ noncromagenicum, sólo pudieron ser identificadas mediante APR y no por las pruebas tradicionales de identificación.

\section{DisCUSIÓN}

La identificación de especies en micobacterias no tuberculosas es una etapa crítica en el manejo de los pacientes infectados, ya que el resultado obtenido es importante para descartar o confirmar una patología concordante con micobacteriosis ${ }^{14-16}$. La identificación correcta de las micobacterias no tuberculosas, sumado al estudio de susceptibilidad, permite la elección de un esquema terapéutico adecuado, si se trata de una especie potencialmente patógena, aislada en forma repetida y en cantidad abundante.

Es por tanto, importante el desarrollo de métodos que proporcionen resultados rápidos y confiables, que puedan ser utilizados en los Laboratorios de Referencia de Micobacterias ${ }^{17}$.

En este trabajo se comparó la identificación de especies de micobacterias por métodos tradicionales y mediante el análisis de los patrones de restricción. En todas las cepas de micobacterias no tuberculosas analizadas, se amplificó un fragmento de $440 \mathrm{pb}$ del gen que codifica para la proteína de shock térmico
Hsp65. El análisis con ambos métodos de las 7 cepas de colección de micobacterias, demostró que las pruebas tradicionales identificaron emóneamente, las cepas de $\mathrm{M}$ triviale y $\mathrm{M}$ chitae, sin embargo, el método APR las identificó correctamente.

En 87,5\% de las muestras clínicas hubo correlación en la identificación por ambos métodos. Sin embargo, una de las características más importante de la tipificación mediante APR, es que permitió identificar especies como $\mathrm{M}$ terrae, $\mathrm{M}$ chitae y $\mathrm{M}$ noncromagenicum, que no fueron identificadas correctamente por los métodos tradicionales. Este nuevo método, además, permitió diferenciar los complejos avium-intracelular y fortuitum-chelonae y clasificar las especies en subtipos. La subdivisión de las especies de micobacterias podría ser una herramienta epidemiológica importante para diferenciar aquellas especies que sean más patogénicas.

En 12,5\% de las muestras no hubo una correlación entre los resultados obtenidos por ambos métodos. La identificación mediante el análisis genético del ARN ribosomal 16S de estas muestras, confirmó, los resultados obtenidos con el método APR.

La identificación mediante APR, también ha sido útil en la identificación del complejo tuberculosis, especialmente en muestras donde la identificación morfológica de la tuberculosis no es concluyente.

La principal desventaja en el uso en forma rutinaria de $\mathrm{APR}$, se debe a diferencias en la interpretación de los patrones obtenidos en distintos laboratorios ${ }^{17}$. Esto se debe principalmente al tipo de agarosa utilizada y a diferencias en el tiempo de la electroforesis ${ }^{10,17}$. Por lo tanto, es fundamental que los laboratorios utilicen los mismos reactivos y las mismas condiciones de electroforesis. A su vez es importante el uso de programas

Tabla 3. Resultados discordantes entre la identificación por APR y los métodos tradicionales

\begin{tabular}{|lcc|}
\hline Métodos tradicionales & APR & Secuenciamiento genético \\
\hline M flavescens & M fortuitum tipo 1 & M fortuitum \\
CMAI & M simiae tipo 1 & M simiae \\
M fortuitum & M terrea tipo 1 & M terrae \\
M flavescens & M gordonae tipo 3 & M gordonae \\
Micobacteria no-tuberculosa & M simiae tipo 1 & M simiae \\
M scrofulaceum & M gordonae tipo 1 & M gordonae \\
M scrofulaceum & M gordonae tipo 1 & M gordonae \\
M gastri & M nomcromogenicum tipo 2 & M nomcromogenicum \\
\hline
\end{tabular}


bio-informáticos para corregir las diferencias en las condiciones de corrida, para facilitar la interpretación de los patrones de ADN obtenidos ${ }^{17}$.

El análisis de los patrones de restricción es un método alternativo, simple y económico, para una rápida identificación y podría ser implementado

\section{REFERENCIAS}

1. Branger B, Gouby a, Oules R, Balducci JP, Mourad G, FouRCADE J ET AL. Mycobacterium haemophilum and Mycobacterium xenopi associated infection in a renal transplant patient. Clin Nephrol 1985; 23: 46-9.

2. Dever L, Martin JW, Seaworth B, Jorgensen JI. Varied presentations and responses to treatment of infections caused by Mycobacterium haemophilum in patients with AIDS. Clin Infect Dis 1992; 14: 1195-200.

3. Straus WL, Ostroff SM, Jernigan DB, Kiehn TE, SordiLo E, Armstrong M et al. Clinical and epidemiological characteristics of Mycobacterium haemophilum, an emerging pathogen in immunocompromised patients. Ann Intern Med 1994; 120: 119-25.

4. White MH, Papadopoulos EB, Small TN, Kiehn TE, ARMSTRONG D. Mycobacterium haemophilum infections in bone marrow transplant recipients. Transplantation 1995; 60: 957-60.

5. Devalois A, Seng K, Rasogi N. Rapid identification of Mycobacterium to species level by PCR-restriction fragment length polymorphism analysis of the hsp 65 gene and proposition of an algorithm to differentiate 34 Mycobacterial species. J Clin Microbiol 2002; 35: 2969-73.

6. Da Silna-Rocha A, Barreto W, Campos C, Vilalobos M, FonsECA I, SAAD M ET aL Novel allelic variants of Mycobacterium isolates in Brazil as determined by PCR-restriccion enzyme analysis of hsp 65. J Clin Microbiol 2002; 40: 4191-6.

7. Palomino JC, Martin A, Portaels F. New methods for the diagnosis and drug resistance detection in mycobacteria. Recent Res Devel Microbiol 2002; 2: 297-318.

8. Telenti A, Marchesi F, Balz F, Baly E, Böttger E, BODMER T. Rapid identification of mycobacteria to the species level by polymerase chain reaction and restriction enzyme analysis. J Clin Micribiol 1993; 31: 175-8.

9. Devalois A, Goh KS, Rastogi N. Rapid identification of mycobacteria to species level by PCR-restriction en forma rutinaria en los Laboratorios de Referencia de Micobacterias. El tiempo para completar la identificación mediante APR es de 48 h, mientras que en la metodología tradicional se requieren cuatro semanas o más para obtener resultados.

fragment length polymorphism analysis of the hsp65 gene and proposition of an algorithm to differentiate 34 mycobacterial species. J Clin Microbiol 1997; 35: 2969-73.

10. Brunelo F, Ligozzi M, Cristem E, Bonora S, Tortol E, Fontana R. Identification of 54 mycobacterial species by PCR-restriction fragment length polymorphism analysis of the hsp 65 gene. J Clin Microbiol 2001; 39: 2799-806.

11. Kent PT, KuBICA GP. Public health mycobacteriology. A guide for the level III Laboratory Center for Disease Control. Atlanta. GA. 1985.

12. Da Silia CF, Ueki M, Geiger D, Cardoso S. hsp 65 PCRrestriction enzyme analysis for identification of Mycobacterium in the clinical laboratory. Rev Inst Med trop 2001; 43: 1-9.

13. Cobos-Marín L, Montes J, Rviera S, Licea A, Gonzáiez J, ESTRADA I. A novel multiplex-PCR for the rapid identification of Mycobacterium bovis in clinical isolates of both veterinary and human origin. Epidemiol Infect 2003; 130: 485-90.

14. Matos DM, Santana MA, Santana MC, Mamede $P$, BECERRA B, PAÑAo ED ET AL. Nontuberculosis micobacterias at a multiresistant tuberculosis reference center in Bahia: clinical epidemiological aspects. The Brazilian Journal of Infectious Diseases 2004; 8: 296-304.

15. WaGNeR D, Young LS. Nontuberculous mycobactenum infections: a clinical review. Infection 2004; 32: 257-70.

16. Ferreira RMC, SaAd MHF, Da Silva MG, Foncesa LS. Non-tuberculous micobacteria I: One year clinical isolates identification in Tertiary Hospital Aids Reference Center, Rio de Janeiro, Brazil, In Pre Highly Active Antiretroviral Therapy Era. Mem Inst Osvaldo Cruz 2002; 97: 725-9.

17. leao SC, Bernarde山l A, Cataldi A, Zumarraga M, Robledo J, REALPE T ET AL. Multicenter evaluation of mycobacterium identification by PCR restriction enzyme analysis in laboratories from Latin America and the Caribbean. Journal of Microbiological Methods 2005; 61: 193-9. 


\section{PROXIMAS PUBUCACIONES DE LAREVSTAMEDICADECHLE}

- Expectativas de estudiantes de medicina de pregrado en relación al perfil de médico esperado.

- Relación estudiante-enfermo: visión del paciente.

- Prevalencia de marcadores serológicos (ANCA y ASCA) en una población con colitis ulcerosa.

- Identificación de mutaciones en el gen CYBB que llevan al fenotipo de la enfermedad granulomatosa crónica ligada al cromosoma X: reporte de una nueva mutación.

- Programa de trastornos de alimentación en adolescentes y jóvenes chilenos: variaciones a seis meses de tratamiento.

- Genotipificación de aislados clínicos de Helicobacter pylori en base a genes asociados a virulencia cagA, vacA y babA2.

- Resultados terapéuticos en pacientes acromegálicos: es tiempo de intervenir.

- Estudio endoscópico en familiares de primer grado de pacientes operados por cáncer colorrectal.

- Expresión inmunohistoquímica del complejo E-caderina-catenina en cáncer gástrico. Relación con variables clínico-morfológicas y sobrevida de pacientes.

- Resonancia magnética de médula espinal y cerebro en el correlato clínico de la paraparesia espástica progresiva que se asocia al virus humano linfotrópico Tipo-1 (HTLV-I).

- Asistencia ventricular mecánica como puente al trasplante en pacientes en shock cardiogénico: experiencia preliminar en Chile con ABIOMED BVS $5000^{\circledR}$.

- Tratamiento endoluminal de disección aguda complicada en aorta descendente.

- Streptococcus constellatus: agente etiológico asociado en empiema pleural.

- Barrera intestinal del paciente crítico: realidades y tendencias.

- Vino, fibrinolisis y salud.

- Recomendaciones para la valoración nutricional del paciente crítico.

- Valsalva, mucho más que una maniobra. Antonio María Valsalva (1666-1723). 


\title{
Eficacia del infliximab en pacientes con síndrome de Behçet portadores de úveo-retinitis grave
}

\author{
G uillermo Merino ${ }^{1,2}$, G onzalo Varas ${ }^{3 a}, G$ onzalo Díaz ${ }^{4 a}$, \\ Miguel Gutiérrez ${ }^{5}$, Loreto Massardo ${ }^{5}$, Daniel Pacheco ${ }^{6}$, \\ Francisco Villarroel ${ }^{7}$ y Miguel Cuchacovich ${ }^{8,9}$. \\ Effectiveness of infliximab in patients \\ with Behçet syndrome and severe \\ uveoretinitis. Report of five cases
}

The efficacy and safety of repeated administration of infliximab was evaluated in five patients (two men, three women) with Behçet syndrome accompanied by severe uveoretinitis. Ocular and extra ocular inflammation was suppressed in all patients during the observation period without any serious adverse reactions. The results in these patients suggests that TNF- $\alpha$ blockade is effective in patients with severe ocular Behçet syndrome (Rev Méd Chile 2006; 134: 875-82).

(Key words: Behçet syndrome; Infliximab; Retinitis; Uveitis)

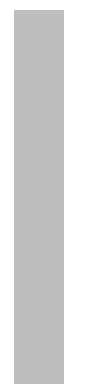

\begin{abstract}
Recibido el 12 de julio, 2005. Aceptado el 10 de enero, 2006.
${ }^{1}$ Departamento de Oftalmología, Clínica Santa María, Santiago, Chile. ${ }^{2}$ Centro Oftalmológico Luis Pasteur, Santiago, Chile. ${ }^{3}$ Facultad de Medicina, Pontificia Universidad Católica de Chile. ${ }^{4}$ Facultad de Medicina, Universidad de Chile. ${ }^{5}$ Departamento de Inmunología Clínica y Reumatología, Facultad de Medicina, Pontificia Universidad Católica de Chile. ${ }^{6}$ Sección de Reumatología, Departamento de Medicina, Hospital San Borja Arriarán, Campus Centro, Facultad de Medicina, Universidad de Chile. ${ }^{7}$ Fundación Oftalmológica Los Andes, Santiago, Chile. ${ }^{8}$ Sección de Reumatología, Departamento de Medicina, Hospital Clínico de la Universidad de Chile, Santiago, Chile. ${ }^{9}$ Sección de Reumatología, Departamento de Medicina, Clínica Las Condes, Santiago, Chile.

aAyudante alumno de Medicina
\end{abstract}

$\mathrm{E}^{1}$ síndrome de Behçet (SB) es una enfermedad inflamatoria crónica, multisistémica, de baja frecuencia en nuestro medio, que se caracteriza por la presencia de úlceras mucosas recurrentes, lesiones cutáneas como eritema nodoso y pseudo-

Correspondencia a: Dr. Miguel Cuchacovich. San Pío X, № 2460, Oficina 607, Providencia, Santiago, Chile. E mail: mcuchaco@yahoo.com. foliculitis, uveítis y tromboflebitis ${ }^{1,2}$. La uveoretinitis (UR) es una complicación mayor del SB que puede llevar a secuelas severas y amaurosis ${ }^{3}$.

Los inmunosupresores (como la ciclosporina A y la azatioprina) son agentes efectivos en el control de los ataques de UR en la mayoría de los pacientes portadores de SB. Sin embargo, en algunos pacientes los inmunosupresores son ineficaces o la aparición de efectos colaterales impide su utilización en dosis adecuadas. 
El factor de necrosis tumoral- $\alpha$ (TNF- $\alpha$ ) es una citoquina proinflamatoria capaz de agravar la uveítis en modelos animales de uveoretinitis experimental autoinmune (UEA) y los anticuerpos monoclonales anti TNF- $\alpha$ son capaces de inhibir la aparición de UEA ${ }^{4,5}$. Ha sido demostrado que clones de linfocitos $\mathrm{T}$ intraoculares y monocitos periféricos de pacientes con SB con UR activa presentan mayor producción de TNF- $\alpha$ que los controles normales ${ }^{6,7}$. Lo anterior sugiere que el TNF- $\alpha$ estaría involucrado en la actividad de la UR en pacientes con SB.

El infliximab es un anticuerpo monoclonal quimérico anti-TNF- $\alpha$ altamente efectivo en el control de los síntomas y de la progresión del daño radiológico en pacientes con artritis reumatoidea ${ }^{8,9}$ y otras enfermedades inmunológicamente mediadas.

A la fecha, hay comunicaciones preliminares de casos clínicos aislados y series pequeñas que sugieren que el infliximab puede ser un agente eficaz en el control de los síntomas clínicos del $\mathrm{SB}^{10-12}$.

El presente estudio tiene por objeto comunicar nuestra experiencia en 5 pacientes con SB activo tratados con infliximab. Todos los pacientes presentaban una severa UR activa antes de iniciar la administración de infliximab. El SB mejoró significativamente en todos ellos sin la aparición de reacciones adversas graves.

\section{PACIENTES Y MÉTODOS}

Cinco pacientes (tres mujeres y dos hombres) fueron incluidos en este estudio. La Tabla 1 muestra las características demográficas de los pacientes. El diagnóstico de SB consideró la presencia de al menos tres criterios clásicos, incluyendo úlceras mucosas recurrentes, severas y UR en todos los pacientes. Todos tenían un PPD menor de $4 \mathrm{~mm}$ y una radiografía de tórax normal al inicio del tratamiento con infliximab.

El infliximab fue administrado en dosis de 3 a $5 \mathrm{mg} / \mathrm{kg}$ a las semanas $0,2,6$ y luego cada 8 a 10 semanas en infusión intravenosa por un período de entre 2 y $3 \mathrm{~h}$. En caso de refractariedad se disminuyó el intervalo entre las dosis a 4 semanas.

Se registró la respuesta clínica tanto a nivel ocular como extraocular en controles periódicos cada 4 semanas.

Paciente 1. Hombre de 26 años con antecedentes de úlceras orales, genitales y foliculitis a repetición desde 1993. En 2001 presentó un accidente vascular isquémico de troncoencéfalo. Consultó en julio de 2003 por visión borrosa y disminución de la agudeza visual. El examen oftalmológico demostró una panuveítis bilateral con edema macular mayor en ojo derecho (OD). La agudeza visual (AV) era de 0,05 en el OD y de 0,2 en el ojo izquierdo (OI). Se indicó 3 pulsos de $1 \mathrm{~g}$ de metil prednisolona por pulso, seguido de prednisona 1 $\mathrm{mg} / \mathrm{kg} /$ día sin experimentar mejoría a los 7 días, por lo que se decidió iniciar tratamiento con infliximab.

Paciente 2. Mujer de 24 años que en agosto de 2004 comenzó con eritema nodoso de ambas extremidades inferiores. Tres semanas después se agregaron múltiples lesiones ulceradas dolorosas (al menos 15) en la mucosa oral y dos lesiones ulceradas en la mucosa vaginal. Consultó el 6 de octubre de 2004 por visión borrosa. El examen oftalmológico mostró Tyndall celular $(+++)$ en cámara anterior en ojo derecho e izquierdo (ODI), sinequias posteriores en OI, presencia de células $(+)$ en el vítreo anterior en ambos ojos. El fondo

Tabla 1. C aracterísticas demográficas de los pacientes incluidos en la serie

\begin{tabular}{|lll|}
\hline & Mujeres & Hombres \\
\hline Número & 3 & 2 \\
Rango de edad (años) & $24-49$ & $26-40$ \\
Promedio de edad (años) \pm DE & $34,66 \pm 12,9$ & $33 \pm 9,8$ \\
\hline
\end{tabular}


de ojo mostró trombosis de rama venosa, exudados algodonosos retinales a nasal y vasculitis moderada en OD. El OI mostraba trombosis de vena central, infiltrados retinales múltiples y severa vasculitis (Figura 1a). La angiofluoroesceinografía reveló además la presencia de zonas de isquemia retinal en OI (Figura 1b). La agudeza visual era de 0,6 en OD y de 0,15 en OI. Se encontraba sin tratamiento al momento de iniciar el infliximab.

Paciente 3. Mujer de 31 años que en mayo de 2000 comenzó con un síndrome febril no infeccioso con adenopatías cervicales de 1 mes de duración que remitió espontáneamente. En julio del mismo año presentó una vasculitis retinal. Refería el antece-

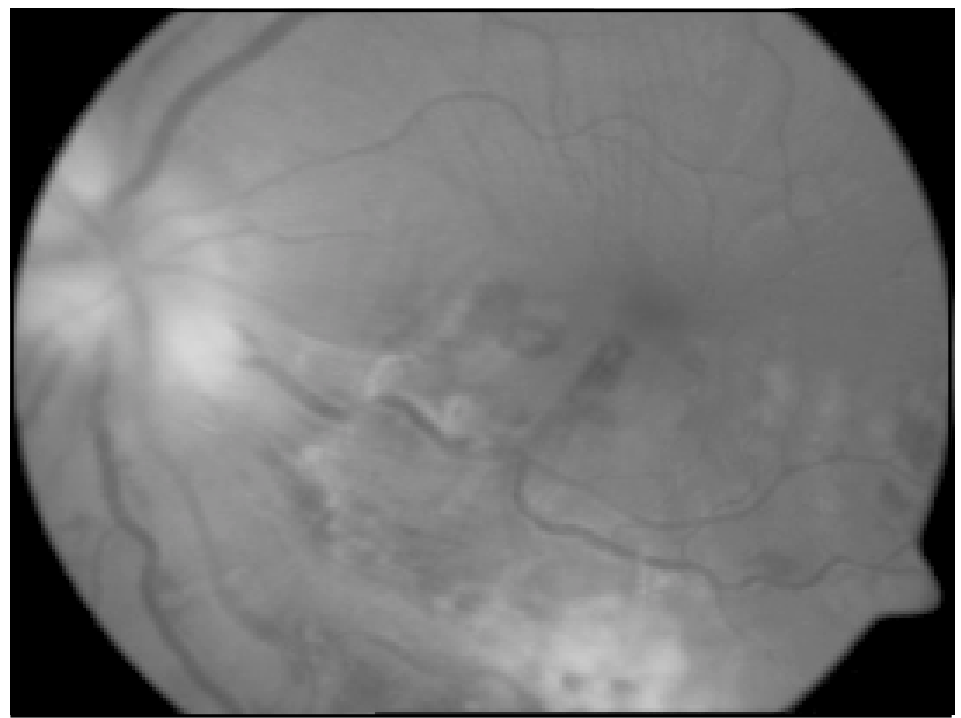

Figura 1a. Fondo de ojo de la paciente 2 al momento de iniciar terapia con infliximab. Se observa trombosis de vena central de la retina, numerosas hemorragias retinales en polo posterior y exudados algodonosos en relación a arcada temporal inferior.

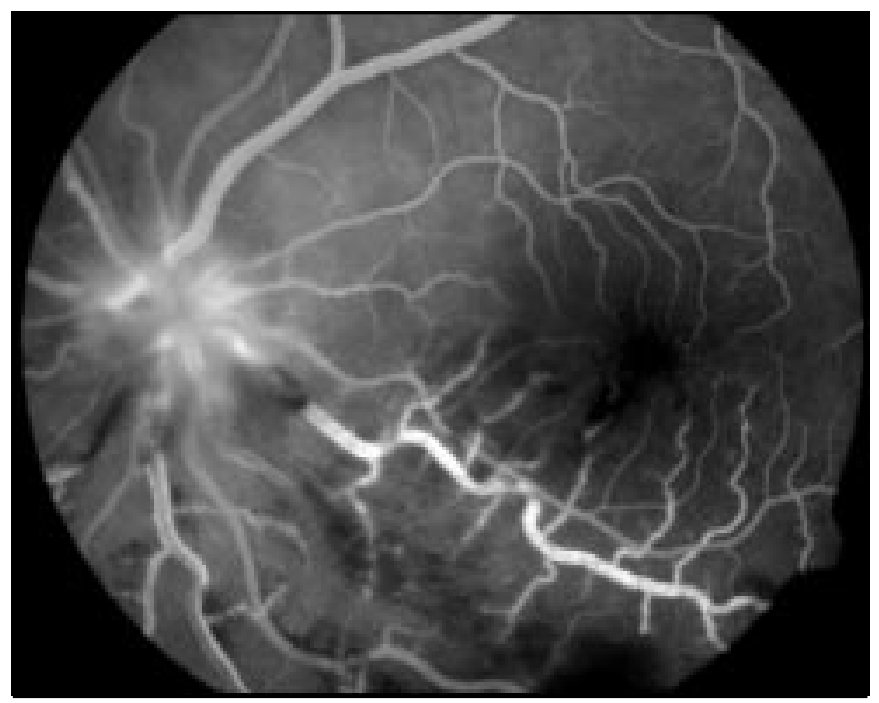

Figura 1b. Angiofluoroesceinografía de la paciente 2 al momento de iniciar terapia con infliximab. Se observa trombosis de vena central de la retina, hemorragias retinales, vasculitis arterial e isquemia retinal penipapilar inferior. 
dente de úlceras orales a repetición y úlceras genitales en dos oportunidades. Se solicitó HLA B51, cuyo resultado fue (+). Recibió tratamiento con metil prednisolona oral en dosis $64 \mathrm{mg} /$ día y ciclosporina A en dosis de 150 mg/día. Evolucionó satisfactoriamente y se redujeron los fármacos en forma progresiva hasta su suspensión en junio de 2003. En octubre de 2004 presentó nueva crisis ocular por lo que se inició tratamiento con prednisona en dosis de $60 \mathrm{mg} /$ día. Al mes de tratamiento se agregó disminución de la agudeza visual $(\mathrm{OD}=$ 0,6 y $\mathrm{OI}=0,2$ ) por lo que la paciente fue derivada a nuestro centro. Al examen oftalmológico el OD se encontraba normal. OI con células escasas en cámara anterior y en vítreo. El fondo de ojo en OI mostraba palidez papilar leve a temporal y sospecha de edema macular.

Paciente 4. Mujer de 49 años con historia clínica que data de 1996 cuando presentó una vasculitis de troncoencéfalo. En los meses y años siguientes se agregaron úlceras orales a repetición, eritema nodoso, foliculitis y un episodio de vasculitis retinal y panuveítis en $\mathrm{OD}$, con recurrencias sistémicas de la enfermedad en forma periódica con brotes de 2 a 3 meses de duración e intervalos libres variables de aproximadamente 6 meses. Consultó por un brote de panuveítis en OI en octubre de 2002, con agudeza visual de 0,8 en OD y cuenta dedos en OI. En ese momento la paciente se encontraba recibiendo prednisona 20 $\mathrm{mg} /$ día, azatioprina $100 \mathrm{mg} /$ día y talidomida en dosis de 200 mg/día.

Paciente 5. Hombre de 40 años que en diciembre de 2002 presentó úlceras orales recurrentes y eritema nodoso en extremidades inferiores. En febrero de 2003 se asoció un cuadro de uveítis anterior aguda y maculopatía en OD tratado con esteroides locales, obteniéndose regresión parcial del cuadro. Consultó médico internista quien planteó un SB e inició tratamiento con metil prednisolona $8 \mathrm{mg} /$ día, metotrexato (MTX) en dosis de $15 \mathrm{mg} / \mathrm{semanal}$ y pentoxifilina $400 \mathrm{mg} /$ día. Permaneció estable hasta abril de mismo año en que presentó un nuevo brote de uveítis, esta vez bilateral por lo que se agregaron esteroides locales que lograron controlar la crisis. Evolucionó en forma estable con metil prednisolona y MTX en igual dosis hasta noviembre de 2003 en que presentó nueva crisis de úlceras orales y genitales, compromiso del estado general, reactivación de la uveítis, piodermitis, eritema nodoso y artritis de ambos tobillos. En el examen ocular se constató un Tyndall (+) en OD y (+) en OI. Opacidades vítreas en OD con edema macular. La agudeza visual era de 0,4 en OD y de 1,0 en OI.

\section{Resultados}

El paciente 1 inició el tratamiento con infliximab y prednisona $1 \mathrm{mg} / \mathrm{kg} /$ día el 11 de julio de 2003. Se observó una respuesta clínica a las 48 h de la administración del infliximab y una franca mejoría al cabo de 2 semanas de la primera dosis. La agudeza visual mejoró a 0,5 en OD y 0,8 en OI. No de detectó inflamación a la biomicroscopia. Durante las siguientes 4 semanas la agudeza visual continuó mejorando a 0,8 parcial en OD y a 1,0 en OI, logrando suspender la prednisona a la sexta semana de tratamiento. Al cabo de la tercera dosis de infliximab debió suspender el tratamiento por realización de uretroplastia.

Permaneció inactivo del SB hasta el 20 de marzo de 2004 en que presentó una recaída del compromiso ocular, diagnosticándose una panuveítis bilateral y pesquisándose una disminución de la agudeza visual a 0,5 en el OI. Se reinició tratamiento con infliximab logrando controlar la inflamación intraocular y recuperando la visión en ambos ojos a 1,0 al mes de tratamiento. A la fecha se encuentra recibiendo infliximab cada 8 semanas. Su visión es normal y presenta mínima inflamación residual de la retina periférica en OI.

La paciente 2 inició infliximab el 8 de octubre de 2004. Se detectó una mejoría de la agudeza visual desde 0,6 a 1,0 en OD y desde 0,15 a 1,0 en OI a las 4 semanas de iniciado el tratamiento. El fondo de ojo de esa fecha mostró solamente fístulas venosas peripapilares en la arcada temporal inferior del OI (Figura 2a). La angiofluoroesceinografía del OI reveló resolución completa de la trombosis de la vena central de la retina, ausencia de vasculitis, persistiendo sólo hemorragias retinales escasas y pequeña fístula venosa peripapilar en arcada temporal inferior (Figura $2 b$ ). A la fecha se encuentra recibiendo infliximab cada 8 semanas sin presentar inflamación intraocular ni síntomas sistémicos. 


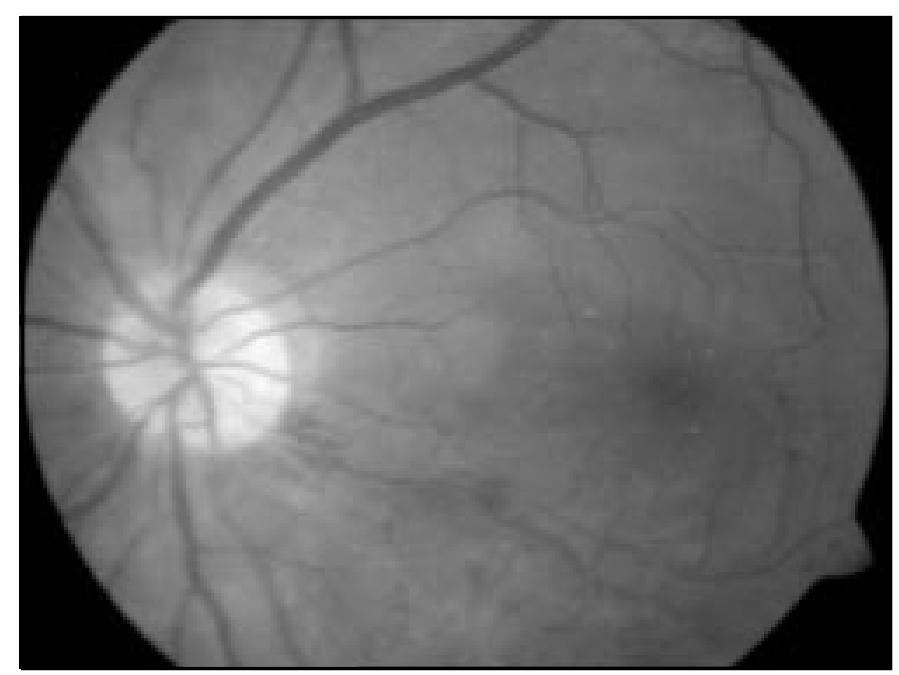

Figura 2a. Fondo de ojo de la paciente 2 a las cuatro semanas de iniciado el tratamiento con infliximab. Se observan escasas hemorragias retinales y pequeña fístula venosa peripapilar.

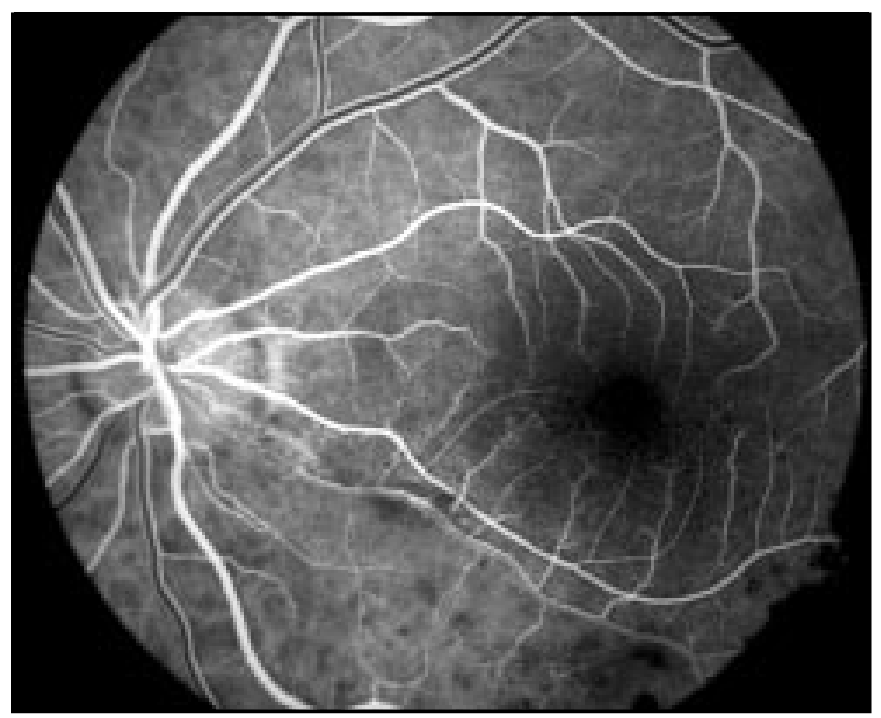

Figura 2b. Angiofluoroesceinografía de la paciente 2 a las cuatro semanas de iniciado el tratamiento con infliximab. Se observa sólo pequeña fístula venosa peripapilar y escasas hemorragias retinales.

La paciente 3 inició el infliximab el 15 de octubre de 2004. A los 10 días después de la primera infusión se apreció una mejoría de la agudeza visual en OD desde 0,6 a 1,0 y en OI desde 0,2 a 0,7 . La biomicroscopia era normal en ambos ojos. El fondo de ojo era normal en OD y mostraba una hemorragia retinal periférica a temporal en el OI. A la fecha la paciente se encuentra recibiendo infliximab cada 10 semanas y prednisona $5 \mathrm{mg} /$ día. La agudeza visual es 1,0 en ambos ojos y no hay inflamación ocular ni síntomas sistémicos. 
La paciente 4 inició infliximab en octubre de 2002 con recuperación de la visión en OI desde «cuenta dedos»a 0,6 a las tres semanas y 0,8 a las seis semanas. A la fecha se mantiene inactiva en terapia con infliximab cada 10 semanas.

El paciente 5 inició tratamiento con infliximab el 18 de noviembre de 2003 y se mantiene la metil prednisolona en dosis de $8 \mathrm{mg} /$ día y el MTX en 15 $\mathrm{mg} /$ semanal. Al mes de iniciada la terapia desaparecieron completamente las úlceras mucosas y el compromiso cutáneo, persistiendo la artritis de tobillos. La VOD mejoró de 0,4 a 0,6 y se mantuvo en 1,0 en el OI. El Tyndall era (-) en ambos ojos. Debido a la refractariedad de la artritis debió mantenerse con infusiones mensuales de infliximab, logrando inactivar la artritis al cabo de la cuarta dosis. Recibió un total de 5 infusiones al cabo de las cuales el paciente discontinuó el control en marzo de 2004. Continuó en tratamiento con metil prednisolona y MTX hasta junio de 2004 en que consultó por una nueva crisis de úlceras mucosas, poliartritis y uveítis por lo que se reinició el tratamiento con infliximab cada 4 semanas, logrando controlar el cuadro de uveítis después de la tercera dosis de infliximab y la artritis después de la sexta dosis del fármaco.

La Tabla 2 muestra un resumen de la respuesta al tratamiento con infliximab en los 5 pacientes.

Efectos colaterales. No se detectaron efectos adversos mayores como la aparición de tuberculosis, infecciones respiratorias graves, celulitis o pielonefritis aguda en los pacientes tratados.

\section{DisCUSIÓN}

El SB es la principal causa de ceguera en países como Japón y Turquía. Si bien no existen estudios de prevalencia en nuestro país, el diagnóstico de esta entidad se realiza con baja frecuencia en la práctica clínica en nuestro medio. Lo anterior puede explicarse por la participación de factores genéticos y por un subdiagnóstico del cuadro. Sin embargo, se estima que $10 \%$ de los pacientes con SB son refractarios a los esteroides e inmunosupresores.

En este estudio se incluyeron pacientes portadores de SB grave. Todos ellos presentaban severo compromiso ocular y ha sido reportado que el TNF- $\alpha$ es un importante mediador de la inflamación intraocular ${ }^{12}$. Hemos comunicado recientemente que pacientes portadores de SB activo presentan altos títulos de anticuerpos de clase IgG deglicosilada anti-acido lipoteicoico (LTA) (un antígeno de origen estreptocócico) y que estos anticuerpos activan complemento in vitro. Del mismo modo los monocitos periféricos de estos pacientes producen gran cantidad de interleuquina-8 (IL-8) frente al estímulo con LTA ${ }^{13}$. A su vez ha sido reportado que el LTA es capaz de inducir la producción de TNF- $\alpha$, IL-1ß, IL-6 y de IL-8 en monocitos humanos in vitro ${ }^{14}$. Es decir es posible postular que antígenos ambientales podrían estimular la producción de citoquinas proinflamatorias en células mononucleares de pacientes con SB lo que contribuiría a explicar la reactivación de la enfermedad. Estas observacio-

Tabla 2. C aracterísticas del compromiso ocular, respuesta al infliximab y efectos adversos graves

\begin{tabular}{|ccccc|}
\hline Paciente & $\begin{array}{c}\text { Agudeza visual } \\
\text { pretratamiento }\end{array}$ & $\begin{array}{c}\text { Agudeza visual } \\
\text { luego de 3 dosis de } \\
\text { infliximab }\end{array}$ & $\begin{array}{c}\text { Control de la } \\
\text { inflamación } \\
\text { ocular al año de } \\
\text { seguimiento }\end{array}$ & $\begin{array}{c}\text { Efectos adversos } \\
\text { graves a los 6 } \\
\text { meses }\end{array}$ \\
\hline 1 & OD 0,05 OI 0,2 & OD 0,8 OI 1,0 & + & - \\
2 & OD 0,6 OI 0,15 & OD 1,0 OI 1,0 & + & - \\
3 & OD 0,6 OI 0,2 & OD 1,0 OI 1,0 & + & - \\
4 & OD 0,8 OI CD & OD 0,8 OI 1,0 & + & - \\
5 & OD 0,4 OI 1,0 & OD 0,6 OI 1,0 & + & - \\
\hline
\end{tabular}

$\mathrm{CD}=$ Cuenta Dedos, OD= ojo derecho, $\mathrm{OI}=$ ojo izquierdo. 
nes sobre la patogenia del SB son concordantes con la eficacia del tratamiento anti-TNF- $\alpha$ en esta enfermedad.

El infliximab administrado en dosis de entre 3 a $5 \mathrm{mg} / \mathrm{kg}$ demostró ser eficaz en el control de los síntomas y signos oculares en nuestros pacientes. Nuestros resultados son concordantes con los de otros autores, que reportan un dramático efecto del infliximab en el control del compromiso ocular en el SB ${ }^{10,11,15}$.

En relación al compromiso extraocular, el infliximab parece ser igualmente eficaz ya que tanto las úlceras mucosas como la piodermitis desaparecieron con el tratamiento, tal como ha sido reportado por otros autores ${ }^{16}$. Un problema aparte es la artritis. El paciente 5 presentaba una severa artritis la que fue de difícil control y obligó a acortar el intervalo de administración del fármaco. Este paciente recibió una dosis de $5 \mathrm{mg} / \mathrm{kg}$ que es superior a la utilizada en la artritis reumatoidea y aun así requirió de administraciones más frecuentes que las reportadas en la artritis reumatoidea. Lo anterior enfatiza la necesidad de identificar la dosis terapéutica eficaz de los fármacos anti TNF- $\alpha$ en cada patología por separado y no extrapolar resultados obtenidos en otras patologías inflamatorias que también producen sinovitis. Del mismo modo la eficacia del infliximab en UR asociada al SB no puede ser extrapolada a pacientes con otros tipos de uveítis. El diagnóstico de uveítis involucra una serie de patologías

\section{REFERENCIAS}

1. Kaklamani VG, Vaiopoulos G, Kaklamanis G. Behçet's disease. Semin Arthritis Rheum 1998; 27: 197-217.

2. Sakane T, Takeno M, Suzuki N, Inaba G. Behçet's disease. N Engl J Med 1999; 341: 1284-91.

3. Nussenblatt RB. Uveitis in Behçet's disease. Int Rev Immunol 1997; 14: 67-79.

4. Nakamura S, Yamakawa $T$, Sugita M, Kijima $M$, ISHIOKA $M$, TANAKA $S$ ET aL. The role of tumor necrosis factor-alpha in the induction of experimental autoimmune uveoretinitis in mice. Invest Ophthalmol Vis Sci 1994; 35: 3884-9. heterogéneas, muchas de las cuales pueden completar criterios diagnósticos meses o años después del primer brote de inflamación ocular y los fármacos anti TNF- $\alpha$ no son necesariamente eficaces en todas ellas.

$\mathrm{Si}$ bien, los reportes publicados sugieren que el infliximab parece ser bien tolerado en el SB, nos parece importante destacar que el número de pacientes tratados a la fecha es muy pequeño como para poder detectar efectos colaterales significativos. Ha sido reportado que el TNF- $\alpha$ posee un efecto antitrombótico ${ }^{17}$ y existen reportes preliminares que sugieren que el infliximab podría aumentar la incidencia de fenómenos tromboembólicos durante el tratamiento anti$\mathrm{TNF}^{18}{ }^{18}$. Una de las manifestaciones clínicas del SB es la trombosis arterial y venosa, por lo que estos pacientes deberían ser observados acuciosamente durante el tratamiento para descartar la aparición de un fenómeno trombótico.

En conclusión, el tratamiento anti-TNF- $\alpha$ parece ser una alternativa eficaz en el manejo del SB severo y/o refractario a terapia esteroidal e inmunosupresora. El efecto benéfico de este tratamiento apoya la hipótesis que el TNF- $\alpha$ es un mediador importante en el patogenia del SB. Nuestros resultados así como los de otros autores enfatizan la necesidad de diseñar estudios prospectivos randomizados que evalúen la eficacia de la terapia anti-TNF- $\alpha$ en los pacientes con SB. 
8. Lipsky PE, van der Heijde DM, St Clair EW, Furst DE, BReEDVeld FC, KaLden JR et al. Infliximab and methotrexate in the treatment of rheumatoid arthritis. N Engl J Med 2000; 343: 1594-602.

9. Cuchacovich M, Ferreira L, Aliste M, Soto L, Cuenca J, Cruzat A et al. TNF- $\alpha$ levels and influence of -308 TNF- $\alpha$ promoter polymorphism on the responsiveness to infliximab in patients with rheumatoid arthritis. Scand J Rheumatol 2004; 33: 228-32.

10. Sfikakis PP, Theodossiadis PG, Katsiari CG, KakiaMANIS P, MaRKOMICHELAKIS NN. Effect of infliximab on sight-threatening panuveitis in Behçet's disease. Lancet 2001; 58: 295-6.

11. Ohno S, Satoshi N, Hori S, Shimakawa M, Kawashima $\mathrm{H}$, MochizUKi M ET AL. Efficacy, safety, and pharmacokinetics of multiple administration of infliximab in Behçet's disease with refractory uveoretinitis. J Rheumatol 2004; 31: 1362-8.

12. Lacomba SM, Martin MC, Galardo Galera JM, Gómez Vidal MA, CoLantes Estévez E, Ramírez Chamond R et aL. Aqueous humor and serum tumor necrosis factor-alpha in clinical uveitis. Ophthalmic Res 2001; 33: 251-5.
13. Cuchacovich M, Merino G, Yamamoto J, Viliarroel F, SAAVEDRA T, Jofré $S$ et al. Behçet's disease patients present high levels of deglycosylated anti-lipoteichoic acid IgG and high IL-8 production after lipoteichoic acid stimulation. Clin Exp Rheumatol 2005; 23: S27-S34.

14. Mancuso G, Tomasello F, Ofek I, Teti G. AntiLipoteichoic acid antibodies enhance release of cytokines by monocytes sensitized with lipoteichoic acid. Infect Immun 1994; 62: 1470-3.

15. Muñoz-Fernández S, Hidalgo V, Fernández-Melón J, SCHLiNCKer A, Martín Mola E. Effect of infliximab on threatening panuveitis in Behçet's disease. Lancet 2001; 358: 1644.

16. Haugeberg G, Velken M, Johnsen V. Successful treatment of genital ulcers with infliximab in Behçet's disease. Ann Rheum Dis 2004; 63: 744-5.

17. Cambien B, Bergmeier W, Saffaripour S, Mitchel HA, WAGNER DD. Antithrombotic activity of TNFalpha. J Clin Invest 2003; 112: 1589-96.

18. RosenBAUM JT. Blind Insight: Eyeing anti-tumor necrosis factor treatment in uveitis associated with Behçet's Disease. J Rheumatol 2004; 31: 1241-3. 


\title{
Encefalomielitis aguda diseminada de presentación atípica: utilidad de la biopsia estereotáctica para su diagnóstico. Caso clínico
}

\author{
Pedro Vázquez $\mathbf{S}^{1}$, Andrés Reccius $\mathbf{M}^{1}$, Mario Díaz $\mathbf{S}^{1}$, \\ Lía Sáez $U^{2}$, Patricia 0 rellana $P^{3}$, Cristián Valdés $W^{1}$, \\ Violeta Díaz T¹. \\ Diagnosis of acute disseminated \\ encephalomyelitis using a stereotaxic \\ biopsy. Report of one case
}

We report a 15 year-old female presenting with behavioral disturbances, headache, left hemiparesis and paresis of the vertical gaze. CAT scan and magnetic resonance showed an involvement of right thalamus, third ventricle and medial temporal lobe suggesting an encephalitis or lymphoma. ${ }^{201}$ Thalium SPECT suggested a lymphoma. A stereotaxic biopsy showed a subacute demyelinizing lesion, compatible with an acute disseminated encephalomyelitis. The patient was treated with Methylprednisolone with resolution of symptoms. She remains in good condition after one year of follow-up (Rev Méd Chile 2006; 134: 883-6).

(Key w ords: Biopsy, needle; encephalomyelitis; Methylprednisolone)

Recibido el 15 de septiembre, 2005. Aceptado el 29 de noviembre, 2005.

Departamentos de ${ }^{1}$ Neurología-Neurocirugía, ${ }^{2}$ Anatomía Patológica e ${ }^{3}$ Imagenología, Hospital Clínico de la Universidad de Chile. Santiago de Chile.

L a encefalomielitis aguda diseminada (ADEM) es una enfermedad inflamatoria desmielinizante del sistema nervioso central (SNC). Se caracteriza por presentar defectos neurológicos multifocales, de inicio agudo o subagudo, habitualmente de curso monofásico, y por lo general presenta una buena recuperación. Puede ser precedida por una infección viral o una vacunación ${ }^{1}$. La ADEM afecta principalmente a niños y adultos jóvenes. Posiblemente, una exposición a un antígeno (infección o vacuna) gatillaría una respuesta inmune mediada

Correspondencia a: Dr. Pedro Vázquez. Neurocirugía. Santos Dumont 999. Teléfono: 7773882. Fax: 7378546. E mail: pvazquezs@yahoo.es por células $\mathrm{T}$ contra la proteína básica de la mielina u otro autoantígeno. Esto estaría causado por un mimetismo molecular o por activación inespecífica de un clon de células $\mathrm{T}$ autorreactivas ${ }^{2}$.

El proceso diagnóstico puede llegar a ser muy complejo. Se basa en el cuadro clínico, los hallazgos en la resonancia nuclear magnética cerebral (RNM) y el líquido cefalorraquídeo, debiéndose realizar, ocasionalmente, un estudio histopatológico, con biopsia de la lesión del cerebro $^{3-5}$. Según su forma de presentación y las neuroimágenes se plantea el diagnóstico diferencial con esclerosis múltiple, otras enfermedades desmielinizantes, encefalitis y procesos expansivos del $\mathrm{SNC}^{4,5}$. El objetivo de la presente publicación es mostrar un caso clínico, en donde la 
biopsia estereotáctica fue fundamental en el diagnóstico y su posterior enfrentamiento terapéutico.

\section{CASO CĹNICO}

Paciente de sexo femenino, de 15 años de edad, sin antecedentes mórbidos de importancia, sin cuadros infecciosos o vacunaciones en los meses previos. Ingresó al Hospital Clínico de la Universidad de Chile por presentar un cuadro de 3 semanas de evolución, caracterizado por cambios conductuales, puerilidad y desinhibición. Se agregó un síndrome confusional y disminución de la fuerza en el hemicuerpo izquierdo, asociado a cefalea holocránea leve a moderada. En el examen neurológi$\mathrm{co}$, al ingreso, destacaba una paciente vigil, pero confusa, con pupilas simétricas fotorreactivas, fondo de ojo sin papiledema, parálisis del $6^{\circ} \mathrm{par}$ craneal derecho, limitación en la mirada vertical ascendente, hemiparesia izquierda leve, y reflejo cutáneo-plantar extensor (Babinski) a izquierda.

La tomografía computada (TC) mostró una moderada hipodensidad alrededor del cuerno tem- poral derecho y otra que comprometió el tálamo del mismo lado, con escaso efecto de masa (Figura 1a) y sin captación significativa de medio de contraste (Figura 1b). En la resonancia nuclear magnética (RNM) se observaron en la secuencia FLAIR extensas lesiones hiperintensas a nivel temporal mesial derecho medial al cuerno temporal (Figura 1c), a nivel del tálamo del mismo lado y alrededor del tercer ventrículo (Figura 1d). También se observó un pequeño foco hiperintenso en la región subinsular anterior izquierda. Estas lesiones presentaban escaso efecto de masa y una evidente alteración de la barrera hematoencefálica, objetivado por un importante incremento de la señal T1, después del uso de Gadolinio, en la periferia de las lesiones, especialmente en aquella adyacente al cuerno temporal (Figuras 1e y 1f). Los hallazgos descritos plantearon los diagnósticos posibles de encefalitis o linfoma, $\mathrm{y}$, menos probable, una lesión desmielinizante pseudotumoral.

Los exámenes generales estaban dentro de límites normales. El estudio inicial de líquido cefalorraquídeo (LCR) mostró 20 leucocitos (100\% mononucleares) con glucosa y proteínas normales.

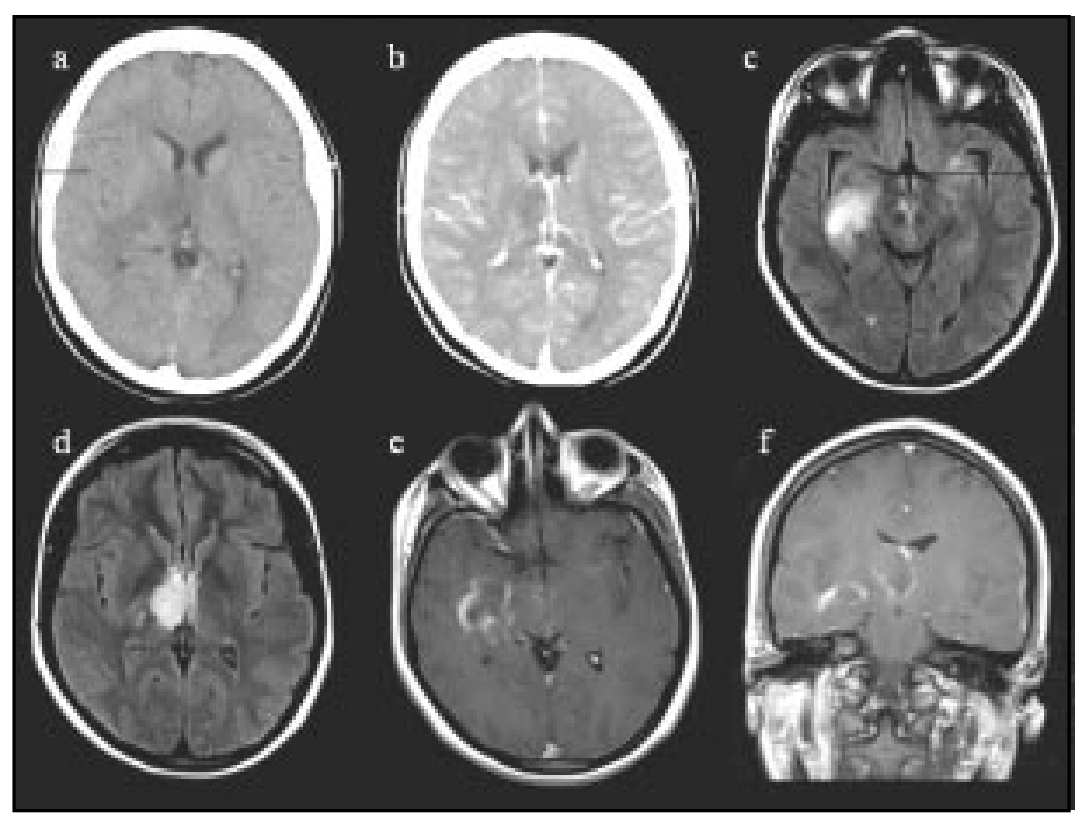

Figura 1. a) y b) TC Cerebral (a) sin medio de contraste, que muestra moderada hipodensidad talámica derecha y (b) con medio de contraste con escasa captación del mismo. c) y d) Secuencias FLAIR de RNM de Cerebro, (c) revela lesiones hiperintensas a nivel temporal mesial, (d) a nivel talámico derecho y alrededor del tercer ventrículo. e) y f) Secuencias T1 de RNM de cerebro con gadolinio de RNM (axial y coronal, respectivamente), muestran importante captación del medio paramagnético en relación a las lesiones descritas. 
Con estos elementos clínicos y ante la gravedad de una posible encefalitis herpética, se inició tratamiento empírico con aciclovir.

Los estudios inmunológicos (FR, ANA, ENA, ANCA) y de linfoma sistémico (LDH, ß2 microglobulina, TC de tórax y abdomen) fueron negativos. La PCR para virus herpes, el estudio de células neoplásicas, las bandas oligoclonales y el índice albúmina/IgG en el LCR resultaron normales. Se suspendió el tratamiento antiviral y se inició tratamiento con betametasona (4 mg cada $8 \mathrm{~h}$ ) para disminuir el edema cerebral, ante la posibilidad de un proceso expansivo.

Sin llegar a un diagnóstico aún, se realizó un SPECT cerebral con Talio 201, que mostró un foco de leve captación en el tálamo derecho que se extendía hacia temporal, sugerente de linfoma, más que lesión desmielinizante (Figura 2a).

La paciente evolucionó con deterioro neurológico progresivo, caracterizado por mayor compromiso de conciencia, llegando al sopor medio, compromiso total de la mirada vertical y hemiplejia izquierda.

Dada la gravedad de la paciente y la falta de diagnóstico, se decidió realizar una biopsia este-

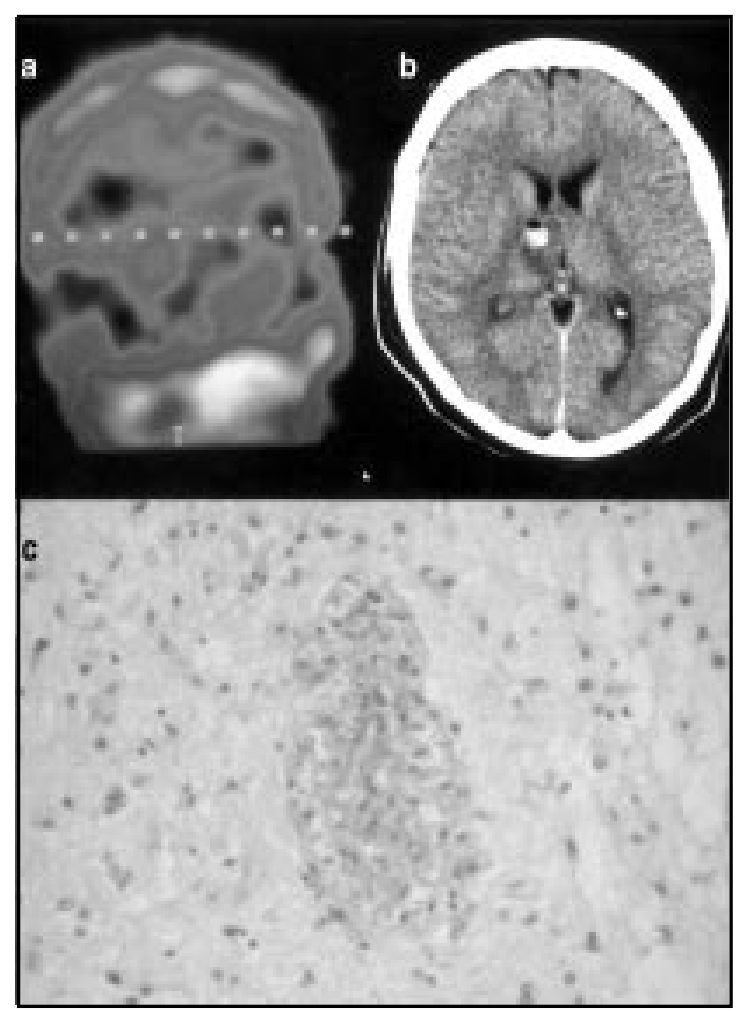

reotáctica. Se utilizó un anillo de arco centrado y un sistema de planificación computacional tridimensional, obteniendo así las coordenadas y ángulos precisos para llegar al blanco, sin lesionar tejido cerebral elocuente, a través de un abordaje precoronal derecho. Se tomaron muestras del centro de la lesión talámica, procedimiento sin complicaciones (Figura $2 b$ ).

El estudio histológico de la biopsia mostró un infiltrado inflamatorio discreto, de predominio mononuclear, de distribución preferentemente perivascular y gliosis reactiva, constituida por gemistocitos y macrófagos de citoplasma espumoso con granulaciones PAS (+). Estos hallazgos son compatibles con una patología desmielinizante de curso subagudo (Figura 2c).

Se inició tratamiento con metilprednisolona en dosis altas (un gramo al día por seis días), con lo que la paciente presentó una mejoría notoria, tanto de su compromiso de conciencia, como de sus defectos neurológicos focales. No volvió a presentar nuevos episodios transcurrido un año de evolución.

\section{Discusión}

En esta paciente el diagnóstico histológico fue compatible con una lesión desmielinizante subaguda. Creemos que por la historia clínica, las neuroimágenes y el estudio del LCR (ausencia de bandas oligoclonales y normalidad del índice albúmina Ig/

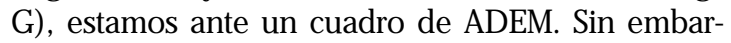
go, no se puede descartar un primer brote de una esclerosis múltiple (EM).

Figura 2. a) SPECT cerebral con Talio ${ }^{201}$. Foco de leve captación talámico derecho que se extiende hacia temporal. b) TC cerebral post biopsia, muestra burbuja de aire en el tálamo derecho en relación al sitio de biopsia. c) Corte histológico con tinción PAS a 1200 x. Infiltrado inflamatorio mononuclear perivascular y gliosis reactiva (gemistocitos y macrófagos con granulaciones PAS +). 
Algunos estudios de RNM han demostrado elementos que son más caractenísticos de ADEM que de EM, como la distribución de las lesiones en sustancia blanca subcortical más que periventricular, y el compromiso de la sustancia gris, tanto cortical como profundo, particularmente de los tálamos ${ }^{4,5}$. Además, se ha encontrado que las lesiones desmielinizantes de la ADEM tienden a ser pobremente marginadas ${ }^{6}$. Finalmente, lo más importante en su diferenciación es que en aquellos pacientes con ADEM de curso monofásico, se ha encontrado en los estudios imagenológicos de control una resolución de las lesiones o gliosis residual, y ausencia de nuevas lesiones, a diferencia de la esclerosis múltiple donde habitualmente aparecen nuevas lesiones asintomáticas?

El diagnóstico de la ADEM puede llegar a ser muy difícil, por lo que ocasionalmente se requiere realizar una biopsia cerebral, para demostrar una lesión desmielinizante. Schwarz ${ }^{8}$, en una serie retrospectiva de 40 casos de ADEM, recurrió a la biopsia en cuatro casos; Tenembaum ${ }^{10}$, en una

\section{REFERENCIA}

1. Bennetto L, Scolding N. Inflammatory/post-infectious encephalomyelitis. J Neurol Neurosurg Psychiatry 2004; 1: 22-8.

2. GARG RK. Acute Disseminated Encephalomyelitis. Postgrad Med J 2003; 79: 11-7.

3. Pohl-Koppe A, Burchett SK, Thiele EA, Hafier DA. Myelin basic protein reactive Th2 $\mathrm{T}$ cells are found in acute disseminated encephalomyelitis. J Neuroimmunol 1998; 91: 19-27.

4. Caldemeyer KS, Smith RR, Harris TM, Edwards MK. MRI in acute disseminated encephalomyelitis. Neuroradiology 1994; 36: 216-20.

5. Singh S, Alexander M, Korah IP. Acute disseminated encephalomyelitis: MR imaging futures. AJR Am J Roentgenol 1999; 173: 1101-7.

6. Dale RC, De Sousa C, Chong WK, Cox TC. Acute disseminated encephalomyelitis, multiphasic disseminated encephalomyelitis and multiple sclerosis in children. Brain 2000; 123: 2407-22.

7. HaRtung HP, GRossman R. ADEM distinct disease or part of the MS spectrum? Neurology 2001; 56: 1257-60.

8. Schwarz S, Mohr A, Knauth M, Wildemann B, Storch-Hagenlocher B. Acute disseminated encephalomyelitis: a follow-up study of 40 serie pediátrica de 84 pacientes, la utilizó en dos casos; Leake ${ }^{11}$, en uno de 42 casos y Hynson ${ }^{12}$ en dos de 31 pacientes. Murthy ${ }^{9}$, en otra serie pediátrica de 18 pacientes, no describe el uso de la biopsia.

En esta paciente, el diagnóstico previo a la biopsia no fue concluyente. La RNM planteaba una probable encefalitis o un proceso expansivo, el estudio de LCR no apoyó ninguna de estas dos etiologías y el SPECT fue compatible más bien con una lesión tumoral. La paciente presentó un rápido deterioro clínico, por lo que frente a un diagnóstico incierto, se recumó a la biopsia estereotáctica, que mostró finalmente una lesión desmielinizante, por lo que se pudo iniciar tratamiento con excelente respuesta.

Se destaca la utilidad de la biopsia estereotáctica en el diagnóstico de lesiones cerebrales de características inciertas. Es una técnica segura, con baja tasa de complicaciones, que van de 1 a $3 \%{ }^{13-}$ 16. En este caso en particular, la biopsia estereotáctica nos ayudó a definir la etiología, con lo que se pudo realizar un manejo adecuado y oportuno.

adult patients. Neurology 2001; 56: 1313-8.

9. Murthy SN, Faden HS, Cohen ME, BaKshi R. Acute disseminated encephalomyelitis in children. $\mathrm{Pe}$ diatrics 2002; 110: 1-7.

10. Tenembaum S, Chamoles $\mathrm{N}$, Fejerman N. Acute disseminated encephalomyelitis: a long-term follow-up study of 84 pediatric patients. Neurology 2002; 59: 1224-31.

11. Leake JA, Aiban S, Kao AS, Senac MO, Bшiman GF, NESPECA MP ET AL Acute disseminated encephalomyelitis in childhood: epidemiologic, clinical and laboratory features. Pediatr Infect Dis J 2004; 23: 756-64.

12. Hynson JL, Kornberg AJ, Coleman LT, Shield L, HaRvey AS, KeAn MJ. Clinical and neuroradiologic features of acute disseminated encephalomyelitis in children. Neurology 2001; 56: 1308-12.

13. V́́zquez P. Biopsia esterotáctica guiada por TAC y asistida por ordenador. Rev Chil Neurocirug 2004; 22: 76-82.

14. Bernstein M, PARRENT AG. Complications of CTguided stereotactic biopsy of intra-axial brain lesions. J Neurosurg 1994; 81: 165-8.

15. ApuZzo ML, SABshin JK. Computed tomographic guidance stereotaxis in the management of intracranial mass lesions. Neurosurgery 1983; 12: 277-85.

16. KeLY PJ. Stereotactic surgery: what is past is prologue. Neurosurgery 2000; 46: 16-27. 


\title{
Pérdida de resincronización biventricular. Causa inhabitual. Caso clínico
}

\author{
Ismael Vergara S, Patricia Frangini S, Rolando G onzález A, \\ Damián Alonso Ma.
}

Loss of biventricular resynchronization due to an uncommon cause. Report of one case

Cardiac resynchronization therapy is a non-pharmacological treatment for patients with dilated cardiomyophaty and congestive heart failure. The success of this therapy depends of permanent biventricular stimulation. We report an 84 year-old man, with intermittent loss of biventricular pacemaker stimulation despite having adequate sensing and stimulation thresholds in the right atrium and both ventricles. The problem was solved after correcting some programming parameters (Rev Méd Chile 2006; 134: 887-92).

(Key words: Cardiac pacemaker, artificial; Cardiomyopathies; Cardiomyopathy, dilated; Heart block)

Recibido el 1 de septiembre, 2005. Aceptado el 17 de noviembre, 2005.

Laboratorio de Electrofisiología Cardíaca, Departamento de Enfermedades Cardiovasculares, Facultad de Medicina, Pontificia Universidad Católica de Chile. Santiago de Chile.

aTécnico en estimulación cardíaca

L a terapia de estimulación con resincronización biventricular en pacientes con miocardiopatía dilatada e insuficiencia cardíaca congestiva avanzada, ha sido validada y aceptada, debido a que produce mejoría en la calidad de vida, función ventricular y en la sobrevida ${ }^{1-6}$. Para lograr esta resincronización, se requiere obtener una adecuada sincronía aurículo-ventricular e interventricular, manteniendo $100 \%$ de estimulación biventricular. Sin embargo, debido a que los dispositivos utiliza-

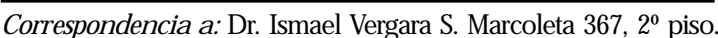
Teléfono: 3546402. Fax: 6327306. E mail: ivergara@med.puc.cl dos son cada día más complejos y con más funciones programables, no basta obtener parámetros adecuados de funcionamiento de los electrodos implantados, para asegurar el funcionamiento óptimo del dispositivo.

Presentamos el caso clínico de un paciente con miocardiopatía dilatada, enfermedad del nódulo sinusal y bloqueo aurículo-ventricular de primer grado, sometido a terapia de resincronización biventricular, en quien, pese a constatarse adecuado funcionamiento de los electrodos y programación correcta del intervalo aurículo-ventricular, se observó estimulación biventricular intermitente. 


\section{CASO CĹNIICO}

Hombre de 84 años, autovalente, portador de insuficiencia renal crónica etapa III y miocardiopatía dilatada idiopática en capacidad funcional III, con bloqueo aurículo-ventricular de primer grado (intervalo PR de 260-280 ms), y bloqueo completo de rama derecha (QRS de $160 \mathrm{~ms}$ de duración). En control ambulatorio se solicitó Holter de arritmias, que demostró enfermedad del nódulo sinusal y extrasistolía ventricular monomorfa aislada frecuente. Se le recomendó implante de marcapaso definitivo con resincronización biventricular, previo al inicio de tratamiento antiarrítmico. Se implantó sin incidentes un marcapaso Medtronic ${ }^{\circledR}$ Insync III modelo 8042, con electrodos endocavitarios bipolares Medtronic ${ }^{\circledR}$, modelo 4076, en la aurícula y ventrículo derecho, y electrodo bipolar de seno coronario Medtronic ${ }^{\circledR}$ modelo 4194, logrando parámetros adecuados de funcionamiento de todos los electrodos en el implante. El dispositivo quedó programado con frecuencia de estimulación entre 60 y 120 latidos por min, con intervalo aurículo-ventricular sensado de $130 \mathrm{~ms}$ y estimulado de $110 \mathrm{~ms}$, con output de estimulación de 4,0 Volt y 0,4 ms en aurícula derecha y ventrículo derecho y de 5,0 Volt y 0,4 ms en ventrículo izquierdo, con periodo refractario auricular post-ventricular (PVARP) en valor nominal y la función de prevención de taquicardia mediada por marcapaso activa.

El electrocardiograma de control, tomado a las $24 \mathrm{~h}$ post-implante, mostró ritmo sinusal con conducción aurículo-ventricular espontánea, con bloqueo aurículo-ventricular de primer grado y bloqueo completo de rama derecha, sin espigas de estimulación (Figura 1). La radiografía de tórax mostró los electrodos en posición adecua$\mathrm{da}$, sin evidencias de desplazamiento. La interrogación del dispositivo, mediante telemetría, mostró funcionamiento adecuado de los electrodos. Se midió en la aurícula una onda $\mathrm{P}$ sensada de 1,0-1,4 mV, umbral de estimulación $<0,5 \mathrm{~V}$ a $0,4 \mathrm{~ms}$, con impedancia de estimulación de 355 Ohms; en el ventrículo derecho se midió onda $\mathrm{R}$ sensada de 15,68-22,4 mV, umbral de estimulación $<0,5 \mathrm{~V}$ a $0,4 \mathrm{~ms}$, con impedancia de estimulación de $485 \mathrm{Ohms;}$ y en el ventrículo izquierdo, se midió onda $\mathrm{R}$ sensada de 4,0-5,6 $\mathrm{mV}$, umbral de estimulación de $1,0 \mathrm{~V}$ a $0,4 \mathrm{~ms}$, con impedancia de estimulación de 552 Ohms. Los histogramas mostraron sólo 94\% de estimulación biventricular desde el implante. Durante la interrogación, se observó que los episodios de

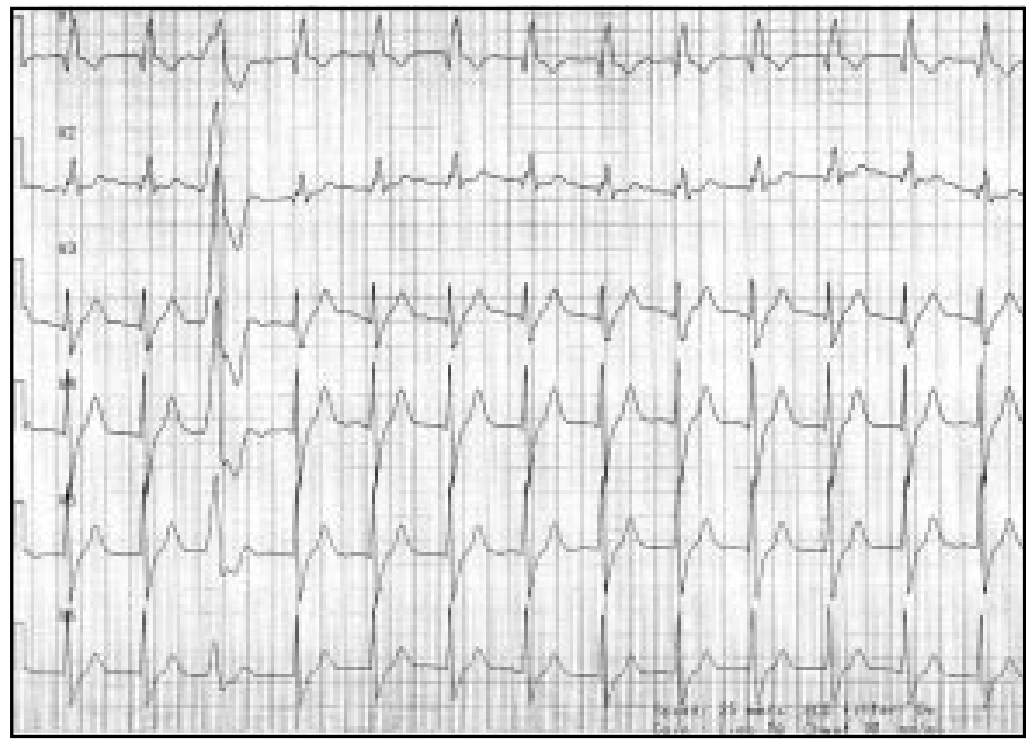

Figura 1. Electrocardiograma de superficie $24 \mathrm{~h}$ postimplante (derivaciones precordiales). Se observa ausencia de espigas de estimulación. El ritmo es sinusal con frecuencia de 95 latidos por min, conducido 1:1 con PR de $260 \mathrm{~ms}$, con imagen de bloqueo completo de rama derecha y extrasistolia ventricular aislada. 
conducción aurículo-ventricular espontánea se producían siempre después de un extrasístole ventricular, el cual era adecuadamente sensado y seguido de una onda P sinusal (actividad auricular espontánea) sensada dentro del período refractario auricular post-ventricular (PVARP). Al existir conducción aurículo-ventricular, el complejo QRS provocado siguiente era sensado antes de completarse el intervalo de escape auricular, volviendo a repetirse este fenómeno completo con el siguiente latido, perdiéndose»la estimulación biventricular (Figura 2). Se optó por reprogramar el PVARP desde su valor nominal dinámico a un valor fijo de $310 \mathrm{~ms}$, con lo que no se volvió a observar el fenómeno descrito. Sin embargo, el ECG de control del día siguiente, nuevamente mostró ausencia de estimulación ventricular. La reinterrogación del dispositivo mostró funcionamiento adecuado de los electrodos ventriculares, y se observó que en forma intermitente ocurría falla de sensado auricular manteniendo un buen umbral de estimulación. La onda $\mathrm{P}$ sensada disminuyó a un valor de $0,5-0,7$ $\mathrm{mV}$, sin evidencias radiológicas de desplazamiento. La ausencia de sensado auricular se asociaba a sensado del QRS espontáneo a una frecuencia por sobre la frecuencia mínima programada, por lo que había inhibición de la estimulación del marcapaso (Figura 3). Esto se corrigió programando la sensibilidad auricular a su valor máximo de 0,18 mV. El seguimiento clínico y Holter de control de electrocardiograma posterior, han mostrado evolución favorable y estimulación biventricular 100\% efectiva. En control ambulatorio se optó por desactivar la función de prevención de taquicardia mediada por marcapaso.

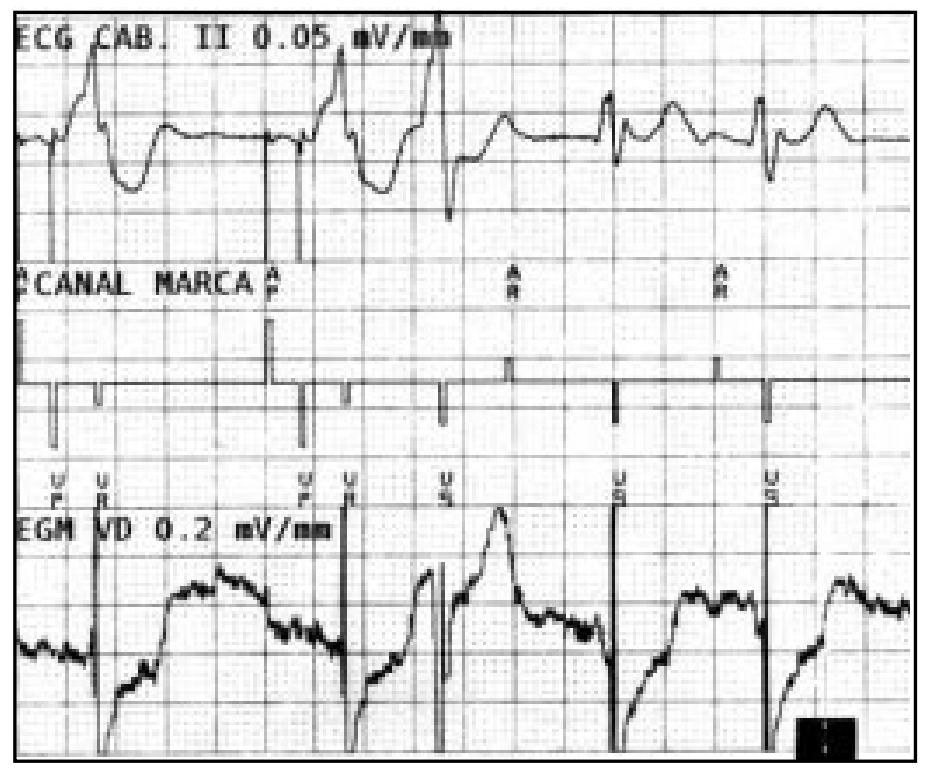

Figura 2. Registro de la interrogación del dispositivo (velocidad del papel $25 \mathrm{~mm} / \mathrm{s}$ ). El primer canal corresponde a electrocardiograma de superficie (derivación DII), el segundo canal muestra los marcadores de eventos registrados por el dispositivo, y el tercer canal corresponde al electrograma del ventrículo derecho. Los primeros dos complejos corresponden a estimulación auricular y ventricular, el tercer complejo es un extrasístole ventricular adecuadamente sensado, apareciendo la onda P sinusal siguiente con un intervalo VA de 230 ms, dentro del periodo refractario auricular post-ventricular, marcada como AR. El cuarto complejo QRS corresponde a conducción espontánea del ritmo sinusal. El siguiente complejo P-QRS muestra ausencia de estimulación bicameral, cayendo la aurícula nuevamente en periodo refractario.

Abreviaciones. AP: evento auncular estimulado. AR: evento aunicular sensado dentro del periodo refractario aunicular. AS: evento auricular sensado fuera del periodo refractario. VP: evento ventricular sensado. VR: evento ventricular sensado dentro del periodo refractario ventricular. VS: evento ventricular sensado fuera del periodo refractario ventricular. 


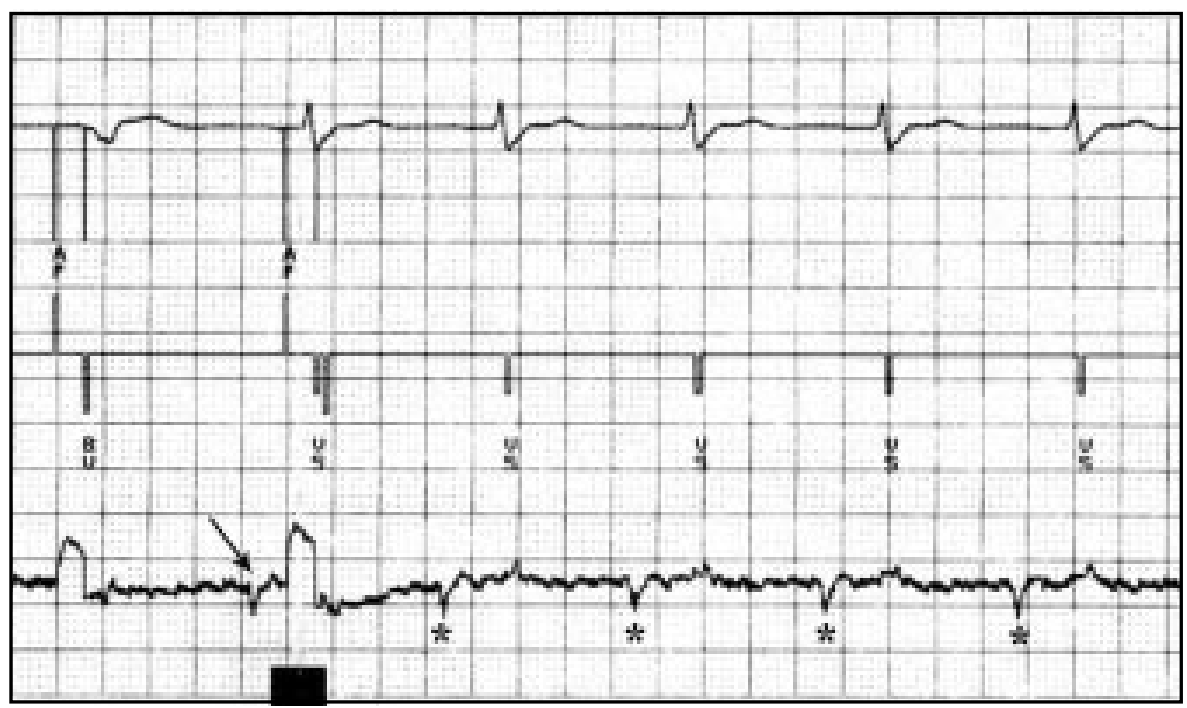

Figura 3. Registro de la interrogación del dispositivo (velocidad del papel $25 \mathrm{~mm} / \mathrm{s}$ ). El primer canal corresponde a electrocardiograma de superficie (derivación DI), el segundo canal muestra los marcadores de eventos registrados por el dispositivo, y el tercer canal corresponde al electrograma de la aunícula derecha. El primer complejo corresponde a estimulación auricular y ventricular. En el segundo complejo se produce falla de sensado de la aunícula (flecha), seguida de espiga de estimulación auricular inefectiva y sensado del QRS producto de la onda P sinusal precedente. A partir del tercer complejo la actividad auricular no es sensada $\left(^{*}\right.$ y el marcapaso sólo detecta el electrograma ventricular con una marca VS, con ausencia de espigas de estimulación.

Abreviaciones. AP: evento auricular estimulado. BV: estimulación biventricular. VS: evento ventricular sensado fuera del periodo refractario ventricular.

\section{Discusión}

Como se mencionó previamente, varios estudios han demostrado que los pacientes sometidos a terapia de resincronización biventricular asociada a terapia farmacológica óptima, presentan una significativa mejoría de sus parámetros clínicos, regresando en al menos una clase funcional de la New York Heart Association, y rindiendo mejor en el test de caminata de seis min y en la medición de consumo máximo de $\mathrm{O}_{2}$, lo que se refleja en alivio de los síntomas, mejoría en las encuestas de calidad de vida, reducción en el número de hospitalizaciones y mejoría en las curvas de sobrevida, resultados que se mantienen a 1 y 2 años plazo ${ }^{1-8}$. Esto ha llevado a que las indicaciones de esta terapia se hayan ampliado y se le ofrezca a pacientes con miocardiopatía dilatada e insuficiencia cardíaca avanzada, con QRS ancho e imagen de bloqueo completo de rama derecha con demostración de asincronía ventricular. Si uno de estos pacientes requiere de estimulación ventricular, como es el caso del paciente presentado, probablemente la estimulación biventricular sea la mejor opción ya que se sabe que la estimulación ventricular derecha provoca deterioro significativo del débito cardíaco y asincronía ventricular iatrogénica $^{9-12}$.

Para que la terapia de resincronización biventricular sea efectiva, se necesita que exista estimulación biventricular permanente. Se ha descrito que en un seguimiento a más de 2 años, hasta $36 \%$ de los pacientes pueden presentar pérdida de la estimulación biventricular en forma permanente 0 transitoria, especialmente en relación a aparición de taquiarritmias auriculares (18\%), pérdida de captura ventricular izquierda (10\%) y falla de sensado auricular derecho (1\%) ${ }^{13-15}$. La programación inadecuada también puede llevar a pérdida del beneficio de la estimulación biventricular. En el 
caso de este paciente, al momento del implante el intervalo PVARP se dejó programado en su valor nominal, que en el marcapaso Medtronic ${ }^{\circledR}$ Insync III modelo 8042 corresponde a un valor dinámico, dependiente de la frecuencia cardíaca, mínimo de $250 \mathrm{~ms}$ y máximo de $400 \mathrm{~ms}$. Al ocurrir un extrasístole ventricular, el algoritmo para prevenir taquicardia mediada por marcapaso prolonga automáticamente el PVARP, para evitar que la probable onda $\mathrm{P}$ retrógrada sea sensada y seguida de estimulación ventricular. Debido a que la frecuencia auricular espontánea del paciente en reposo era de alrededor de 90 latidos por minuto, la extensión del PVARP post extrasístole ventricular producía que la siguiente onda $\mathrm{P}$ sinusal fuera sensada dentro del período refractario y, por lo tanto, no gatillase estimulación biventricular. Al haber conducción espontánea, el complejo QRS siguiente es sensado por el electrodo ventricular antes de completar el ciclo de la frecuencia mínima de estimulación, perdiéndose la estimulación biventricular. Finalmente, al disminuir espontáneamente la frecuencia sinusal, esta actividad auricular era sensada fuera del PVARP y al ser reconocida como actividad, gatillaba la estimulación biventricular en el latido siguiente, respetando el intervalo AV programado. El problema fue solucionado programando el PVARP a un valor fijo de $310 \mathrm{~ms}$. Hay dos casos descritos en que este fenómeno fue gatillado por el algoritmo de prevención de taquicardia mediada por marcapaso sin ocurrencia de un extrasístole ventricular ${ }^{16,17}$. El marcapaso Medtro-

\section{REFERENCIAS}

1. Cieland J, Daubert JC, Erdmann E, Freemantle N, Gras D, Kappenberger L et al. The effect of cardiac resynchronization on morbidity and mortality in heart failure. N Engl J Med 2005; 352: 1539-49.

2. Cazeau S, Leclerco C, Lavergne T, Walter S, Varma C, LiNDe C ET AL, FOR MUSTIC Study Investigators. Effects of multisite biventricular pacing in patients with heart failure and intraventricular conduction delay. N Engl J Med 2001; 344: 873-80.

3. Abraham WT, Fisher WG, Smith AL, Delurgio DB, LeON AR, Loh E et al, For the MIRACLE Study nic ${ }^{\circledR}$ Insync III detecta taquicardia mediada por marcapaso después de ocho latidos consecutivos que cumplan los tres siguientes criterios: (a) intervalo VA $<400 \mathrm{~ms}$, (b) el intervalo se inicia con un evento ventricular estimulado, (c) el intervalo termina con un evento auricular sensado fuera del periodo refractario ${ }^{18}$. Esto, asociado a bloqueo aurículo-ventricular de primer grado, favorece la pérdida de la estimulación biventricular porque el próximo latido auricular sigue cayendo dentro del intervalo PVARP. En estas circunstancias se recomienda programar la función de taquicardia mediada por marcapaso en modo desactivado.

La falla de sensado auricular ha sido descrita en $1 \%$ de los pacientes sometidos a terapia de resincronización biventricular. En la serie de 512 pacientes de Knight et al, en los 5 pacientes con falla de sensado auricular, todos los casos fueron solucionados con reprogramación o revisión quirúrgica del electrodo ${ }^{13}$. En nuestro paciente, la reprogramación fue suficiente para solucionar este problema, dado que este dispositivo permite un margen de programación de la sensibilidad auricular entre $0,18 \mathrm{mV}$ y $4,0 \mathrm{mV}$.

La ocurrencia de falla intermitente de estimulación biventricular puede afectar significativamente la respuesta del paciente a la terapia, y es necesario evaluar un amplio espectro de posibilidades diagnósticas para lograr su corrección. Esta es una de las razones por lo que la terapia de resincronización biventricular debe ser manejada por médicos especialistas en marcapasos.

GrouP. Cardiac resynchronization in chronic heart failure. N Eng J Med 2002; 346: 1845-53.

4. Bradiey JB, Bradiey EA, Baughman KL, Berger RD, Calkins H, Goodman SN et al. Cardiac resynchronization and death from progressive heart failure. A meta-analysis of randomized controlled studies. JAMA 2003; 289: 730-40.

5. Young JB, Abraham WT, Smith AL, Leon AR, LEBERMAN R, WILKOFF B ET AL, FOR THE MIRACLE ICD Trial InVESTIGators. Combined cardiac resynchronization and implantable cardioversion defibrillation in advanced chronic heart failure. The MIRACLE ICD trial. JAMA 2003; 289: 2685-94. 
6. Bristow MR, Saxon LA, Boehmer J, Krueger S, Kass DA, DeMarco T ET AL, FOR THE COMPANION INVESTIGATORS. Cardiac-resynchronization therapy with or without an implantable defibrillator in advanced chronic heart failure. N Engl J Med 2004; 350: 2140-50.

7. Linde C, Lecierco C, ReX S, Garrigue S, Lavergne T, Cazeau S et al, (MUSTIC Study Group). Long-term benefits of biventricular pacing in congestive heart failure: Results from the Multisite Stimulation in Cardiomyopathy (MUSTIC) Study. J Am Coll Cardiol 2002; 40: 111-18.

8. Linde C, Braunschweig F, Gadier F, Baileul C, DAUBERT JC. Long-term improvement in quality of life by biventricular pacing in patients with chronic heart failure: Results from the MUSTIC study. Am J Cardiol 203; 91: 1090-95.

9. Montagna R, Asenjo $R$, Morris R, Schumacher E, Aguayo R, Ortiz M et al. Ventricular resynchronization therapy in patients with previous pacemaker for the management of advanced refractory heart failure. Rev Chil Cardiol 2005; 24: 48-59.

10. Owen CH, Esposito DJ, Davis JW, Glower DD. The effects of ventricular pacing on left ventricular geometry, function, myocardial oxygen consumption, and efficiency of contraction in conscious dogs. Pacing Clin Electrophysiol 1998; 21: 1417-29.
11. Nielsen J, Kristensen L, Andersen H, Mortensen P, Pedersen O, Pedersen A. A randomized comparison of atrial and dual-chamber pacing in 177 consecutive patients with sick sinus syndrome. J Am Coll Cardiol 2003; 42: 614-23.

12. Giudici MC, Thornburg GA, Buck DL, Coyne EP, Walton MC, Paul DL et al. Comparison of right ventricular outflow tract and apical lead permanent pacing on cardiac output. Am J Cardiol 1997; 79: 209-12.

13. Knight BP, Desai A, Coman J, Faddis M, Yong P. Long-term retention of cardiac resynchronization therapy. J Am Coll Cardiol 2004; 44: 72-7.

14. Van Erven L, Molhoek SG, Van der Wall EE, Schalu MJ. Cyclic appropriate mode switching and inappropriate back switching of a biventricular pacemaker during atrial tachyarrhythmia. Pacing Clin Electrophysiol 2004; 27: 249-51.

15. Eidelman RS, Dieguez FJ, Tolentino A, Zebede J. Malfunction of a biventricular pacing device? Pacing Clin Electrophysiol 2004; 27: 1453-4.

16. Richardson K, Cook K, Wang PJ, Al-Ahmad Amin. Loss of biventricular pacing: What is the mechanism? Heart Rhythm 2005; 2: 110-1.

17. BAROLD SS, Herweg B. Mysterious loss of resynchronization during biventricular pacing. Pacing Clin Electrophysiol 2005; 28: 571-2.

18. Medtronic Inc. Insync III device model 8042 Reference Manual 2000; 5.5-5.7. 


\title{
Levodopa en la enfermedad de Parkinson. ¿Q ué hemos aprendido?
}

\author{
Carlos Juri $\mathbf{C}^{1}$, Pedro Chaná $\mathbf{C}^{2}$. \\ Levodopa for Parkinson's disease. \\ What have we learned?
}

\begin{abstract}
Parkinson's disease (PD) is the second most common neurodegenerative disease in the world. Dopamine deficit is the cornerstone of its clinical manifestations. Levodopa, the main treatment for this condition, was first used for PD more than 40 years ago and today it still is the most powerful treatment for this disease. In recent years many advances have been made for understanding of the neurochemical mechanisms of this drug. Furthermore, new insights about the genesis of motor complications secondary to its use are known, specially related with the mode of its administration. This article updates the pharmacology of levodopa and its implications for the pathophysiology and treatment of PD. The new available presentations of levodopa are also reviewed. The implications of these advances for the treatment of this disease are commented (Rev Méd Chile 2006; 134: 893-901). (Key words: Dopamine; Levodopa; Parkinson disease)
\end{abstract}

Recibido el 23 de septiembre, 2005. Aceptado el 12 de enero, 2006.

${ }_{1}^{1}$ Departamento de Neurología, Facultad de Medicina, Pontificia Universidad Católica de Chile. Santiago, Chile. ${ }^{2}$ Centro de Trastornos del Movimiento (CETRAM), Facultad de Ciencias Médicas, Universidad de Santiago de Chile, Santiago, Chile.

$\mathrm{D}$ esde su introducción en la medicina a inicios de la década de 1960, la L-3,4- dihidroxifenilalanina o levodopa se ha convertido en uno de los fármacos más sorprendentes en neurología. Su capacidad de inducir una mejoría casi milagrosa en sujetos portadores de enfermedad de Parkinson (EP), rápidamente la convirtieron en el medicamento de elección para esta enfermedad ${ }^{1}$. Han pasado casi 50 años desde aquella irrupción de la

Correspondencia a: Dr. Carlos Juri C. Marcoleta 367. Santiago. Chile. Fonos: 3546886-3543316. Fax: 6326221. E mail: cjuri@puc.cl levodopa en la neurología y continúa siendo el principal fármaco para tratar la $\mathrm{EP}$, al que todos los portadores de esta enfermedad recurrirán durante su evolución.

En los últimos años, diversas investigaciones han aportado nuevos conocimientos sobre los mecanismos de acción y la fisiopatología de las complicaciones inducidas por ella. También han surgido nuevas formas de administración y combinaciones terapéuticas con levodopa. Todo esto ha revitalizado el debate sobre este compuesto y ha introducido nuevos aspectos a considerar para su uso.

El objetivo de esta revisión es repasar estos aspectos y entregar algunas recomendaciones actualizadas para su empleo en la EP en etapa inicial. 
Farmacología. En la EP se produce, por causas aún desconocidas, la muerte de neuronas dopaminérgicas, preferentemente en la sustancia nigra pars compacta. Esto produce disminución de la concentración de dopamina estriatal, lo que condiciona la aparición de rigidez muscular, lentitud de los movimientos y temblor, que caracterizan a la $\mathrm{EP}^{2}$.

La dopamina no cruza la barrera hematoencefálica (BHE), lo que impide su uso oral para el tratamiento de la $\mathrm{EP}^{3}$. La tirosina, aminoácido esencial, se transforma en levodopa, precursor de la dopamina, mediante la enzima tiroxina hidroxilasa, que actúa como enzima reguladora, por lo que la administración de una mayor cantidad de tirosina tampoco genera un incremento significativo de dopamina.

La levodopa es un aminoácido neutro de cadena larga, está presente en forma natural en ciertas legumbres. En los mamíferos sólo existe como un paso metabólico intermedio en la vía de síntesis de la dopamina ${ }^{4,5}$.

La levodopa administrada por vía oral es absorbida en su totalidad en el duodeno y primeras porciones del yeyuno, el estómago actúa como reservorio, su ingreso al torrente circulatorio desde el intestino es mediado por transporte activo ${ }^{6}$. En este paso compite con otros aminoácidos para su absorción, por ello, aminoácidos aromáticos y de cadenas ramificadas de los alimentos pueden afectar su absorción ${ }^{7}$. En el plasma sufre metabolismo hepático y aclaramiento renal ${ }^{6,8}$ (Figura 1).

La levodopa absorbida es convertida a dopamina por la enzima dopadecarboxilasa (DDC). La levodopa en el plasma, en presencia de inhibidor de la DDC, es metabolizada a nivel hepático, músculos, riñones y glóbulos rojos por la catecol orto metil transferasa (COMT) formando 3-o-metil dopa (3-OMD), éste tiene una vida media de $15 \mathrm{~h}$ en el plasma y se acumula en concentraciones varias veces mayores a la de levodopa. Altas dosis de 3-OMD interfieren el paso de la levodopa a nivel de la BHE. Sin embargo, en la práctica clínica contribuyen poco al pool de aminoácidos neutros de cadena larga que compiten por la entrada de la levodopa a nivel de la BHE.

La conversión de levodopa en dopamina es altamente eficiente. La dopamina que circula en el plasma, luego de la acción de la DDC sobre la levodopa, produce múltiples y frecuentes efectos

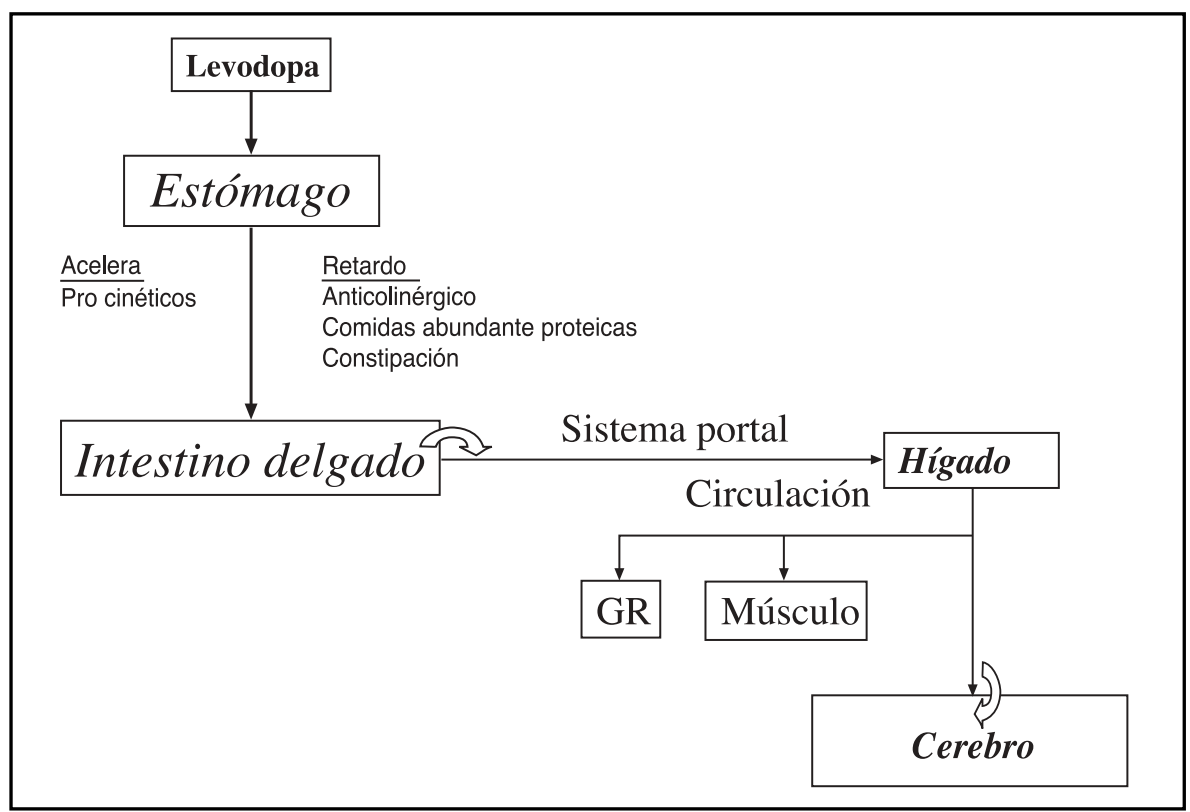

Figura 1. Farmacocinética de la levodopa. 
adversos, siendo la estimulación del área postrema del bulbo, específicamente el centro del vómito, la que genera náuseas y vómitos que hacen intolerable el tratamiento con levodopa ${ }^{9}$. La levodopa es metabolizada a dopamina en el estómago, por lo que sólo $30 \%$ de la dosis administrada será encontrada a nivel sanguíneo ${ }^{6,10}$. Por este motivo, se requiere inhibidores eficientes de la DDC. Actualmente disponemos de dos: carbidopa y benzerasida. Todas las formulaciones de levodopa para uso clínico llevan asociado un inhibidor de la DDC. La administración de levodopa sin éste, genera que sólo 5\% de la levodopa administrada alcance el sistema nervioso central, lo que se incrementa en $25 \%$ al utilizar inhibidor de la DDC 3,11 . Existe para la carbidopa dos presentaciones, una con relación entre levodopa/carbidopa 10:1 y otra 4:1, estas dos presentaciones se explican porque la dosis necesaria para inhibir la decarboxilasa a nivel gástrico es de $75 \mathrm{mg} /$ día, haciendo necesario para iniciar la terapia tener presentaciones con una mayor proporción de carbidopa, la asociación levodopa/benserazida tiene una relación de 4:13,8.

La decarboxilación de la levodopa a nivel gástrico aumenta en presencia de factores que retarden su vaciamiento, como la disminución del $\mathrm{pH}$ gástrico, estreñimiento y los fármacos con efecto anticolinérgico, los que generan enlentecimiento y reducción de la absorción de la levodopa ${ }^{12}$. Por el contrario, los que aumenten el vaciamiento, como los fármacos procinéticos, se traducirán en un aumento en la velocidad de absorción y mayor disponibilidad. Es por ello que la administración de la levodopa separada al menos $30 \mathrm{~min}$ de las comidas es una medida útil para optimizar su cinética. Otras medidas prácticas de utilidad en este sentido son:

1. Diluir las tabletas de levodopa (formulaciones líquidas o dispersables). 2. Tomar la medicación con estómago vacío. 3. Evitar el uso de anticolinérgicos. 4. Evitar exceso alimentario. 5. Redistribuir las proteínas disminuyéndolas en el día, dejándolas de preferencia por la noche. 6 . Uso de procinéticos gástricos. 7. Evitar estreñimiento. 8. Tratar Helicobacter pylori gástrico, si estuviera presente ${ }^{13,14}$.
Las dietas ricas en proteína con 65 a $100 \mathrm{~g}$ de proteínas interfieren el paso de la levodopa a nivel de la BHE, reduciendo el efecto de la levodopa; esto es especialmente evidente en aquellos pacientes que son más dependientes de los niveles plasmáticos para tener una adecuada respuesta, como se ve en las etapas más avanzadas de la enfermedad. El uso de dietas bajas en proteínas, o libres de aminoácidos neutros de cadena larga o redistribución de las proteína, administrándolas en la noche, son alternativas terapéuticas utilizadas para enfrentar este problema. Se recomienda dietas con $0,8 \mathrm{~g}$ de proteínas por kilo de peso día ${ }^{15,16}$.

La triple asociación de levodopa, inhibidores de la DDC y fármacos que inhiben la catecol orto metil transferasa (ICOMT) han demostrado inhibir la degradación de la levodopa a 3-OMD, disminuyendo las variaciones plasmáticas y aumentando la disponibilidad de la levodopa, logrando mantener niveles plasmáticos más estables de levodopa con claros beneficios para los pacientes con fluctuaciones motoras, aumentando su periodos en estado ON y mejorando la calidad de vida ${ }^{17,18}$.

Históricamente, el uso de levodopa en EP comienza en 1961, cuando Birkmayer y Hornykiewicz describieron el uso de pequeñas dosis por vía intravenosa ${ }^{19}$. Un año antes, Hornykiewicz había descrito el déficit de dopamina estriatal en estudios postmortem de portadores de $\mathrm{EP}^{20}$. Sin embargo, el empleo clínico por vía oral de la levodopa se inició años más tarde, cuando en 1967 Cotzias comunicó su empleo entre 4 y $8 \mathrm{~g}$ al día, reportando de modo irrefutable la utilidad de este fármaco por vía oral para la $\mathrm{EP}^{21}$. Las altas dosis empleadas y el alto porcentaje de conversión de la levodopa en dopamina retrasaron su uso clínico masivo hasta la introducción de los inhibidores de la DDC. Esto mancó el inicio de una combinación terapéutica que se mantiene hasta hoy.

Mecanismos de acción. La levodopa cruza la BHE por medio de transportadores de la misma clase que permiten su ingreso desde el intestino. Una vez en la circulación encefálica, entra a la neurona directamente y es convertida mediante la DDC en dopamina. La levodopa y sus productos siguen 
diversas vías metabólicas intra y extra neuronales (Figura 2) ${ }^{6}$.

El efecto de la levodopa es ejercido fundamentalmente a través de la dopamina producida en la neurona. La dopamina actúa estimulando directamente los receptores dopaminérgicos tipo 1 y tipo 2. Los receptores del tipo 1 se asociarían con mayor riesgo de complicaciones motoras, mientras que los de tipo 2 no tendrían dichos problemas.

La liberación de la dopamina desde la terminal sináptica se haría siguiendo el patrón de descarga tónico y fásico característico de la sinapsis dopaminérgica. La dopamina liberada al espacio sináptico es recaptada por la neurona dopaminérgica a través del transportador de dopamina (DAT) y realmacenada para su liberación. Este mecanismo de aclaramiento sináptico es altamente eficiente ${ }^{6}$. Probablemente, la levodopa además de convertirse en dopamina, sufre transformación a noradrenalina, así como a productos trazas de aminas, los cuales actúan en receptores no dopaminérgicos. Del mismo modo la dopamina sería capaz de estimular receptores GABA inhibitorios en la sustancia negra.
La combinación de estos fenómenos podrían explicar la magnífica potencia de este fármaco en $\mathrm{EP}$, superior en todas las etapas a la obtenida por la estimulación directa de los receptores mediante el empleo de agonistas dopaminérgicos ${ }^{22}$.

Levodopa y progresión de la enfermedad de Parkinson. La levodopa es el tratamiento más potente disponible para la EP, reduciendo incluso la mortalidad asociada en esta población ${ }^{23}$.

Tras 5 años de tratamiento con levodopa, cerca de $40 \%$ de los pacientes desarrollan complicaciones motoras manifestadas por la disminución de la duración del efecto (wearing-off o deterioro de fin de dosis) y por la aparición de movimientos involuntarios (discinesias) ${ }^{24}$. Lo anterior, junto con estudios in vitro que muestran muerte neuronal acelerada por la presencia de levodopa, han planteado la posibilidad de que la levodopa sea tóxica para las neuronas remanentes en $\mathrm{EP}^{25}$. Sin embargo, estudios en modelos experimentales con cultivos de tejido neuronal, en donde existe glia y mecanismos de protección al estrés oxidativo han fallado en replicar los estudios en células aisladas $^{26}$. Asimismo, la mayoría de los estudios

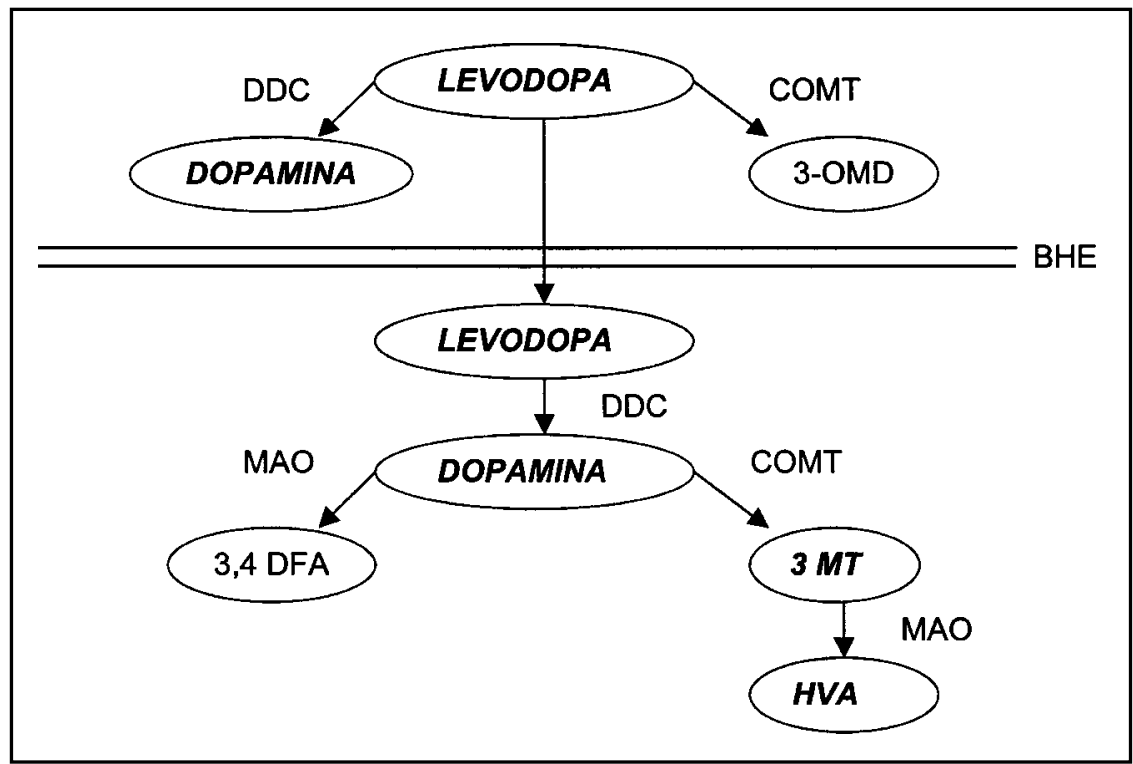

Figura 2. Vías del metabolismo de la levodopa.

DDC: Dopa decarboxilasa. COMT: catecol orto metil transferasa. BHE: barrera hematoencefálica. 3-OMD: 3 orto metil dopa. MAO: mono amino oxidasa. 3,4 DFA: ácido 3,4 dihidroxifenil acético. 3 MT: 3 metoxitiramina. HVA: ácido homovanílico. 
en modelos con animales parkinsonizados no han sido capaces de demostrar muerte neuronal acelerada por el uso de levodopa ${ }^{9,25}$.

En los últimos 10 años, se han efectuado estudios comparando progresión de la EP en pacientes tratados con levodopa versus agonistas dopaminérgicos (bromocritpina ${ }^{27}$, pergolide ${ }^{28}$, cabergolina ${ }^{29}$, pramipexole 30,31 y ropinirole ${ }^{32}$ ). En ellos, la aparición de complicaciones motoras se retrasa en los tratados con agonistas respecto de los tratados con levodopa a plazos de seguimiento entre 3 y 5 años. Asimismo, el uso de neuroimágenes funcionales ${ }^{31,32}$ para evaluar el grado de pérdida de actividad del sistema dopaminérgico, reveló que los tratados con levodopa presentan mayor pérdida de captación del radioligando durante seguimiento, planteando que tienen mayor muerte neuronal que los tratados con agonistas. Estos estudios son difíciles de interpretar, puesto que carecen de grupo placebo y existe duda que el uso de levodopa reduzca la captación del radiofármaco, sin que esto refleje realmente muerte neuronal ${ }^{33}$.

En un ensayo aleatorio, doble ciego y contra placebo, se comparó ${ }^{34}$ el uso de distintas dosis de levodopa durante 9 meses en portadores de EP en estadio inicial, la evaluación final se realizó 2 semanas después de suspendido el tratamiento. Un grupo de pacientes fue sometido a tomografía por emisión de fotón único (SPECT), para medir transportador de dopamina, al inicio y a 9 meses de seguimiento, aún tomando la medicación. El objetivo del trabajo fue evaluar la diferente progresión de los síntomas motores entre los tratados con levodopa y con placebo, la evaluación final fue la situación motora final. Se encontró que usuarios de levodopa presentaron mejoría de los síntomas motores de modo dosis dependiente, el beneficio se mantuvo tras 2 semanas de suspensión del tratamiento. Estos hallazgos sugieren efecto protector de la levodopa, sin embargo, es posible que refleje efecto sintomático de largo plazo. La SPECT mostró pérdida acelerada de la captación dopaminérgica en los usuarios de levodopa versus los usuarios de placebo, lo que podría interpretarse como daño acelerado por levodopa, sin olvidar la posible interferencia de la levodopa en las imágenes. En resumen, este estudio no revela claramente toxicidad por levodopa en EP y muestra un efecto sintomático de muy largo plazo o un efecto neuroprotector antes no conocido.

Estimulación dopaminérgica pulsátil. Existe evidencia respecto a la posibilidad que la aparición de las complicaciones motoras, especialmente las discinesias, dependa parcialmente del modo de administración de la levodopa. Normalmente, la concentración de dopamina estriatal es estable en el día ${ }^{35}$. En portadores de EP, en especial en etapas avanzadas, las concentraciones de levodopa varían de modo significativo en relación con cada toma del fármaco. Portadores de EP con discinesias, tratados mediante infusiones de levodopa por vía enteral, conservando la misma dosis diaria, presentan marcada reducción de las discinesias, sin deterioro del estado motor ${ }^{36}$.

Es difícil lograr estimulación dopaminérgica continua mediante el uso de levodopa, por su compleja farmacocinética oral, incluso, la infusión gástrica continua induce niveles plasmáticos erráticos ${ }^{37}$. Un modo de entregar estimulación dopaminérgica menos pulsátil es utilizando agonistas dopaminérgicos, que por sus vidas medias más prolongadas (algunos hasta más de $24 \mathrm{~h}$ ), entregan un estímulo más constante que la levodopa sobre los receptores dopaminérgicos. El uso de agonistas dopaminérgicos reduce la incidencia de discinesias, pero dado su menor potencia el beneficio motor obtenido por los pacientes es inferior al observado con levodo$\mathrm{pa}^{27,29,30}$. Otra forma de disminuir la pulsatilidad del estímulo dopaminérgico, es empleando levodopa asociado con inhibidor de la $\mathrm{COMT}^{38,39}$, actualmente se encuentra en marcha un estudio clínico para determinar si el uso precoz de esta combinación disminuye o retrasa la aparición de las discinesias ${ }^{40}$.

Otras posibles complicaciones a largo plazo derivadas del uso de levodopa. La levodopa sufre diversas modificaciones metabólicas. Una de sus vías de metabolización es mediante la COMT, la que por metilación convierte la levodopa en 3-OMD 6 . Este paso emplea S-adenosil metionina como donante de grupo metilo, convirtiéndose luego en S-adenosil homocisteína y posteriormente en homocisteína ${ }^{41}$. El uso de inhibidor de la DDC en conjunto con levodopa genera que la vía metabólica se desvíe preferentemente por la COMT, aumentando los niveles de homocisteína ${ }^{42}$. Ellos se elevan sobre los valores normales en portadores de EP tratados con 
levodopa ${ }^{41-43}$. Estudios en otras poblaciones de pacientes han demostrado que la homocisteína es un factor de riesgo para eventos vasculares y aparición de deterioro cognitivo ${ }^{44}$. Se desconoce el rol de la homocisteína en la aparición de complicaciones en $\mathrm{EP}^{42}$.

El uso de vitaminas B12, B6 y ácido fólico reducen los niveles de homocisteína, lo mismo ocurre al emplear inhibidores de la $\mathrm{COMT}^{43,45}$. Aún falta información para hacer recomendaciones sobre este aspecto ${ }^{46}$.

Nuevas presentaciones de la levodopa. A continuación se mencionan algunas nuevas presentaciones de levodopa originadas por asociación con otros compuestos o por modificaciones químicas que le confieren distintas características farmacocinéticas. Las presentaciones disponibles en Chile están en la Tabla 1.

Triple combinación: combinación de levodopa con un inhibidor de la DDC y un inhibidor de la COMT $\left(\right.$ Stalevo $\left.^{\mathrm{MR}}\right)$. Ha sido aprobado por la administración norteamericana de fármacos y alimentos (FDA) para uso en portadores de EP que presentan deterioro de fin de dosis. Prolonga la duración del efecto en 30 min por toma y permite una reducción de la dosis diaria de levodopa en 100 a $200 \mathrm{mg}^{38,47}$. Puede aumentar las discinesias, lo que se resuelven reduciendo la dosis total. Puede ocurrir coloración oscura de la orina y otros de menor frecuencia.
Levodopa metil éster (Melevodopa ${ }^{\mathrm{MR}}$ ): prodroga que se convierte en levodopa, altamente soluble en agua; administrada por vía oral reduce el tiempo necesario para alcanzar el estadio de beneficio motor, sería especialmente útil en portadores de EP con complicaciones motoras ${ }^{48}$. Está en evaluación en un estudio fase III en Europa.

Parcopa $^{\mathrm{MR}}$ : forma de presentación de levodo$\mathrm{pa} /$ carbidopa de disolución oral, recientemente introducida en el mercado estadounidense. Su mayor ventaja radica en la facilidad para la ingestión ${ }^{49}$.

Uso de levodopa en la enfermedad de Parkinson en etapa inicial. El tratamiento de cada paciente debe ser individualizado según la etapa de la enfermedad, las condiciones médicas y sociales asociadas y debe considerar educación y grupos de soporte, además del tratamiento farmacológico. A modo de sugerencia entregamos recomendaciones sobre el uso de levodopa en EP en estadio inicial (Figura 3$)^{50}$. Queda fuera de los alcances de esta revisión repasar su empleo en etapas avanzadas de la enfermedad.

Los datos disponibles avalan la seguridad de levodopa sobre el proceso neurodegenerativo, mas la incidencia de complicaciones motoras depende especialmente del inicio de la levodopa $\mathrm{y}$ de las dosis utilizadas ${ }^{24}$, por ese motivo se recomienda en portadores de EP en etapas iniciales comenzar tratamiento con agonistas dopami-

Tabla 1. Formulaciones de levodopa disponibles en Chile

\begin{tabular}{|lcc|}
\hline Combinación & Dosis & Observaciones \\
\hline Levodopa/carbidopa & $25 / 250$ & \\
& $25 / 100$ & \\
Levodopa/benserazida & $50 / 250$ & Formulación de liberación retardada \\
& $50 / 200$ & \\
& $25 / 100$ & Formulación dispersable \\
Levodopa/carbidopa/ entacapone & $25 / 100$ & Formulación de liberación retardada \\
& $50 / 12,5 / 200$ & \\
& $100 / 25 / 200$ & \\
& $150 / 37,5 / 200$ & \\
\hline
\end{tabular}




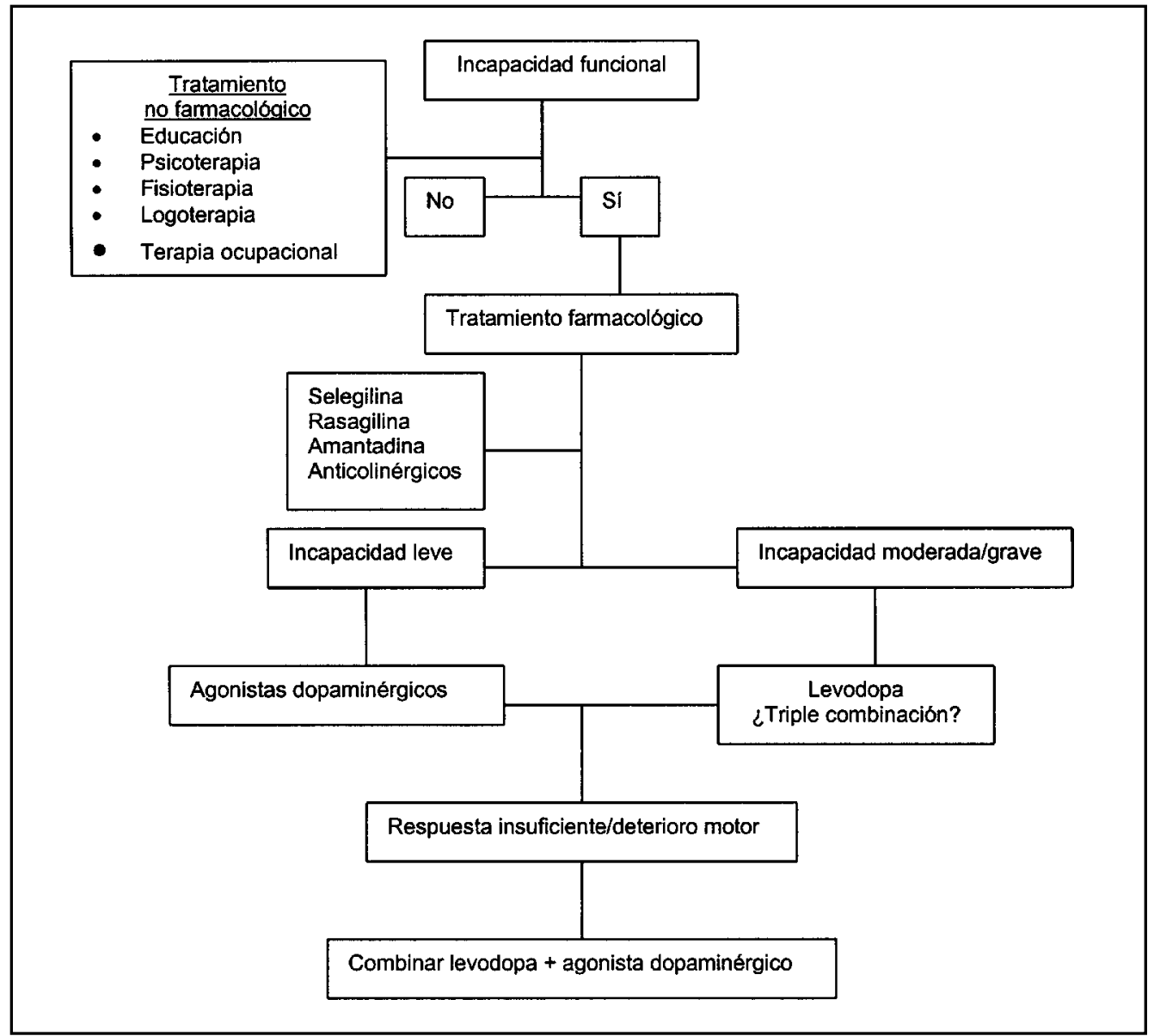

Figura 3. Algoritmo de tratamiento de la Enfermedad de Parkinson en estadio inicial.

ID inhibidor de la descarboxilasa, ICOMT inhibidor de la COMT. Modificado de referencia ${ }^{50}$.

nérgicos buscando retrasar la aparición de complicaciones. Dado la menor potencia de estos fármacos, en un grupo de pacientes será necesario introducir prontamente la levodopa ${ }^{9}$. El inicio de levodopa en esta población se recomienda con las dosis efectivas más bajas, repartidos en 3 tomas, teniendo la precaución de comenzar lentamente y titular la dosis según respuesta.

Un grupo especial de pacientes en etapa inicial son aquellos de edad avanzada y los portadores de deterioro cognitivo. En ellos, dado el mayor riesgo de desarrollar confusión que se asocia con los agonistas dopaminérgicos se recomienda utilizar levodopa como tratamiento desde el inicio.
Desconocemos si la triple combinación ofrecerá ventajas sobre las formulaciones tradicionales de levodopa al inicio del tratamiento 40 .

\section{CONCLUSIONES}

La EP es una enfermedad asociada al déficit dopaminérgico y el uso de levodopa ha sido desde hace décadas el fármaco utilizado para tratarlo. Diversos avances en los últimos años han permitido conocer mejor los mecanismos de acción y plantear estrategias terapéuticas para disminuir las complicaciones derivadas de este tratamiento. 


\section{REFERENCIAS}

1. Carlsson A. Treatment of Parkinson's with LDOPA. The early discovery phase, and a comment on current problems. J Neural Transm 2002; 109: 777-87.

2. CiARKe CE. Neuroprotection and pharmacotherapy for motor symptoms in Parkinson's disease. Lancet Neurol 2004; 3: 466-74.

3. Mizutani $Y$, Okada $Y$, Ogawa $M$, Hasegawa $T$, NABESHIMA T. Pharmacokinetic model of oral levodopa and role of carbidopa in parkinsonian patients. Biol Pharm Bull 1995; 18: 1729-37.

4. Apaydin H, Ertan S, Ozekmekci S. Broad bean (Vicia faba) - a natural source of L-dopa-prolongs «on» periods in patients with Parkinson's disease who have «n-off» fluctuations. Mov Disord 2000; 15: 164-6.

5. Katzenschlager R, Evans A, Manson A, Patsalos PN, Ratnaraj N, Watt H et al. Mucuna pruriens in Parkinson's disease: a double blind clinical and pharmacological study. J Neurol Neurosurg Psychiatry 2004; 75: 1672-7.

6. Juncos JL Levodopa: pharmacology, pharmacokinetics, and pharmacodynamics. Neurol Clin 1992; 10: 487-509.

7. NuTt JG, Woodward WR. Levodopa pharmacokinetics and pharmacodynamics in fluctuating parkinsonian patients. Neurology 1986; 36: 739-44.

8. Contin M, Riva R, Albani F, Baruzzi A. Pharmacokinetic optimization in the treatment of Parkinson's disease. Clin Pharmacokinet 1996; 30: 463-81.

9. JANKovic J. Levodopa strengths and weaknesses. Neurology 2002; 58: S19-32.

10. Andersson I, Granerus AK, Jagenburg R, Svanborg A. Intestinal decarboxylation of orally administered L-dopa. Influence of pharmacological preparations, dose magnitude, dose sequence and food intake. Acta Med Scand 1975; 198: 415-20.

11. Nutt JG, Woodward WR, ANderson JL. The effect of carbidopa on the pharmacokinetics of intravenously administered levodopa: the mechanism of action in the treatment of parkinsonism. Ann Neurol 1985; 18: 537-43.

12. Chana P, Kuntsmann C, Reyes-Parada M, SáezBRIONES P. Delayed early morning turn «ON» in response to a single dose of levodopa in advanced Parkinson's disease: pharmacokinetics should be considered. J Neurol Neurosurg Psychiatry 2004; 75: 1782-3.
13. Pierantozzi M, Pietroiusti A, Galante A, Sancesario G, Lunardi G, Fedele E et al. Helicobacter pyloriinduced reduction of acute levodopa absorption in Parkinson's disease patients. Ann Neurol 2001; 50: 686-7.

14. Nutt JG, Woodward WR, Gancher ST, Merrick D. 3O-methyldopa and the response to levodopa in Parkinson's disease. Ann Neurol 1987; 21: 584-8.

15. Pincus JH, BARRY KM. Plasma levels of amino acids correlate with motor fluctuations in parkinsonism. Arch Neurol 1987; 44: 1006-9.

16. Nutt JG, Woodward WR, Hammerstad JP, Carter JH, ANDERSON JL. The 〈on-off» phenomenon in Parkinson's disease. Relation to levodopa absorption and transport. N Engl J Med 1984; 310: 483-8.

17. Ravina B, Eideiberg D, Ahiskog JE, Albin RL, Brooks DJ, CARBON M ET AL. The role of radiotracer imaging in Parkinson disease. Neurology 2005; 64: 208-15.

18. Koler W, Guarnieri M, Hubbie J, Rabinowicz AL, Silver D. An open-label evaluation of the tolerability and safety of Stalevo (carbidopa, levodopa and entacapone) in Parkinson's disease patients experiencing wearing-off. J Neural Transm 2005; 112: 221-30.

19. BIRKMaYer W, HorNykiewicz O. [The L-3,4dioxyphenylalanine (DOPA)-effect in Parkinsonakinesia.]. Wien Klin Wochenschr 1961; 73: 787-8.

20. EHringer H, Hornykiewicz O. Distribution of noradrenaline and dopamine (3-hydroxytyramine) in the human brain and their behavior in diseases of the extrapyramidal system. Klin Wochenschr 1960; 38: 1236-9.

21. Mena I, CotZias GC. Protein intake and treatment of Parkinson's disease with levodopa. N Engl J Med 1975; 292: 181-4.

22. Mercuri NB, Bernardi G. The 'magic' of L-dopa: why is it the gold standard Parkinson's disease therapy? Trends Pharmacol Sci 2005; 26: 341-4.

23. Clarke CE. Mortality from Parkinson's disease in England and Wales 1921-89. J Neurol Neurosurg Psychiatry 1993; 56: 690-3.

24. Obeso JA, Rodríguez-Oroz MC, Chana P, Lera G, Rodríguez M, Olanow CW. The evolution and origin of motor complications in Parkinson's disease. Neurology 2000; 55: S13-20.

25. MuLer T, HeFter $H$, Hueber R, Jost WH, Leenders KL, OdIN P ET AL. Is levodopa toxic?J Neurol 2004; 251 Suppl 6: VI/44-6.

26. CAmp DM, LoefFler DA, LeWitt PA. L-DOPA does not enhance hydroxyl radical formation in the nigrostriatal dopamine system of rats with a 
unilateral 6-hydroxydopamine lesion. J Neurochem 2000; 74: 1229-40.

27. RAMAKER C, Hilten JJ. Bromocriptine/levodopa combined versus levodopa alone for early Parkinson's disease. Cochrane Database Syst Rev 2002; CD003634.

28. Ciarke CE, Speler JM. Pergolide for levodopainduced complications in Parkinson's disease. Cochrane Database Syst Rev 2000; CD000235.

29. Bracco F, Battagla A, Chouza C, Dupont E, Gershanik O, Marti Masso JF et al. The long-acting dopamine receptor agonist cabergoline in early Parkinson's disease: final results of a 5-year, double-blind, levodopa-controlled study. CNS Drugs 2004; 18: 733-46.

30. Howoway RG, Shoulson I, Fahn S, KiebuRtz K, Lang A, Marek K et al. Pramipexole vs levodopa as initial treatment for Parkinson disease: a 4-year randomized controlled trial. Arch Neurol 2004; 61: 1044-53.

31. Parkinson Study Group. Pramipexole vs levodopa as initial treatment for Parkinson disease: A randomized controlled trial. Jama 2000; 284: 1931-8.

32. Whone AL, Watts RL, Stoessl AJ, Davis M, Reske $\mathrm{S}$ ET AL. Slower progression of Parkinson's disease with ropinirole versus levodopa: The REAL-PET study. Ann Neurol 2003; 54: 93-101.

33. Guttman M, Stewart D, Hussey D, Wilson A, Houle S, KISH S. Influence of L-dopa and pramipexole on striatal dopamine transporter in early PD. Neurology 2001; 56: 1559-64.

34. Fahn S, Oakes D, Shoulson I, Kieburtz K, Rudolph A, Lang A ET AL. Levodopa and the progression of Parkinson's disease. N Engl J Med 2004; 351: 2498-508.

35. Olanow CW, Agid Y, Mizuno Y, Albanese A, Bonuccelu U, Damier $P$ et al. Levodopa in the treatment of Parkinson's disease: current controversies. Mov Disord 2004; 19: 997-1005.

36. Stocchi F, Vacca L, Ruggieri S, Olanow CW. Intermittent vs continuous levodopa administration in patients with advanced Parkinson disease: a clinical and pharmacokinetic study. Arch Neurol 2005; 62: 905-10.

37. Kurlan R, Nutt JG, Woodward WR, Rothfield K, LuChter D, Miuer C et al. Duodenal and gastric delivery of levodopa in parkinsonism. Ann Neurol 1988; 23: 589-95.

38. Deane KH, Sieker S, Clarke CE. Catechol-Omethyltransferase inhibitors versus active comparators for levodopa-induced complications in
Parkinson's disease. Cochrane Database Syst Rev 2004; CD004553.

39. Olanow CW, Kieburtz K, Stern M, Watts R, Langston JW, Guarnieri M et al. Double-blind, placebo-controlled study of entacapone in levodopa-treated patients with stable Parkinson disease. Arch Neurol 2004; 61: 1563-8.

40. Pharma NaO. first Parkinson's disease study to explore potential of delaying motor complications with Stalevo. http://dominoext.novartis.com/ NC/NCMediaRel9798.nsf/0/35bb47eda0348167c1 256f8000421bd9?OpenDocument (consultado el 30 de septiembre de 2005).

41. Yasui K, Nakaso K, Kowa $H$, Takeshima T, NaKashima $\mathrm{K}$. Levodopa-induced hyperhomocysteinaemia in Parkinson's disease. Acta Neurol Scand 2003; 108: 66-7.

42. O'Suileabhain P, Díaz-ARRastia R. Levodopa elevates homocysteine: is this a problem? Arch Neurol 2004; 61: 633-4.

43. Lamberti P, Zoccolelia S, Ilceto G, Armenise E, Fraddosio A, de Mari M et al. Effects of levodopa and COMT inhibitors on plasma homocysteine in Parkinson's disease patients. Mov Disord 2005; 20: 69-72.

44. McIlroy SP, Dynan KB, Lawson JT, Patterson CC, PASSMore AP. Moderately elevated plasma homocysteine, methylenetetrahydrofolate reductase genotype, and risk for stroke, vascular dementia, and Alzheimer disease in Northem Ireland. Stroke 2002; 33: 2351-6.

45. Postuma RB, Lang AE. Homocysteine and levodopa: should Parkinson disease patients receive preventative therapy? Neurology 2004; 63: 886-91.

46. Castro A, Valudeoriola F, Linazasoro G, RodríguezOroz MC, Stochi F, Marín C ET al. [Optimization of use of levodopa in Parkinson's disease: role of levodopa-carbidopa-entacapone combination]. Neurologia 2005; 20: 180-8.

47. Deane KH, Spieker S, Ciarke CE. Catechol-Omethyltransferase inhibitors for levodopa-induced complications in Parkinson's disease. Cochrane Database Syst Rev 2004; CD 004554.

48. Swope DM. Rapid treatment of swearing off» in Parkinson's disease. Neurology 2004; 62: S27-31.

49. Keating GM, Lyseng-Wimamson KA. Tolcapone: a review of its use in the management of Parkinson's disease. CNS Drugs 2005; 19: 165-84.

50. Grandas F, Obeso J, Tolosa E. Tratado sobre la enfermedad de Parkinson. Madrid: Luzan, 2004; 472. 


\title{
Actualización en el diagnóstico y terapéutica en hipertensión pulmonar arterial
}

\author{
Mónica Zagolin $\mathrm{B}^{1}$, Eduardo Wainstein $\mathrm{G}^{3}$, Polentzi \\ U riarte $\mathbf{G}^{2}$.

\section{Update in the diagnosis and therapy for pulmonary arterial hypertension}

Pulmonary Arterial Hypertension includes a heterogeneous group of disorders with a common genetic, pathological and hemodinamyc origin. It is characterized by a high pulmonary artery pressure due to a primary vascular disease, as a consequence of genetic and environmental factors. The common pathway is a vascular imbalance towards vasoconstriction and proliferation inside the small vessels. According to the World Health Organization, 2003, Pulmonary Arterial Hypertension is classified as idiopathic, familiar or associated to connective tissue diseases, HIV, drugs, porto-pulmonary hypertension, congenital intracardiac shunts and others. The diagnosis is based in hemodynamics. Echocardiogram is a non invasive and right ventricular catheterization is an invasive diagnostic tool. Follow up is based on a clinical and functional assessment through functional class classification, dyspnea scores and 6-minute walking test. The prognosis is historically devastating but new therapies are changing the natural history of the disease. New treatments have demonstrated improvement in symptoms, hemodynamic profiles and survival. Intravenous, subcutaneous or inhaled prostanoids such as Epoprostenol, Treprostinil or lloprost respectively have been approved for Pulmonary Arterial Hypertension treatment as well as oral endothelial receptor blockers. They are all considered first line treatments for arterial pulmonary hypertensive patients with even better benefits than lung transplantation. Phosphodiesterase inhibitors (Sildenafil), have been recently approved for the treatment of pulmonary arterial hypertension (Rev Méd Chile 2006; 134: 902-9).

(Key words: Hypertension, pulmonary; Prostaglandins; Receptors, vascular endothelial growth factor; Sildenafil)

\footnotetext{
Recibido el 6 de mayo, 2005. Aceptado el 23 de diciembre, 2005.

${ }^{1}$ Departamento de Medicina del Instituto Nacional del Tórax. ${ }^{2}$ Departamento de Cardiología del Instituto Nacional de Tórax. ${ }^{3}$ Departamento de Medicina, Clínica Las Condes y Escuela de Medicina, Universidad Andrés Bello.
}

La a hipertensión pulmonar arterial (HPA) es una entidad poco frecuente, de evolución progresiva y devastadora, que afecta principalmente a

Correspondencia a: Mónica Zagolin Blancaire. José Manuel Infante 717, Providencia, Santiago. E mail: mzagolin@torax.cl mujeres jóvenes en plena edad productiva. Se ha comunicado, para HPA primaria o idiopática, según nueva nomenclatura, una incidencia de 1-2 pacientes nuevos por millón de habitantes por año ${ }^{1}$. Su etiología es desconocida, pero parece ser el resultado de una interacción anormal entre 
factores genéticos y medioambientales, que llevan finalmente a un daño vascular centrado en un desequilibrio endotelial a favor de la vasoconstricción y proliferación vascular. Desde un punto de vista histopatológico, el compromiso vascular va desde hipertrofia de la íntima y capa media de la arteriola pulmonar, asociada a trombosis in situ, hasta lesiones plexiformes fibróticas en su etapa terminal 2,3 .

Aproximadamente, 6\% sigue una distribución familiar, con una relación similar hombre-mujer y de transmisión autosómica dominante con penetrancia incompleta, es decir, suele saltar generaciones. La presencia del gen no implica desarrollo de la enfermedad $^{4}$ y es así como uno de los genes identificados como responsables de la enfermedad, conocido como PPH1 (locus 2q 31-32), tiene una expresión clínica en menos de $20 \%$ de los portadores $^{5}$. Recientemente, se ha correlacionado a las mutaciones en el gen II del receptor de la proteína morfogenética ósea (BMPR II) con las lesiones vasculares proliferativas observadas en los pacientes con HPA, sugiriendo que se trataría del mismo gen $\mathrm{PPH}^{6}$.

La HPA afecta con mayor frecuencia a las mujeres en una relación 1,7:1 y, comúnmente, se expresa en la cuarta década de la vida. El diagnósti- co habitualmente es efectuado entre 18 y 24 meses posterior al inicio de los síntomas, debido al carácter inespecífico de ellos, tales como disnea, fatiga 0 dolor torácico, de modo que es frecuente pesquisar enfermos con severa limitación funcional y estrecho margen terapéutico. La sobrevida histórica promedio es de 2,8 años luego del diagnóstico ${ }^{1,7,8}$.

Se define HPA mediante el estudio hemodinámico (cateterismo derecho) ante la presencia de presión media de la arteria pulmonar (PAPM) $>25$ $\mathrm{mmHg}$ en reposo o $>30 \mathrm{mmHg}$ en ejercicio, acompañado de resistencia vascular pulmonar (RVP) $>160$ dinas/seg $\mathrm{x} \mathrm{cm}^{-5}$ 1,5.

\section{CiASIFICACIÓN}

La Organización Mundial de la Salud (OMS), en 1998, reclasificó la hipertensión pulmonar $(\mathrm{HP})^{5}$, efectuando algunas modificaciones en $2003^{9}$ que se ilustran en la Tabla 1. Estas apuntan a sugerir el uso del término HPA idiopática (sin causa subyacente) en vez de primaria, término usado desde 1951 por Dresdale ${ }^{10}$, y además se incorporó en este grupo a la enfermedad veno-oclusiva y la angiomatosis capilar pulmonar.

Tabla 1. Clasificación actual de la Hipertensión Pulmonar de la O rganización M undial de la Salud (2003)

I. Hipertension Arterial Pulmonar

- Idiopática

- Familiar

- Asociada a: colagenopatías, cortocircuitos intracardiacos, hipertensión portal; virus inmunodeficiencia humana, drogas y toxinas, hipertiroidismo, enfermedad de Gaucher, hemoglobinopatías, desórdenes mieloproliferativos, telangectasia hereditaria familiar, esplenectomía.

- Enfermedad veno-oclusiva.

- Angiomatosis capilar pulmonar

II. Hipertensión Venosa Pulmonar

- Asociada a aumento de presión ventricular y/o auricular izquierda, enfermedad valvular izquierda.

III. Asociada a Enfermedad Pulmonar o Hipoxemia

- Enfermedad pulmonar obstructiva crónica, enfermedad pulmonar intersticial, trastornos del sueño, síndrome de hipoventilación alveolar.

IV. Asociada a Enfermedad Tromboembólica Crónica

- Tromboembolia arterial pulmonar proximal.

- Obstrucciones distales en arterias pulmonares.

V. Misceláneas

- $\quad$ Sarcoidosis, histiocitosis X, linfangioleiomiomatosis 
En la categoría «HP asociada a» se encuentran las enfermedades colágeno vasculares tales como esclerodermia, lupus, enfermedad mixta del tejido conectivo, dermatopolimiositis, artritis reumatoide y síndrome de Sjögren 1,3,5,9. La entidad más frecuentemente asociada es la esclerosis sistémica limitada, variante CREST. La prevalencia de esta asociación es variable, sin embargo, recientemente se ha estimado, mediante estudio hemodinámico invasivo, cercana a $12 \% 11$. En este grupo también se encuentran los pacientes con HIV $(0,5 \%)^{12}$, usuarios de drogas anorexígenas (aminorex, fenfluramina, dexfenfluramina) ${ }^{13}$, con hipertensión portal $(2-5 \%)^{14}$ y comunicaciones intracardiacas congénitas de derecha a izquierda (prevalencias alrededor de 50\% para los defectos ventriculares y $10 \%$ para defectos auriculares) ${ }^{15}$.

\section{Diagnóstico}

El diagnóstico clínico es tardío. Suele manifestarse con disnea progresiva, asociada a fatigabilidad, dolor torácico, mareo, palpitaciones y, ocasionalmente, a lipotimia o síncopes, siendo este último síntoma un marcador de mal pronóstico. Los estadios más avanzados son identificados por signos y síntomas secundarios a la falla ventricular derecha ${ }^{3,5,9}$.

En la evaluación diagnóstica se sugiere efectuar un estudio serológico que incluya detección de VIH, factor reumatoideo, anticuerpos anticardiolipinas, anticuerpos antinucleares (ANA) y anticuerpos antifracciones extractables del núcleo (ENA: Ro, La, Sm, RNP y Jo-1). Además, se recomienda efectuar un perfil hepático, de coagulación, tiroideo y test de embarazo. El estudio funcional respiratorio que incluye una espirometría, estudio de difusión y volúmenes, permite investigar o descartar entidades asociadas al compromiso parenquimatoso pulmonar? ${ }^{3}$.

El ecocardiograma es el mejor examen en el inicio del estudio de pacientes con sospecha de HP, permitiendo la medición de la presión arterial pulmonar sistólica (PAPS), función del ventrículo derecho y la detección de cortocircuitos intracardíacos. El nivel de precisión de la ecocardiografía es variable, por lo que es fundamental en todo paciente efectuar un estudio hemodinámico confirmatorio. En operadores expertos, la PAPS que puede ser estimada en 59 a $72 \%$ de los pacientes ${ }^{16,17}$.
El test de caminata de 6 min es un examen simple y no invasivo, de extraordinaria utilidad en la evaluación inicial de los pacientes con HPA, en el seguimiento y en el análisis de la respuesta terapéutica. Se ha reportado una excelente comelación pronóstica entre la distancia recomida y la evolución a largo plazo, documentándose una peor evolución en aquellos que caminan menos de $332 \mathrm{mt}^{16,18}$.

La radiografía de tórax puede ser normal hasta en $10 \%$. Clásicamente, se observa prominencia de las arterias pulmonares (90\%) y amputación periférica de los vasos. El cintigrama de ventilación perfusión, generalmente, muestra un patrón de perfusión irregular difuso, caracterizado por múltiples defectos subsegmentarios. Su principal aporte se encuentra en el estudio de pacientes con enfermedad tromboembólica crónica (ETC), en la que se observa grandes defectos de perfusión. En esta patología, la tomografía axial computada con contraste permite una adecuada visualización de las arterias pulmonares centrales, presencia de trombos e información adicional sobre el estado del parénquima pulmonar. En los casos en que se sospecha ETC, la resonancia nuclear magnética y la angiografía suelen ser de ayuda complementaria $3,5,9$.

Finalmente, el diagnóstico de certeza lo otorga el estudio hemodinámico a través de la cateterización de arteria pulmonar con catéter de Swan-Ganz y medición precisa de la presión de arteria pulmonar, capilar pulmonar, gasto cardíaco y oximetrías sectoriales. Este permite, además, evaluar la vaso-reactividad pulmonar, que puede efectuarse mediante la administración de adenosina (usada en nuestro medio en dosis hasta $250 \mathrm{mcg} / \mathrm{kg} / \mathrm{min}$ ), óxido nítrico (ON) inhalado (18 partes por millón) o epoprostenol (20 ng/ $\mathrm{kg} / \mathrm{min}$ i.v. $)^{1,5}$. Clásicamente, se ha considerado una respuesta positiva a una disminución del orden de $20 \%$ en la PAPM o la resistencia vascular pulmonar (RVP) sin caída del débito cardíaco ${ }^{3}$, aunque actualmente se considera un resultado positivo a una disminución de la PAPM o RVP a cifras más cercanas a lo normal (PAPM inferior a $40 \mathrm{mmHg}$ ). Esta condición sugiere un mejor pronóstico y una respuesta favorable a la terapia con bloqueadores de canales de calcio $(\mathrm{BCC})^{19}$. En la expeniencia de expertos, no más allá de $10-12 \%$ de los pacientes con HPA idiopática son vaso-reactivos. En atención a estos resultados es que hoy se desaconseja el uso empírico de $\mathrm{BCC}^{20}$.

El seguimiento y control de la terapia es clínico y funcional. La escala más usada en la 
evaluación de la capacidad funcional es la de la OMS, muy similar a la New York Heart Association (NYHA), que considera no sólo disnea, sino también la presencia de síncopes, dolor torácico y fatiga y separa en estadios I a IV ${ }^{5}$. La disnea es evaluada fundamentalmente a través de la puntuación de Borg (de 0 a 10), siendo 10 el grado máximo de disnea. La distancia recorrida medida en el test de caminata de 6 min es el examen, por excelencia, para el seguimiento de estos pacientes por su sencillez, reproducibilidad y adecuada correlación pronóstica ${ }^{16,18}$. El estudio hemodinámico, como método de control de la terapia establecida, es usado principalmente cuando existe un protocolo de investigación en curso o un deterioro clínico funcional pese al tratamiento.

\section{HPA Y EMBARAZO}

Constituye un aspecto relevante de tratar, ya que la mortalidad de un embarazo en una paciente con HPA fluctúa entre 30 y $56 \%{ }^{21}$; esto, sin considerar el riesgo de teratogenicidad asociada a terapias tales como antiendotelinas o anticoagulantes. Se debe aconsejar un método anticonceptivo definitivo y seguro. No es recomendable el uso de anticonceptivos orales o dispositivos intrauterinos por los riesgos inherentes (trombogénesis, hemorragia).

\section{TRATAMIENTO}

La HPA afecta la calidad de vida de los pacientes en forma progresiva y sólo se ha descrito remisión espontánea en casos aislados, asociados al uso y posterior suspensión de anorexígenos ${ }^{13}$.

Por muchos años, las únicas alternativas terapéuticas disponibles se basaron en anticoagulación, $\mathrm{BCC}$, diuréticos y oxígeno en casos específicos y desde la década 1990-99, el trasplante pulmonar 0 cardiopulmonar. La anticoagulación ha sido recomendada en todos los pacientes con HPA, en base a dos pequeños estudios que sugieren que su uso mejora la sobrevida, sustentados en los hallazgos histopatológicos de trombosis in situ y trombogénesis aumentada, ambos elementos que promueven la progresión de la enfermedad 3,9 .

En HPA se considera que un tratamiento es efectivo si es capaz de prolongar sobrevida, aliviar síntomas, mejorar capacidad funcional y al mismo tiempo si es seguro, fácil de usary de costo razonable.

En los últimos 10 años se han desarrollado fármacos que han cambiado la historia natural de la enfermedad, lo que ha permitido anteponer estas terapias al trasplante y se ha generado una verdadera explosión de nuevas alternativas terapéuticas que a continuación se detallan y se ilustran en la Tabla 2.

\section{BLOQUeADORES DE LOS CANALES DE CALCIO}

Son sólo una alternativa útil y económica para un restringido grupo de enfermos en los que el test de vaso-reactividad es positivo ${ }^{19}$, con un beneficio a largo plazo limitado ${ }^{20}$. Los BCC tales como diltiazem o amlodipino están indicados en pacientes en clase funcional WHO II o III y su uso suele estar limitado por los efectos adversos asociados a las elevadas dosis requeridas del orden de $960 \mathrm{mg}$ de diltiazem o $240 \mathrm{mg}$ de nifedipino, tales como eritema facial, edema o hipotensión ${ }^{1}$.

\section{PROSTACICLINAS}

El uso de prostaciclinas endovenosas (iv) tales como epoprostenol o iloprost ha demostrado beneficios tanto sintomáticos, hemodinámicos y en la sobrevida a corto y largo plazo en los pacientes con HPA. La terapia con prostaciclinas vía iv es considerada la mejor altemativa terapéutica disponible para los pacientes en clase funcional III y IV; sin embargo, no está exenta de toxicidad, es de alto costo y requiere un alto nivel de comprensión y colaboración de parte del paciente. Ella involucra el uso de un catéter permanente, ya sea endovenoso o subcutáneo con su respectiva bomba infusora portátil o el uso de nebulizadores ultrasónicos, para uso por la vía inhalatoria ${ }^{3}$.

Epoprostenol. Es una prostaglandina sintética (PGI2), cuyo efecto vasodilatador selectivo pulmonar fue evidenciado por Higgenbottam en la década 1980-89. Desde entonces, numerosos estudios han demostrado significativos beneficios en el alivio sintomático, mejonía funcional, hemodinámica y en la sobrevida ${ }^{22}$. El beneficio de epoprostenol (Flolan ${ }^{\circledR}$ ) no sólo se debe a sus propiedades vasodilatadoras, ya que además disminuye la agregación y migración plaquetaria y posee propiedades antiproliferativas. Epopros- 
Tabla 2. Comparación entre los diferentes ensayos terapéuticos y drogas anti-H PA

\begin{tabular}{|c|c|c|c|c|c|}
\hline Terapia & Autor/Año & Tipo de estudio & «»» & Seguimiento & Resultados \\
\hline $\begin{array}{l}\text { Epoprostenol } \\
\text { endovenoso }\end{array}$ & $\begin{array}{l}\text { Barst } \\
1996\end{array}$ & RP-DC-CP & 81 & 12 semanas & $\begin{array}{l}\text { Mejoría sintomática, } \\
\text { hemodinámica, } \\
\text { distancia (47 mt) } \\
\text { y sobrevida }\end{array}$ \\
\hline $\begin{array}{l}\text { Treprostinil } \\
\text { subcutáneo }\end{array}$ & $\begin{array}{l}\text { Simonneau } \\
2002\end{array}$ & M-RP-DC-CP & 470 & 12 semanas & $\begin{array}{l}\text { Mejoría sintomática, } \\
\text { distancia (16 mt) } \\
\text { y hemodinámica }\end{array}$ \\
\hline $\begin{array}{l}\text { Iloprost } \\
\text { inhalado }\end{array}$ & $\begin{array}{l}\text { Olshewski } \\
2002\end{array}$ & M-RP-DC-CP & 203 & 12 semanas & $\begin{array}{l}\text { Mejoría sintomática, } \\
\text { distancia ( } 36 \mathrm{mt}) \\
\text { y hemodinámica }\end{array}$ \\
\hline $\begin{array}{l}\text { Bosentan } \\
\text { Oral }\end{array}$ & $\begin{array}{l}\text { Rubin } \\
2002\end{array}$ & M-RP-DC-CP & 213 & 16 semanas & $\begin{array}{l}\text { Mejoría sintomática } \\
\text { distancia ( } 44 \mathrm{mt}) \\
\text { y hemodinámica }\end{array}$ \\
\hline $\begin{array}{l}\text { Sildenafil } \\
\text { Oral }\end{array}$ & $\begin{array}{l}\text { Sastri } \\
2004\end{array}$ & $\begin{array}{l}\mathrm{RP}-\mathrm{CP} \\
\text { Cross-over }\end{array}$ & 22 & 6 semanas & $\begin{array}{l}\text { Mejoría sintomática, } \\
\text { mejoría test } \\
\text { ejercicio } \\
\text { (Naughton), } \\
\text { calidad de vida }\end{array}$ \\
\hline
\end{tabular}

n: Tamaño de la muestra. M: Multicéntrico. RP: Randomizado, prospectivo. DC: Doble ciego. CP: Control placebo.

tenol es el tratamiento de elección para los pacientes en clase funcional III y IV, por su beneficio ampliamente demostrado en la sobrevida a largo plazo en seguimientos que superan los 10 años ${ }^{23}$. La sobrevida reportada con epoprostenol a 1, 3 y 5 años es de 85\%, $63 \%$ y $55 \%$, respectivamente, comparada con $58 \%$, $33 \%$ y $28 \%$, en el mismo tiempo, en los controles 24 . Su uso está aprobado por las sociedades europea y americana de la especialidad.

Sus beneficios han sido reportados en HPA idiopática, familiar, asociada a drogas o esclerodermia, shunts debido a malformaciones congénitas, hipertensión portal, sarcoidosis, HIV y en tromboembolismo pulmonar crónico no quirúrgico ${ }^{25}$. El elevado costo ha obstaculizado su disposición a nivel nacional y el interés se ha volcado hacia nuevas alternativas más económicas. Entre ellas, se encuentran las prostaglandinas inhaladas (iloprost), orales (beraprost), subcutáneas (treprostinil), los bloqueadores de receptores de endotelinas tipo I (bosentan) y los antifosfodiesterasa V (sildenafil).

Iloprost inhalado. Es una prostaciclina análoga para uso inhalatorio. Su beneficio a corto y largo plazo ha sido demostrado en un estudio multicéntrico, prospectivo, randomizado contra placebo, tanto del punto de vista sintomático y funcional como hemodinámico, por lo que se recomienda para pacientes en clase funcional III y IV ${ }^{26}$. Su vida media reducida exige un uso repetido entre 6 y 9 veces al día, entre 5 y 15 min cada vez ${ }^{26}$. Su uso está aprobado por las sociedades europea y americana de la especialidad.

Beraprost. Análogo oral, tiene una vida media más larga que epoprostenol; sin embargo, sus resultados provienen de pequeños estudios en HPA idiopática y asociada a enfermedad cardíaca congénita, con mejoría hemodinámica sólo a corto plazo $^{27}$. Por el momento, se requiere mayor investigación al respecto para su recomendación. Sólo se encuentra aprobada en Japón.

Treprostinil. Prostaciclina de uso subcutáneo (Remodulin ${ }^{\circledR}$ ), en infusión continua. Treprostinil ha demostrado tener un beneficio no sólo sintomático, sino también en las variables funcionales y hemodinámicas en un gran estudio multicéntrico, randomizado, prospectivo ${ }^{28}$. Si bien su uso es más 
simple que su símil endovenoso, su costo sigue siendo elevado y presenta una elevada tasa de abandono prematuro por dolor en la pared abdominal en el sitio de infusión (8\%). Sólo aprobado para su uso en Estados Unidos de Norteamérica (EE.UU) y en algunos países de Europa.

Bosentan. Bosentan $\left(\right.$ Tracleer $\left.^{\circledR}\right)$ es la primera droga oral aprobada en EE.UU, Canadá y Suiza para el tratamiento de la HPA. El bloqueo dual de los receptores A y B de endotelina (ET-1) es una nueva y revolucionaria alternativa terapéutica, que ha demostrado efectividad clínica, funcional y hemodinámica en los pacientes con HPA idiopática y asociada a ETC ${ }^{29}$. El único efecto adverso de significación es su potencial hepatotoxicidad (2\%), con reversibilidad absoluta luego del retiro de la droga. Su uso está aprobado en EE.UU y Europa para clase funcional II, III y IV y se ha constituido, junto con epoprostenol, en la terapia de elección en el paciente con HPA. Se encuentra contraindicado en el embarazo o en asociación a ciclosporina A o glyburide.

$\mathrm{Si}$ bien el bloqueo dual de receptores de endotelina es beneficioso, los ET1-B se expresan predominantemente en la célula endotelial, donde su activación estimula la liberación de agentes como ON y prostaciclina bajo condiciones fisiológicas normales, por lo que parece razonable el intento de un bloqueo más selectivo de receptores de ET1. Actualmente se encuentran en proceso de evaluación dos bloqueadores específicos ET1-A tales como ambrisentan y sitaxsentan.

Sildenafil. Es un bloqueador altamente específico de la enzima fosfodiesterasa 5, ampliamente distribuida en el territorio pulmonar, cuya función es inhibir a cGMP, el segundo mensajero del ON. Sildenafil, al bloquear esta enzima, previene la caída de cGMP y favorece una mayor disponibilidad de $\mathrm{ON}$ en la vasculatura pulmonar y su consecuente efecto vasodilatador pulmonar selectivo.

Existen muchas comunicaciones y series clínicas pequeñas que comunican resultados beneficiosos. Hasta el momento, el único ensayo randomizado publicado que demuestra su beneficio, fue efectuado en 22 pacientes con modalidad cross-over, con 6 semanas de seguimiento y control con técnicas no invasivas ${ }^{30}$. Los resultados del estudio multicéntrico Super-1 han sido comu- nicados en los últimos congresos de la especialidad y son favorables.

En un estudio en agudo, comparando sildenafil (Viagra ${ }^{\circledR}$ ) con ON, se demostró una caída significativa de la presión de arteria pulmonar con sildenafil ${ }^{31}$. También se ha reportado su beneficio en un grupo selecto de pacientes con ETC no quirúrgica, con resultados favorables en relación a la capacidad de ejercicio y hemodinamia ${ }^{32}$.

Otros. Los resultados con drogas como ß-bloqueadores, agonistas $\alpha$-adrenérgicos, nitratos, hidralazina 0 inhibidores de la enzima de conversión de angiotensina han sido desalentadores. Se encuentran aún en evaluación alternativa como L-Arginina (sustrato para la síntesis de $\mathrm{ON}$ ), estatinas, antiendotelinas específicos entre otras 3,9 .

Septostomía. En pacientes extremadamente graves, refractarios a terapia médica y como un puente al trasplante, se ha visto un efecto beneficioso a corto plazo con la creación de un defecto auricular septal artificial (septostomía), que permite aliviar la carga al ventrículo derecho, mejorando el débito cardiaco con el costo de una inmediata caída de la saturación arterial ${ }^{33}$.

Trasplante pulmonar (TP). HPA es una de las indicaciones clásicas de TP; sin embargo, con la aparición de nuevas terapias, en la actualidad da cuenta de sólo 3,8\% del total de los TP. Esto se explica por las cifras de sobrevida alcanzadas a 1, 3 y 5 años de $65 \%$, 55\% y 44\%, inferiores a las reportadas con epoprostenol ${ }^{34}$. En los pacientes con cardiopatías congénitas complejas es preferido el bloque corazón-pulmón; sin embargo, en los otros grupos no hay acuerdo respecto al trasplante de pulmón único o bilateral, el primero asociado a mayor mortalidad precoz, el segundo conllevaría una menor disponibilidad de órganos ${ }^{35}$.

\section{PRONÓSTICO}

Son indicadores de mal pronóstico: clase funcional de la OMS IV, distancia recorrida inferior a 332 $\mathrm{m}$, presión arterial pulmonar media superior a 55 $\mathrm{mmHg}$, presión de aurícula derecha superior a 10 $\mathrm{mmHg}$, índice cardíaco inferior a $2,0 \mathrm{l} / \mathrm{min} / \mathrm{m}^{2} \mathrm{y}$ saturación arterial pulmonar inferior a $63 \%{ }^{8}$. 


\section{SOBREVIDA}

El registro norteamericano de sobrevida demuestra que la historia natural de la enfermedad es progresiva y devastadora. Es así como los pacientes en clase funcional I y II tienen una sobrevida promedio de 58 meses, comparada con menos de 6 meses en los en clase IV ${ }^{7}$.

La causa de muerte es una progresiva falla ventricular derecha y brusca caída del débito cardíaco ${ }^{3,5,7,9}$.

\section{EXPERIENCIA NACIONAL}

En el sistema público de salud, sólo se dispone de bloqueadores de los canales de calcio. En algunos centros de referencia, de alta complejidad, se dispone de prostaciclinas endovenosas o inhalato-

\section{REFERENCIAS}

1. The International Primary Pulmonary Hypertension Study Group. The International Primary Pulmonary Hypertension Study (IPPHS). Chest 1994; 105 (Suppl): 37S-41S.

2. RuBin LJ. Primary pulmonary hypertension. Chest 1993; 104: 236-50.

3. British Cardiac Society Guidelines and Medical Practice Committee, and approved by the British Thoracic Society and the British Society of Rheumatology. Recommendations on the Management of Pulmonary Hypertension in Clinical Practice Heart 2001; Volume 86 (Supplement 1): i1-i13.

4. LANGLeBEN D. Familial primary pulmonary hypertension. Chest 1994; 105: 13-6S.

5. RiCH S, EDITOR. Primary pulmonary hypertension. Executive Summary from the World Symposium. Primary Pulmonary Hypertension. World Health Organization, 1998.

6. Deng Z, Morse JH, Slager SL, Cuervo N, Moore KJ, Venetos G et AL. Familial primary pulmonary hypertension (gene PPH 1) is caused by mutations in the bone morphogenetic protein receptor-II gene. Am J Hum Genetics 2000; 67: 737-44.

7. Rich S, Dantzker DR, Ayres SM, Bergofsky EH, Brundage BH, Detre KM et al. Primary pulmonary hypertension: a national prospective study. Ann Intern Med 1987; 107: 216-23. rias, inhibidores de fosfodiesterasa y posibilidad de reclutamiento en protocolos fase III con ambrisentan. La experiencia publicada hasta la fecha se limita exclusivamente al reporte de casos especiales, como el de HP y embarazo ${ }^{36}$.

La experiencia del Instituto Nacional del Tórax en el estudio y tratamiento de estos pacientes será comunicada próximamente. A modo preliminar, es posible señalar que en el lapso de dos años, el diagnóstico de HPA se ha confirmado en 41 pacientes, la mayoría mujeres, jóvenes, en capacidad funcional III con HPA moderada. En 20 pacientes tratados con sildenafil por 6 meses se observó una mejonía clínica y funcional significativa.

Finalmente recomendamos que los pacientes sean referidos lo antes posible, sin inicios empíricos de terapias específicas, a centros de mayor complejidad con experiencia en esta entidad.

8. D’Alonzo GE, Barst RJ, Ayres SM, Bergofsky EH, Brundage BH, Detre KM et al. Survival in patients with primary pulmonary hypertension: results from a national prospective registry. Ann Intern Med 1991; 115: 343-9.

9. Simonneau G, Galié N, Rubin LJ, Langleben D, Seeger W, Domenighetti G ET aL. Clinical classification of pulmonary hypertension. J Am Coll Cardiol 2004; 43: 5S-12S.

10. Dresdale D, Schultz M, Michton R. Primary pulmonary hypertension: I. Clinical and Hemodynamic study. Am J Med 1951; 11: 686-94.

11. Mukerjee D, St. George D, Coleiro B, Knight C, Denton CP, Davar J et al. Prevalence and outcome in systemic sclerosis associated pulmonary arterial hypertension: application of a registry approach. Ann Rheum Dis 2003; 62: 1088-93.

12. Speich R, Jenni R, Opravil M. Primary pulmonary hypertension in HIV infection. Chest 1991; 100: 1268-71.

13. Abenhaim L, Moride Y, Brenot F, Rich S, Benichou J, Kurz X et al, for the International Primary PulmoNARY HyPERTENSION Study Group. Appetite suppressant use and the risk of primary pulmonary hypertension. N Engl J Med 1996; 335: 609-16.

14. Hadengue A, Benhayoun MK, Lebrec D, Benhamou JP. Pulmonary hypertension complicating portal hypertension: prevalence and relation to splachnic hemodynamic. Gastroenterology 1991; 100: 520-8 
15. Kidd L, Driscoll DJ, Gersony WM, Hayes CJ, KeANe JF, O’FALON WM ET AL. Second natural history study of congenital heart defects. Results of treatment of patients with ventricular septal defects. Circulation 1993; 87(2 Suppl): 138-51.

16. McGoon M, Gutterman D, Sten V, Barst R, McCRORY DC, Fortin TA ET AL. Screening, early detection, and diagnosis of pulmonary arterial hypertension. ACCP Evidence-Based Clinical Practice Guidelines. Chest 2004; 126: 14S-34S.

17. Berger M, Haimowitz A, Van Tosh A, Berdoff RL, GOLDBERG E. Quantitative assessment of pulmonary hypertension in patients with tricuspid regurgitation using continuous wave Doppler ultrasound. AJ Am Coll Cardiol 1985; 6: 359-65.

18. Miramoto S, Nagaya N, Satoh T, Kyotani S, SakamaKI F, FuJITA M ET AL. Clinical correlates and prognostic significance of six-walk test in patients with primary pulmonary hypertension. Am J Respir Crit Care Med 2000; 161(2 Pt 1): 487-92.

19. Rich S, BRuNdage BH. High-dose calcium channelblocking therapy for primary pulmonary hypertension: evidence of long-term reduction in pulmonary arterial pressure and regression of right ventricular hypertrophy. Circulation 1987; 76: 135-41.

20. RuBIN LJ, BADESCH DB. Evaluation and management of the patient with pulmonary arterial hypertension. Ann Intern Med 2005; 143: 282-92.

21. Weiss BM, Zemp L, SeIFerT B, Hess OM. Outcome of pulmonary vascular disease in pregnancy: a systematic overview from 1978 through 1996. J Am Coll Cardiol 1998; 31: 1650-7.

22. Barst RJ, Rubin LJ, Long WA, McGoon MD, Rich S, BADESCH DB ET AL. A comparison of continuous intravenous epoprostenol (Prostacyclin) with conventional therapy for primary pulmonary hypertension. N Engl J Med 1996; 334: 296-301.

23. Higgenbottam T, Siddons T. Trials of inhaled iloprost and other new vasodilating prostaglandins. Eur Respir J 2000; 17: 6-7.

24. Sitbon O, Humbert M, Nunes H, Parent F, García G, HeRve $P$ ET AL. Long-term intravenous epoprostenol infusion in primary pulmonary hypertension: prognostic factors and survival. J Am Coll Cardiol 2002; 40: 780-8.

25. McLaughun VV, Genthner DE, Panela MM, Rich S. Reduction in pulmonary vascular resistance with long-term epoprostenol (prostacyclin therapy in primary pulmonary hypertension). N Engl J Med 1998; 338: 273-7.

26. Olschewski H, Simonneau G, Nazzareno G, HigenbotTam T, NaEje R, Rubin LJ et al. Inhaled Iloprost for severe pulmonary hypertension. N Engl J Med 2002; 347: 322-9.

27. Barst RJ, McGoon M, McLaughlin V, Tapson V, Oudiz R, Shapiro S Et al. Beraprost Study Group. Beraprost therapy for pulmonary arterial hypertension. J Am Coll Cardiol 2003; 41: 2119-25.

28. Simonneau G, Barst RJ, Gale N, Naeje R, Rich S, Bourge RC ET AL. Continuous subcutaneous infusion of treprostinil, a prostacyclin analogue, in patients with pulmonary arterial hypertension: a double-blind, randomized, placebo-controlled trial. Am J Respir Crit Care Med 2002; 165: 800-4.

29. Rubin LJ, Badesch DB, Barst RJ, Galle N, Biack CM, KEOGH A ET AL. Bosentan therapy for pulmonary arterial hypertension. NEngl J Med 2002; 346: 896-903.

30. Sastry BKS, Narasimhan C, Krishna Reddy N, Soma Raju B. Clinical efficacy of sildenafil in primary pulmonary hypertension: a randomized, placebo-controlled, double-blind, crossover study. JACC 2004; 43: 1149-53.

31. Michelakis E, TymchaK W, Lien D, Webster L, НASнimoto K, ARcheR S. Oral sildenafil is an effective and specific pulmonary vasodilator in patients with pulmonary arterial hypertension. Circulation 2002; 105: 2398-403.

32. Ghofrani HA, Schermuly RT, Rose F, Wiedemann R, Kohstall MG, KReckel A et al. Sildenafil for longterm treatment of nonoperable chronic thromboembolic pulmonary hypertension. Am J Respir Crit Care Med 2003; 167: 1139-41.

33. Rich S, Dodin E, McLaughun VV. Usefulness of atrial septostomy as a treatment for primary pulmonary hypertension and guidelines for its application. Am J Cardiol 1997; 80: 369-71.

34. United Network for Organ Shaning. US scientific registry for transplant recipients and the organ procurement and transplantation network: transplant data: 1990-2000. Annual report. Washington, US Department of Health and Human Services, 2002.

35. Meyers BF, Lynch J, Trulock EP, Guthrie TJ, Cooper JD, Patterson GA. Lung transplantation: a decade of experience. Ann Surg 1999; 230: 362-70.

36. Valdés G, Matthei R, Fernández MS, Schacht C, Corthorn J, Germain A. Hipertensión pulmonar y embarazo. Rev Méd Chile 2002; 130: 201-8. 


\title{
Utilidad de la deoxiglucosa marcada con flúor-18 (FD G) en el manejo de los linfomas
}

\author{
Teresa Massardo V $\mathrm{M}^{1,2,3}$, José Canessa G $\mathrm{G}^{2,4}$, \\ $M$ Josefina Jofré $M^{2}$, Patricio $G$ onzález $E^{1,2,3,5}$, \\ Pamela Humeres $A^{5,2}$, Paulina Sierralta $\mathbf{G}^{2}$. \\ Role of ${ }^{18}$ Fluorine-deoxyglucose \\ (FDG) positron emission tomography \\ in the management of lymphomas
}

\begin{abstract}
Positron emission tomography (PET) with fluorine-18 labeled deoxyglucose (FDG) is useful in the management of lymphomas. In this review, some general concepts of this metabolic test are defined. It has an excellent diagnostic yield in Hodgkin disease as well as in most non Hodgkin lymphomas. Staging, restaging residual mass evaluation and the control of therapy are the main indications for FDG-PET. Images with FDG have a high diagnostic and prognostic value, that is superior to anatomical images and conventional staging techniques. They are also helpful for the assessment of tumor activity in abnormal lymph nodes or large masses that have been treated and reduce their size slowly or show an incomplete resolution. Currently, the resolution of dedicated PET equipments is $6 \mathrm{~mm}$ and bigger lesions can easily be detected. The main differences and advantages of FDG versus gallium-67 in lymphoma are also discussed, as well as the initial local experience with the technique in lymphoma patients (Rev Méd Chile 2006; 134: 910-9).

(Key words: Fluorine-18-fluorodeoxyglu cose; Hodgkin disease; Lymphoma, non-Hodgkin; Positron-emission tomography)

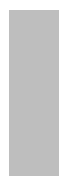

Recibido el 18 de octubre, 2005. Aceptado el 19 de enero, 2006.

${ }^{1}$ Sección Medicina Nuclear, Departamento de Medicina, Hospital Clínico Universidad de Chile. ${ }^{2}$ Centro PET de Imágenes Moleculares, Hospital Militar de Santiago. ${ }^{3}$ Centro Radiológico Fleming. ${ }^{4}$ Medicina Nuclear Hospital Dipreca. ${ }^{5}$ Medicina Nuclear, Clínica Santa María, Santiago de Chile.
\end{abstract}

$\mathrm{E}$ linfoma es una patología maligna del sistema linfático, potencialmente curable en una importante proporción de pacientes, con buena respuesta a quimioterapia, radioterapia o ambas.

Correspondencia a: Dra. Teresa Massardo Vega. Centro PET de Imágenes Moleculares, Hospital Militar de Santiago. Sección Medicina Nuclear, Departamento de Medicina, Hospital Clínico Universidad de Chile. Santos Dumont 9991E, Independencia, Santiago, Chile. Teléfono: 7770569. Fonofax: 7777618. E mail: tmassardo@redclinicauchile.cl
La incidencia de linfoma no Hodgkin (LNH) está en aumento en el mundo occidental y se ha observado asociación con diversas patologías virales, en especial con infección por virus de inmunodeficiencia humana. El linfoma de Hodgkin (LH) también ha aumentado su incidencia, asociándose a otras infecciones virales. Paralelamente, la terapia y sobrevida han mejorado, lo cual conduce a mayor número de pacientes que pueden presentar efectos indeseables tardíos de la terapia, más relevantes en población de menor 
edad, por lo que se debiera monitorizar precozmente la eficacia de la terapia; uno de los problemas secundarios a este buen éxito es el riesgo de aparición de segundos tumores, que va aumentando en el tiempo, lo cual obliga a plantear la disminución de cantidad y duración de las terapias ${ }^{1}$. Conocer el grado histológico, obtener una óptima etapificación (estado nodal y extranodal), así como disponer y controlar las terapias indicadas es básico en esta enfermedad. La introducción de la tomografía de emisión de positrones (PET) puede mejorar la relación costo beneficio del estudio del paciente y ayudar a mejorar la sobrevida ${ }^{2-5}$.

La PET con deoxiglucosa marcada con Flúor-18 (FDG) se basa en la alta actividad glucídica de las células neoplásicas de variados tumores, relacionada con proteínas transportadores de glucosa Glut de la membrana celular y con la hexoquinasa. La molécula de FDG, análoga de la glucosa, es fosforilada y luego queda atrapada en el intracelular. La distribución habitual de la FDG es mayor en los tejidos con mayor actividad metabólica: cerebro y miocardio. En general, la FDG se acumula en los tumores en forma proporcional a la tasa de metabolismo glucídico y mitótico y, secundariamente, al grado de indiferenciación. Algunos aspectos técnicos ya han sido revisados por Jofré y cols $^{6}$.

El rendimiento en estudios diagnósticos y pronósticos ha sido demostrado en los linfomas, tanto $\mathrm{LH}$ como LNH, en especial, en casos de tumores de mayor grado. Inicialmente, se observó menor captación en linfomas con grados más bajos y en los de tipo indolente, como linfocíticos de células pequeñas y asociados a mucosas (MALT). Sin embargo, se ha demostrado buen rendimiento en linfomas de bajo grado, en especial, en foliculares ${ }^{7}$. Elstrom y cols ${ }^{8}$ analizaron la utilidad de la FDG en un grupo de 172 pacientes con linfoma clasificados de acuerdo a OMS; sugieren que las características biológicas intrínsecas de subtipos histológicos específicos determinan la utilización de glucosa y captación de FDG. El linfoma folicular tuvo alta captación de FDG en casi todos los casos, así, el grado histológico no es el predictor más importante de avidez de captación; asimismo, hubo variabilidad en los resultados de linfomas de células marginales y de células $\mathrm{T}$ periféricas sugerentes de que los mecanismos de regulación de la linfomagénesis son complejos. Además, en $80 \%$ de 105 de esos casos hubo concordancia con el informe de biopsia de médula ósea. La FDG, según Najjar y cols ${ }^{9}$, tiene sensibilidad de $83 \%$ y especificidad de 100\%, similar a la obtenida con tomografía computada (TC) en la evaluación de linfomas de bajo grado.

Debe considerarse que la mayoría de los trabajos publicados son de tipo retrospectivo y pudieran estar sesgados por antecedentes clínicos o de imágenes, así como por la gran variedad histológica existente en linfomas ${ }^{10}$.

La introducción en la práctica clínica del PET FDG, ha producido un cambio importante en el diagnóstico y manejo del linfoma. Medicare de Estados Unidos de Norteamérica aprobó el examen de cuerpo entero en equipos PET dedicados para diagnóstico, etapificación inicial y reetapificación de linfomas y está aceptado, recientemente, para monitorización de terapia en protocolos de investigación. En general, esto permite tener mayor información en:

a) Etapificación, en que la tomografía computada (TC) y las técnicas anatómicas consideran patológicas sólo lesiones $\geq 1 \mathrm{~cm}$.

b) Reconocimiento de masa residual viable, indistinguible necrosis y fibrosis en imágenes anatómicas.

c) Control de terapia, obviando costos económicos y sintomáticos por efectos colaterales de terapias ineficientes.

d) Diagnóstico y detección de recurrencia.

e) Examen pronóstico, identificar respondedores y no-respondedores a terapia en candidatos de trasplante de médula ósea.

f) Elección de sitio de biopsia, especialmente, de médula ósea.

Para la interpretación, debe considerarse que procesos de tipo inflamatorio pueden presentar mayor actividad glucídica que los tejidos normales. Áreas sometidas a radioterapia o a procedimientos quirúrgicos o diagnósticos de tipo invasivo, también pueden ser hipercaptantes y esos antecedentes deben conocerse. La proliferación de médula ósea secundaria a quimioterapia 0 a estimulantes de colonias de granulocitos produce hipercaptación difusa leve o moderada por hiperplasia benigna, lo cual se asocia a mayor captación esplénica. La hiperplasia tímica precoz posquimioterapia en niños y adolescentes es observada frecuentemente ${ }^{11-14}$. 
Equipos disponibles para estudios de FDG. Existen diversos equipos con capacidad de efectuar estudios con emisores de positrones:

- gamma cámaras convencionales con colimadores de alta energía (no aptas para oncología).

- gamma cámaras híbridas que utilizan detección por coincidencia, su desventaja es menor sensibilidad y límite de resolución espacial $>1-1,5 \mathrm{~cm}$.

- cámaras PET dedicadas para estudio de emisores de positrones; pueden visualizar lesiones captantes de $6 \mathrm{~mm}$.

- cámaras PET dedicadas con equipo TC con adquisición simultánea o inmediatamente diferida, que facilita ubicación anatómica, aunque implican mayor costo y radiación.

En general, respecto al uso de PET/TC en linfomas, tiene utilidad en caso de localización de lesiones inciertas, presencia de grasa parda o delimitación de compromiso óseo ${ }^{15}$; sin embargo, la comparación paralela de imágenes anatómicas y funcionales más la fusión de imágenes de diferentes equipos puede resolver la mayoría de los casos. Por otra parte, el PET/TC tiene la opción de aplicarse para dirigir más certeramente la radioterapia, con selección de las zonas con viabilidad tumoral documentada $^{16}$. En referencia a pacientes jóvenes que requieran seguimiento prolongado, el efectuar controles con equipos PET dedicados, sin utilizar TC concomitante puede tener, a largo plazo, mayor beneficio (radiación total entregada). La TC se puede efectuar posteriormente en forma dirigida, en caso de ser positiva.

\section{ETAPIFICACIÓN Y REETAPIFICACIÓN}

La sensibilidad de la FDG es excelente para etapificación de linfomas; por paciente es $83 \%$ y por sitios comprometidos es $89 \%$, considerando el límite de detección de $1 \mathrm{~cm}$. Los equipos actuales PET de alta resolución tienen capacidad de pesquisar lesiones $>4-6 \mathrm{~mm}$. La FDG puede detectar más sitios enfermos que el algoritmo convencional que incluye TC, resonancia magnética, radiología simple y galio-67 citrato $\left({ }^{67} \mathrm{Ga}\right)^{3,4,17-23}$.

Schiepers y cols ${ }^{24}$ plantean que el estudio FDG de cuerpo entero, para etapificación, es superior a los métodos convencionales (examen físico, de laboratorio e imágenes anatómicas) en 10-20\%.
En LH, Hueltenschmidt y cols ${ }^{25}$ publicaron mejor seguridad global del FDG que con métodos convencionales (83\% versus 56\%). Esto concuerda con análisis en pool de estudios realizados previamen$t^{22}$. Sin embargo, la sensibilidad de FDG es menor para evaluar compromiso infradiafragmático.

En un metaanálisis reciente de Isasi y cols ${ }^{26}$, se concluye que los clínicos debieran considerar el PET FDG para etapificación de linfoma. Incluyeron 14 estudios de pacientes en globo (la mitad considerando sólo lesiones), que muestran sensibilidad de 90,9\% [95\% intervalo de confianza (IC): 88,0-93,4] con tasa de falsos positivos de 10,3\% [IC: 7,4-13,8]; la sensibilidad pareciera ser mayor en $\mathrm{LH}$ que LNH. Este trabajo incluye 7 estudios prospectivos, aunque está basado en revisión de literatura y no en datos individuales ${ }^{27}$.

En los linfomas indolentes, el rendimiento del PET FDG es menor $2,10,26$; este hecho tiene trascendencia, por la mayor frecuencia de compromiso medular al momento del diagnóstico ${ }^{28}$.

La utilidad del PET FDG no es sólo para evaluación de cadenas linfáticas, sino también para hígado, bazo, mesenterio y peritoneo. En el compromiso esplénico, difícil de establecer no invasivamente, tiene excelente rendimiento respecto a la TC y no se basa en tamaño del bazo, sino en intensidad de captación ${ }^{22}$. Para reconocer compromiso de la médula ósea, la FDG puede tener valor, pero no reemplaza a la biopsia medular, aunque ayudaría a seleccionar el sitio del procedimiento, especialmente en casos de biopsias iniciales negativas.

En otro metaanálisis, de Pakos et al, se encontró que la FDG tiene buena concordancia con la biopsia de médula ósea que, aunque no es excelente, se debe considerar como complementaria y puede variar según tipo de linfoma, siendo más sensible en $\mathrm{LNH}$ agresivos ${ }^{29}$.

Específicamente, en casos con extensión extraganglionar, el contar con PET/TC ayuda a tener mejor rendimiento respecto a la tecnología PET dedicado en forma aislada, por ejemplo, en compromiso muscular ${ }^{30}$.

\section{DiFERENCIACIÓN DE MASA RESIDUAL VERSUS FIBROSIS CICATRICIAL}

Como ya se mencionó, existen dificultades para identificar la presencia de tejido tumoral activo. 
Reske publicó un análisis de 15 trabajos que incluyen 723 pacientes estudiados con FDG ${ }^{31}$; consideró que el método, a pesar de no ser perfecto, es el más seguro para detectar viabilidad en linfoma residual. La sensibilidad en este punto varió entre 71 y $100 \%$ y la especificidad entre 69 y $100 \%$. El valor predictivo negativo (VPN) fue alto, entre 80 y 100\%. La especificidad y el valor predictivo positivo (VPP) de la TC fueron menores, entre $4-31 \%$ y $19-82 \%$, respectivamente. Las masas residuales positivas con FDG se han asociado a una baja sobrevida libre de enfermedad, entre 0 y $40 \%$.

\section{EVALUACIÓN DE TERAPIA}

La capacidad de evaluar precozmente la respuesta a quimioterapia ha sido reconocida entre las indicaciones más importantes de la FDG en linfomas, incluso en los primeros ciclos, por disminución de masa tumoral activa. En LNH, Romer y cols, usando análisis cuantitativo, demostraron que se puede predecir a los 7 y 42 días la respuesta terapéutica ${ }^{34}$. La correlación entre positividad de FDG al final del $3^{\text {er }}$ ciclo y sobrevida libre de enfermedad y global es distinta según el resultado del PET FDG de acuerdo a Jerusalem y cols. (Tabla 1). La probabilidad de obtener remisión completa fue menor en pacientes con PET FDG positivo respecto a estudio negativo de $20 \%$ versus $100 \%$ después de algunos ciclos de poliquimioterapia con $\mathrm{p}<0,00001^{35}$.

En linfoma agresivo, la evaluación precoz después de 1 ó 2 ciclos de quimioterapia, tiene buena sensibilidad en el análisis visual con LH y $\mathrm{LNH}^{36-38}$. La disminución de la captación estanda- rizada de glucosa en el tejido (SUV) en $60 \%$ es un excelente punto de corte para separar entre respondedores y no respondedores a terapia, respecto al estudio basal. Schoder y cols ${ }^{39}$ publicaron que se puede diferenciar entre $\mathrm{LNH}$ indolente y agresivo. SUV $>13$ tiene alta probabilidad de ser linfoma agresivo, mientras que en indolente los valores de las lesiones más intensas son $\leq 6^{40}$. También en LNH agresivos, Juweid y $\operatorname{cols}^{41}$ compararon criterios internacionales con TC y PET FDG; demostrando que con FDG se lograba clasificar más adecuadamente la respuesta, identificando pacientes con mejor pronóstico, posquimioterapia.

La utilidad del PET FDG no sólo está en su capacidad de lograr mejor certeza en la identificación de actividad maligna en distintas etapas de evolución de la enfermedad, sino también en evitar toxicidad innecesaria a pacientes con sobrevida prolongada que pudieran presentar nuevos procesos primarios, limitando campos de radiación y con quimioterapia abreviada ${ }^{1}$.

\section{VALOR PRONÓSTICO}

Según el metaanálisis de Talbot y col, la evidencia de tejido metabólicamente activo con FDG es un fuerte predictor de recaída a los 2 años ${ }^{42}$. En contraste, un estudio negativo tiene baja proporción de recaída. Este valor, sin embargo, no es 0\%, pues es posible no visualizar lesiones pequeñas menores a $1 \mathrm{~cm}$, dependiendo también de la intensidad de captación. El valor predictivo positivo, por lo tanto, es más alto que el negativo.

Respecto a la necesidad de contar con evaluación precoz y segura de pronóstico en tratamiento

\section{Tabla 1. Sobrevida global y libre de enfermedad de acuerdo a positividad o negatividad del estudio con FD G , en 28 pacientes con LN H y 3 ciclos de poliquimioterapia, usando análisis de Kaplan M eier. M odificado con autorización de Jerusalem y cols $s^{35}$}

\begin{tabular}{|llll|}
\hline Sobrevida & PET $(+)$ & PET $(-)$ & $\mathrm{p}$ \\
\hline Libre de enfermedad a 1 año & $20 \pm 18 \%$ & $81 \pm 9 \%$ & $\mathrm{p}=0,0001$ \\
Libre de enfermedad a 2 años & $0 \%$ & $62 \pm 12 \%$ & $\mathrm{p}=0,0001$ \\
Global a 1 año & $20 \pm 18 \%$ & $87 \pm 7 \%$ & $\mathrm{p}<0,0001$ \\
Global a 2 años & $0 \%$ & $68 \pm 11 \%$ & $\mathrm{p}<0,0001$ \\
\hline
\end{tabular}

PET: tomografía de emisión de positrones con FDG. 
adaptado a riesgo, Hutchings y cols ${ }^{43}$ acaban de publicar un trabajo multicéntrico prospectivo con 77 pacientes con $\mathrm{LH}$, en que demuestran que la FDG efectuada después de 2 ciclos de quimioterapia, predice falla de tratamiento y sobrevida libre de enfermedad, en pacientes recientemente diagnosticados.

El trasplante autólogo de células madre hematopoyéticas ha tenido un papel importante en terapia de primera línea y de rescate en linfoma indolente y LNH agresivo. Otra nueva aplicación de la FDG, tanto en LH como LNH, es este tipo de terapia, utilizada en casos en que no se haya obtenido remisión completa o que hayan recaído y que se estén tratando con quimioterapia en altas dosis así como posterior al trasplante.

También existe valor pronóstico de la FDG respecto a la quimiosensibilidad y evolución con diferencias entre los pacientes con estudio pretrasplante negativo y positivo ${ }^{44}$. Se ha usado, asimismo, como guía y monitorización de inmunoterapia e infusión de linfocitos de donantes ${ }^{45}$.

Además, Juweid y cols ${ }^{41}$, en un estudio multicéntrico con 54 pacientes, demostraron, una importante diferencia en sobrevida libre de enfermedad de LNH agresivo al agregar resultado de FDG a los criterios del Workshop Internacional, identificando respuestas parciales o completas a quimioterapia.

\section{CAMBIO DE ETAPA O MANEJO}

El cambio de conducta, secundario a cambio en etapificación (upstaging o downstaging), es difícil de definir; puede corresponder a cambio inter 0 intramodalidad o a modificación de extensión del campo de irradiación. Según revisión basada en pool de estudios de pacientes, el cambio estimado en manejo fue $21 \%$ y en recurrencia $10 \% 22$.

Específicamente, en niños, existe utilidad del PET en LH; Depas y cols. estudiaron, retrospectivamente, un grupo con diversas etapas de $\mathrm{LH}$ y LNH; el PET logró cambio de etapa en 10,5\%; sirvió para control de terapia precoz y tardía y de seguimiento; sólo en 2/19 casos la evaluación de respuesta precoz falló en predecir recaída, sin presencia de falsos positivos; sólo 4/75 falsos positivos se observaron en la evaluación al final de terapia 0 en seguimiento sistemático, valor muy inferior a lo descrito con métodos convencionales, con especificidades de 94 y $95 \%$ con FDG versus 56 y $66 \%$ convencional, para tratamiento y seguimiento, respectivamente ${ }^{46}$.

Además, el uso de FDG tiene impacto en manejo de linfoma, pues se han obtenido cambios de etapa clínica en $44 \%$ y en tratamiento en $>60 \%$ de los casos, en trabajo de encuesta a tratantes ${ }^{47}$. Otro trabajo similar, con cuestionario a médicos de pacientes con diversos tumores pediátricos estudiados con FDG, arrojó que de 60 casos de linfoma, se efectuó un cambio de conducta en manejo en $32 \% 48$.

\section{PET FDG VERSUS GALIO-67 CITRATO}

El ${ }^{67} \mathrm{Ga}$, tiene reconocida utilidad en diagnóstico y pronóstico de la mayoría de los linfomas; su captación está relacionada con receptores de transferrina y con otras moléculas con $\mathrm{Fe}$ y es similar a la FDG en que es dependiente de la actividad tumoral. Sin embargo, tiene desventajas relativas que deben ser consideradas:

a) menor sensibilidad por paciente y por lesión que la FDG,

b) mayor duración del examen (72 h o más, pues requiere fijación).

El ${ }^{67} \mathrm{Ga}$-citrato tiene menor rendimiento que la FDG en evaluación de LNH folicular. Gallamini y cols publicaron que es inseguro para etapificar linfomas de bajo grado, pero que tendría valor pronóstico adicional ${ }^{49}$. Su rendimiento puede aumentar con imágenes más tardías, dosis mayores y estudios tomográficos que incluyan región cervical y tóraco abdominal ${ }^{5}$.

El mejor rendimiento observado del FDG en linfomas (incluso con equipos no dedicados), se explica por su relativa mejor resolución, que permite reconocer más lesiones y por mayor visualización de alteraciones abdominales que con ${ }^{67} \mathrm{Ga}$, dificultadas por su alta captación hepática y marcada excreción intestinal ${ }^{50}$. Kostakoglu y cols analizaron ambos trazadores en $\mathrm{LH}$ y $\mathrm{LNH}$ de grado intermedio o alto. La sensibilidad de FDG fue $100 \%$ tanto por sitios como por pacientes y la del ${ }^{67} \mathrm{Ga}$ fue $71,5 \%$ y $80,3 \%$, respectivamente ${ }^{51}$.

Se han comparado equipos PET dedicados con otros de tipo híbrido usando FDG, observándose 
mejor pesquisa en lesiones $<1,5 \mathrm{~cm}$, con los primeros. Respecto a la especificidad de FDG con equipo dedicado, en una revisión sobre 1.100 casos con linfoma, solamente 5\% correspondió a falsos positivos; su principal causa fueron procesos inflamatorios ${ }^{52}$.

La técnica de fusión de imágenes PET y TC o PET y resonancia magnética es una altemativa disponible, en caso de no contarse con equipo PET/TC.

\section{Costo BENEFICIO}

Por último, en el punto de análisis costo versus beneficio, la FDG tiene valor en la evaluación del linfoma, por mayor número de lesiones encontradas y precocidad respecto a su visualización anatómi$\mathrm{ca}^{2,3,18}$. En etapificación inicial, incorporar PET FDG a la evaluación convencional con TC, también tiene mayor seguridad diagnóstica y ahorro significativo, incluso, sin considerar aumento de sobrevida ${ }^{53,54}$.

\section{EXPERIENCIA CHILENA}

Al evaluar los casos efectuados con equipo PET dedicado en el Hospital Militar de Santiago desde el año 2003, los pacientes con linfoma correspondieron a más de $10 \%$ de todos los pacientes oncológicos; en la actualidad, son más de 120 estudios; $8 \%$ de ellos corresponde a niños. En estos últimos, 50\% de los estudios fueron solicitados para evaluar LH y $39 \%$ en adultos. Las principales indicaciones fueron etapificación y reetapificación (19\%), evaluación de masa residual y monitorización de terapia, incluyendo evaluación pretrasplante de médula ósea (36\%), evaluación de masa residual (12\%) y control de terapia (34\%). El 68\% de los estudios fue positivo para actividad maligna. En control de terapia, 55\% fue positivo, lo que apoyó continuar o modificar esquemas. Hay pacientes que tuvieron seguimiento hasta con 5 estudios, para reetapificación, control de masa residual y evaluación terapéutica de $\mathrm{LNH}$ (Figuras 1-4).

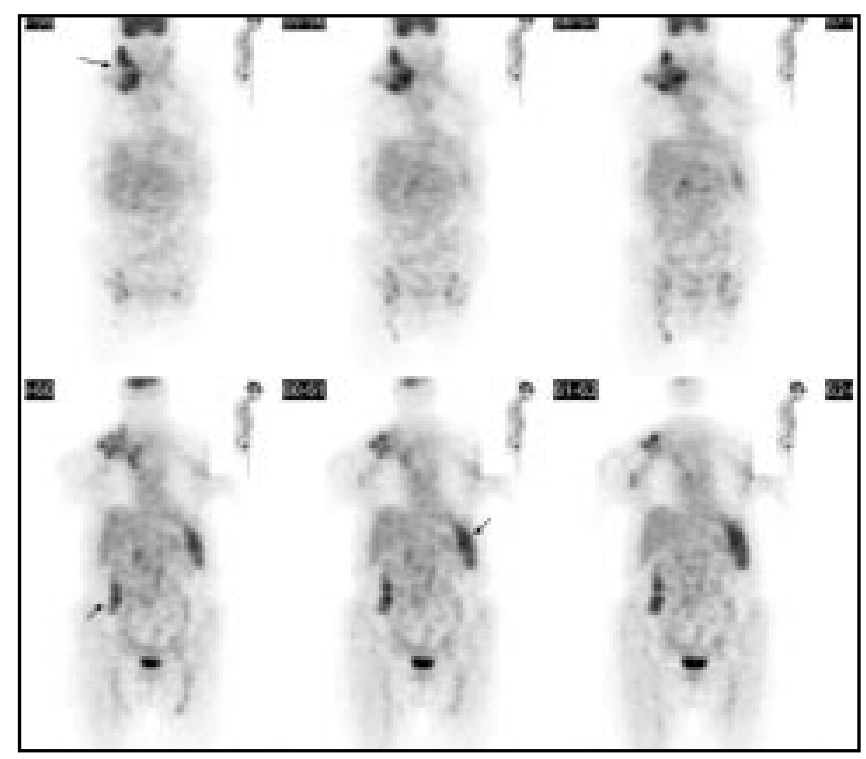

Figura 1. LNH en etapificación. Mujer, 94 años, con masa cervical en que punción aspirativa demuestra LNH. Tiene contraindicación para TC con contraste por disminución de función renal. La FDG de etapificación demuestra importante extensión de la enfermedad, con actividad anormal en bazo, aumentado de tamaño e hipercaptante, en cadenas ganglionares cervicales, mediastino, axilas y también en foco abdominal (selección de cortes coronales). 


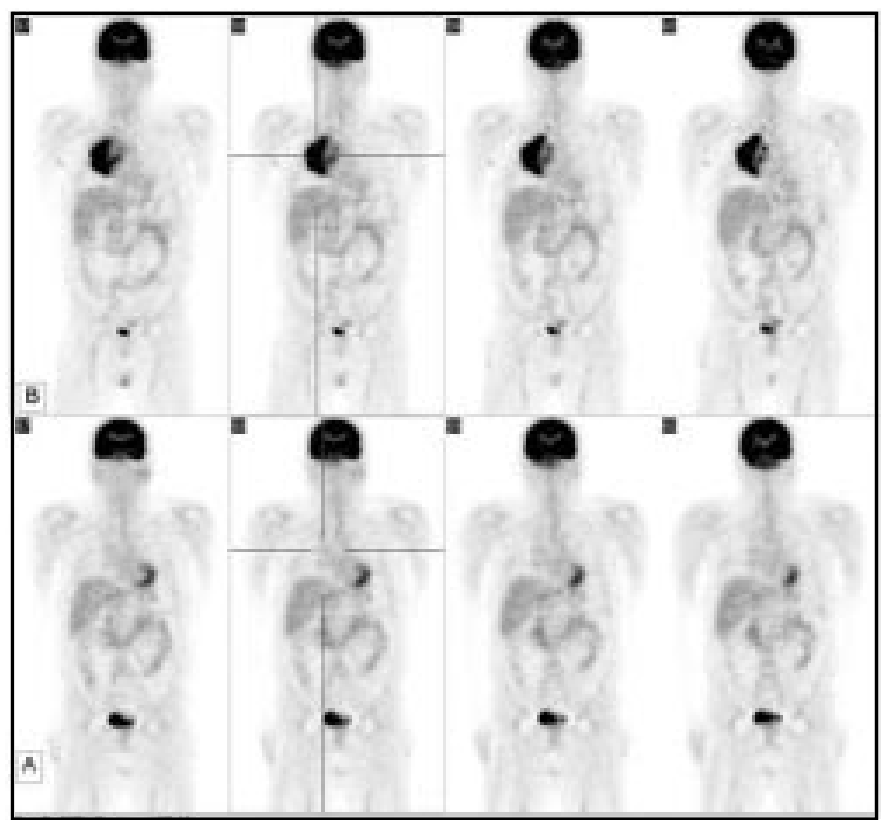

Figura 2. LH etapificación y control de terapia. Paciente hombre de 41 años, evaluado previamente con FDG basal (fila superior, B) que muestra gran masa hipermetabólica mediastínica derecha de marcada intensidad. Además, hay un pequeño foco de leve intensidad sobre esta masa a derecha y otro de menor intensidad axilar derecho, inespecífico. No se aprecian otros focos en la exploración; recibe quimioterapia y se efectúa control metabólico. El FDG realizado a los 4 meses fue negativo, confirmando respuesta completa (fila inferior, A). Se muestran cortes coronales comparativos.

Figura 3. LNH folicular de células pequeñas. Paciente hombre de 72 años con enfermedad conocida hace 3 años, tratado con quimioterapia. Se efectúa reetapificación. Existe lesión sospechosa toracoabdominal en TC. Las imágenes con FDG muestran compromiso prevertebral dorsolumbar y mediastínico, no conocido (flechas). Se efectúa nueva TC de tórax y se encuentra cadena mamaria aumentada. No se realiza biopsia; se decide cambio de conducta terapéutica usando anticuerpos monoclonales.

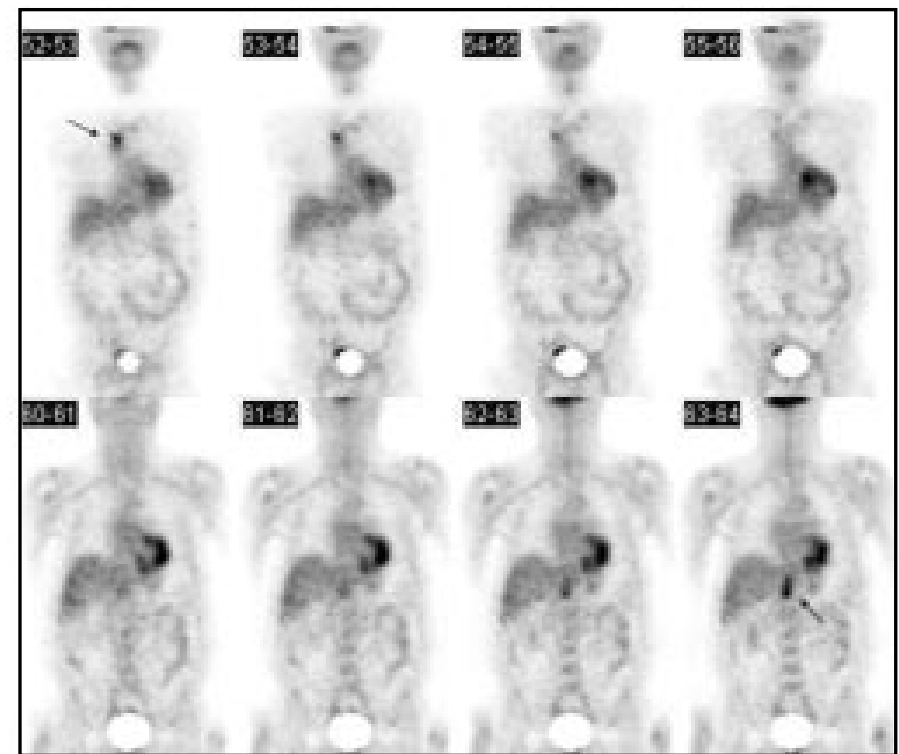




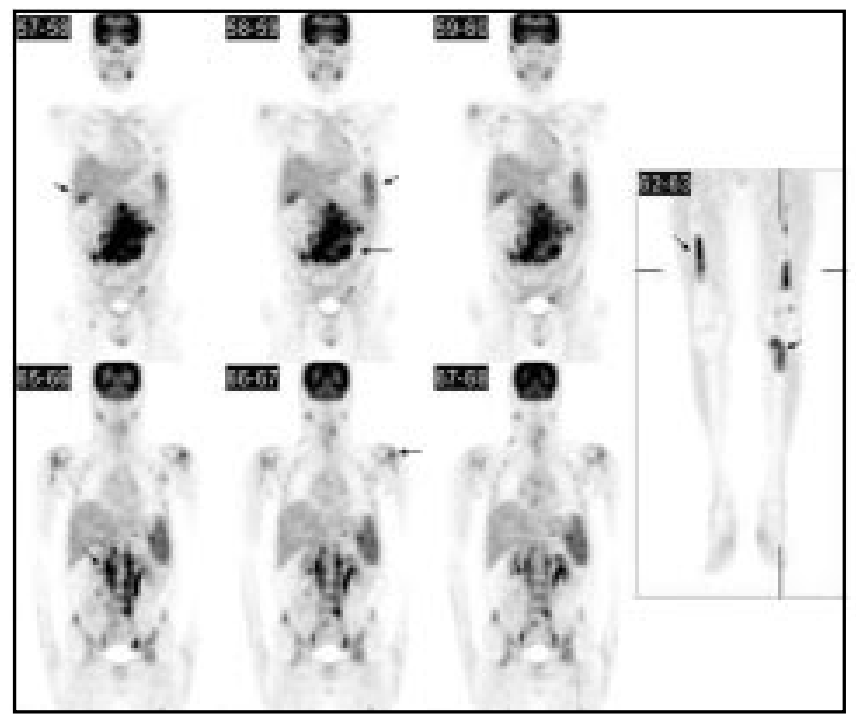

Figura 4. LNH folicular células pequeñas de bajo grado IVB. Hombre de 41 años. TC de cuello, tórax y abdomen muestran compromiso tumoral, FDG de etapificación: se observa intenso compromiso multifocal: esplénico, en lóbulo hepático derecho paravertebral, mesenterio, cadenas ilíacas bilaterales, mediastino, paravertebral bilateral, axilas, cervical, costal, columna dorsal, pelvis, húmeros y cúbito izquierdo. A la derecha, se observa en un corte coronal, las extremidades inferiores con compromiso femoral y tibial. En control posterior a quimioterapia, a los 6 meses, hubo importante y significativa respuesta con sólo mínima captación abdominal probablemente residual (no mostrado).

Concluyendo, las utilidades del PET FDG que han sido reconocidas en el diagnóstico y manejo de los linfomas, han desplazado al ${ }^{67} \mathrm{Ga}$ y son un valioso apoyo complementario a los métodos

\section{REFERENCIAS}

1. Ng AK, Bernardo MV, Weluer E, Backstrand K, Silver B, Marcus KC et al. Second malignancy after Hodgkin disease treated with radiation therapy with or without chemotherapy: long-term risks and risk factors. Blood 2002; 100: 1989-96.

2. Israel O, Keidar Z, Bar-Shalom R. Positron emission tomography in the evaluation of lymphoma. Semin Nucl Med 2004; 34: 166-79.

3. Jerusalem G, Rigo P. PeT imaging in lymphoma. En: Positron emission tomography. Basic Science and clinical practice, Eds: Valk P, Bailey D, Townsend D, Maisey M. London: Editorial Springer, 2003: 547-58.

4. HICKS RJ. PET in lymphoma and malignant melanoma. En: Nuclear Medicine in clinical diagnosis and treatment. Eds.: Ell PJ, Gambhir SS. Editorial Churchill Livingstone, Edinburgh, 2004; 23-34.

5. Kumar R, Mailard I, Schuster S, Alavi A. Utility of fluorodeoxyglucose-PET imaging in the management of patients with Hodgkin's and nonHodgkin's lymphomas. Radiol Clin North Am 2004; 42: 1083-100. convencionales (clínicos, anatómicos e histológicos), con mayor utilidad para etapificación y reetapificación, evaluación de viabilidad tumoral en masas residuales y control terapéutico.

6. Jofré MJ, Massardo T, González P, CAnessa J, Sierralta P, Humeres P et al. Uso de la tomografía de emisión de positrones PET con $\mathrm{F}^{18}$-FDG en la evaluación de lesiones pulmonares. Rev Méd Chile 2005; 133: 583-92.

7. Jerusalem G, Beguin $Y$, Najjar F, Hustinx R, Fassott MF, Rigo P ET AL. Positron emission tomography (PET) with 18F-fluorodeoxyglucose (18F-FDG) for the staging of low-grade non-Hodgkin's lymphoma (NHL). Ann Oncol 2001; 12: 825-30.

8. Elstrom R, Guan L, Baker G, Nakhoda K, Vergilo J, ZhUANG $\mathrm{H}$ ET AL. Utility of FDG-PET scanning in lymphoma by WHO classification. Blood 2003; 101: 3875-6.

9. Najjar F, Hustinx R, Jerusalem G, Filuet G, Rigo P. Positron emission tomography (PET) for staging low-grade non-Hodgkin's lymphomas (NHL). Cancer Biother Radiopharm 2001; 16: 297-304.

10. Friedberg JW, Chengazi V. PET scans in the staging of lymphoma: current status. Oncologist 2003; 8: 438-47.

11. Hownger EF, Alibazoglu H, Au A, Green A, LAMONICA G. Hematopoietic cytokine-mediated FDG uptake simulates the appearance of diffuse 
metastatic disease on whole-body PET imaging. Clin Nucl Med 1998; 23: 93-8.

12. Sugawara Y, Zasadny KR, Kison PV, Baker LH, Wahl RL Splenic fluorodeoxyglucose uptake increased by granulocyte colony-stimulating factor therapy: PET imaging results. J Nucl Med 1999; 40: 1456-62.

13. Kazama T, Faria S, Varavithya V, Phongkitkarun $S$, Ito $\mathrm{H}$, MacAPINLAC H. FDG PET in the Evaluation of Treatment for Lymphoma: Clinical Usefulness and Pitfalls. RadioGraphics 2005; 25: 191-207.

14. BARRINGTON SF, O’DoherTy MJ. Limitations of PET for imaging lymphoma. Eur J Nucl Med Mol Imaging 2003; 30: S117-27.

15. SChÖder H, Larson S, Yeung H. PET/CT in Oncology: Integration into Clinical Management of Lymphoma, Melanoma, and Gastrointestinal Malignancies. J Nucl Med 2004; 45: 72S-81S.

16. Freudenderg LS, Antoch G, Schutt P, Beyer T, Jentzen W, Muler SP et al. FDG-PET/CT in restaging of patients with lymphoma. Eur J Nucl Med Mol Imaging 2004; 31: 325-9.

17. Moog F, Bangerter M, Diederichs CG, GuHLMann A, KOTZERKE J, MERKIE E ET AL. Lymphoma: role of wholebody 2-deoxy-2-[F-18] fluoro-D-glucose (FDG) PET in nodal staging. Radiology 1997; 203: 795-800.

18. Hoh CK, Glaspy J, Rosen P, Dahlbom M, Lee SJ, KuNKEL L ET AL. Whole-body FDG-PET imaging for staging of Hodgkin's disease and lymphoma. J Nucl Med 1997; 38: 343-8.

19. Moog F, Bangerter M, Kotzerke J, Guhlmann A, FRICKHOFEN N, RESKE SN. 18-F-fluorodeoxyglucosepositron emission tomography as a new approach to detect lymphomatous bone marrow. J Clin Oncol 1998; 16: 603-9.

20. Carr R, Barrington SF, Madan B, O’Doherty MJ, Saunders CA, Van Der Walt J et al. Detection of lymphoma in bone marrow by whole-body positron emission tomography. Blood 1998; 91: 3340-6.

21. Moog F, Bangerter M, Diederichs CG, Guhlmann A, Merkie E, FrickHofen N et al. Extranodal malignant lymphoma: detection with FDG PET versus CT. Radiology 1998; 206: 475-81.

22. Gambir SS, Czernin J, Schwimmer J, Silverman DH, Coleman RE, Phelps ME. A tabulated summary of the FDG PET literature. J Nucl Med 2001; 42: 1S-93S.

23. Rini JN, Leonidas JC, Tomas MB, Paiestro CJ. 18FFDG PET versus CT for Evaluating the Spleen During Initial Staging of Lymphoma. J Nucl Med 2003; 44: 1072-4.
24. Schiepers C, Filmont JE, CZernin J. PET for staging of Hodgkin's disease and non-Hodgkin's lymphoma. Eur J Nucl Med Mol Imaging 2003; 30: S82-8.

25. Hueltenschmidt B, Sautter-Bihl ML, Lang O, Maul FD, Fischer J, Mergenthaler HG et al. Whole body positron emission tomography in the treatment of Hodgkin disease. Cancer 2001; 91: 302-10.

26. IsASI CR, Lu P, Biaufox MD. A metaanalysis of (18)F2-deoxy-2-fluoro-D-glucose positron emission tomography in the staging and restaging of patients with lymphoma. Cancer 2005; 104: 1066-74.

27. Stewart LA, Parmar MK. Meta-analysis of the literature or of individual patient data: is there a difference? Lancet 1993; 341: 418-22.

28. SРECHT E. Staging systems and staging investigations, En: Magrath I: The non Hodgkin lymphomas. $2^{\text {nd }}$ Ed. Arnold, Great Britain, 1997; pp: 533-53.

29. Pakos EE, Fotopoulos AD, Ioannidis JP. 18F-FDG PET for evaluation of bone marrow infiltration in staging of lymphoma: a meta-analysis J Nucl Med 2005; 46: 958-63.

30. Hicks RJ, Mac Manus MP, Seymour JF. Initial staging of lymphoma with positron emission tomography and computed tomography. Semin Nucl Med 2005; 35: 165-75.

31. RESKE SN. PET and restaging of malignant lymphoma including residual masses and relapse. Eur J Nucl Med Mol Imaging 2003; 30: S89-S96.

32. Srinivasan R, Fille A, Reynolds J, Chang R, Chow C, Schrump DS ET AL. Positron emission tomography for lymphoma staging: tissue remains the issue. J Natl Cancer Inst 2005; 97: 611-3.

33. Jerusalem G, Hustinx R, Beguin Y, Filet G et al. Evaluation of therapy for lymphoma. Semin Nucl Med 2005; 35: 186-96.

34. Romer W, Hanauske AR, Ziegler S, Thodtmann R, WeBer W, Fuchs C ET al. Positron emission tomography in non-Hodgkin's lymphoma: assessment of chemotherapy with fluorodeoxyglucose. Blood 1998; 91: 4464-71.

35. Jerusalem G, Beguin Y, Fassotte MF, Najjar F, Paulus P, Rigo P ET AL. Persistent tumor 18F-FDG uptake after a few cycles of polychemotherapy is predictive of treatment failure in non-Hodgkin's lymphoma. Haematologica 2000; 85: 613-8.

36. Torizuka T, Nakamura $F$, Kanno T, Futatsubashi $M$, YoshiKaWA E, OKadA H ET AL. Early therapy monitoring with FDG-PET in aggressive non-Hodgkin's lymphoma and Hodgkin's lymphoma. Eur J Nucl Med Mol Imaging 2004; 31: 22-8. 
37. Spaepen K, Stroobants S, Dupont P, Vandenberghe $\mathrm{P}$, ThOMAS J, De Groot T Eт AL. Early restaging positron emission tomography with (18)F-fluorodeoxyglucose predicts outcome in patients with aggressive nonHodgkin's lymphoma. Ann Oncol 2002; 13: 1356-63.

38. Spaepen K, Stroobants S, Verhoef G, Mortelmans L Positron emission tomography with [(18)F]FDG for therapy response monitoring in lymphoma patients. Eur J Nucl Med Mol Imaging 2003; 30: S97-105.

39. SchöDer H, Noy A, Gonen M, Weng L, Green D, ERDI YE ET AL: Intensity of ${ }^{18}$ Flurorodeoxyglucose uptake in PET distinguishes between indolent and aggressive non-Hodgkin's lymphomas. J Clin Oncol 2005; 23: 4643-51.

40. Juweid ME, Cheson BD. Role of Positron Emission Tomography in Lymphoma. J Clin Oncol 2005; 23: 4577-80.

41. Juweid ME, Wiseman GA, Vose JM, Rtchie JM, Menda Y, Wooldridge JE et al. Response assessment of aggressive non-Hodgkin's lymphoma by integrated International Workshop Criteria and fluorine-18-fluorodeoxyglucose positron emission tomography. J Clin Oncol 2005; 23: 4652-61.

42. Taibot JN, Haioun C, Rain JD, Meignan M, Wioland M, MisSET JL ET aL. [18F-FDG positron emission tomography in clinical management of lymphoma patients. Crit Rev Oncol Hematol 2001; 38: 193-221.

43. Hutchings M, Loft A, Hansen M, Møuer Pedersen L, BuHL T, JURLANDER J ET AL. FDG-PET after two cycles of chemotherapy predicts treatment failure and progression-free survival in Hodgkin lymphoma. Blood 2006; 107: 52-9.

44. Spaepen K, Stroobants S, Dupont P, Vandengerghe P, Maertens J, Bormans J et al. Prognostic value of pretransplantation positron emission tomography using fluorine 18-fluorodeoxyglucose in patients with aggressive lymphoma treated with highdose chemotherapy and stem cell transplantation. Blood 2003; 102: 53-9.

45. Hart DP, Avivi I, Thomson KJ, Peggs KS, Morris EC, GOLDSTONE AH ET AL. Use of F-FDG positron emission tomography following allogeneic transplantation to guide adoptive immunotherapy with donor lymphocyte infusions. Br J Haematol 2005; 128: 824-9.

46. Depas G, De Barsy C, Jerusalem G, Hoyoux C, DRESSE MF, FASSOTtE MF ET AL. F-FDG PET in children with lymphomas. Eur J Nucl Med Mol Imaging 2005; 32: 31-8.

47. Schöder H, Meta J, Yap C, Artannejad M, Rao J, Phelps ME ET AL. Effect of whole-body (18)F-FDG PET imaging on clinical staging and management of patients with malignant lymphoma. J Nucl Med 2001; 42: 1139-43.

48. Wegner EA, Barrington SF, Kingston JE, Robinson RO, FERNER RE, TAJ M ET AL. The impact of PET scanning on management of paediatric oncology patients. Eur J Nucl Med Mol Imaging 2005; 32: 23-30.

49. Gallamini A, Biggi A, Fruttero A, Pugno F, CavaleRo G, PRegno P et al. Revisiting the prognostic role of gallium scintigraphy in low-grade nonHodgkin's lymphoma. Eur J Nucl Med 1997; 24: 1499-506.

50. Bar-Shalom R, Yefremov N, Haim N, Dann EJ, Epelbaum R, Keidar Z et al. Camera-based FDG PET and 67Ga SPECT in evaluation of lymphoma: comparative study. Radiology 2003; 227: 353-60.

51. Kostakoglu L, Leonard JP, Kuji I, Coleman M, Valabhajosula S, Goldsmith SJ. Comparison of fluorine-18 fluorodeoxyglucose positron emission tomography and Ga-67 scintigraphy in evaluation of lymphoma. Cancer 2002; 94: 879-88.

52. Castellucci P, Zinzani P, Pourdehnad M, Aunari L, NANN C, Farsad M et al. (18)F-FDG PET in malignant lymphoma: significance of positive findings. Eur J Nucl Med Mol Imaging 2005; 32: 749-56.

53. Klose T, Leidl R, Buchmann I, Brambs HJ, Reske SN. Primary staging of lymphomas: cost-effectiveness of FDG-PET versus computed tomography. Eur J Nucl Med 2000; 27: 1457-64.

54. MAISEY MN. Cost-effectiveness of PET in patient management. En: Positron emission tomography. Basic science and clinical practice. Eds: Valk P, Bailey D, Townsend D, Maisey M. Editorial: Springer, London, 2003; 795-804.

Agradecimientos

Al Dr. Guillermo Conte L de la Sección de Hematología, Departamento de Medicina del Hospital Clínico de la Universidad de Chile y al Dr. Carlos Regonesi M. del Departamento de Oncología de Clínica Las Condes, por su colaboración y revisión del manuscrito. 


\title{
Calidad metodológica de un artículo de tratamiento de cáncer gástrico adoptado como protocolo por algunos hospitales chilenos
}

\author{
Carlos Manterola ${ }^{1,2}$, Rodrigo Torres ${ }^{1}$, Luis Burgos ${ }^{1}$, \\ Manuel Vial ${ }^{1,2}$, Viviana Pineda ${ }^{1}$. G rupo MIN CIR. \\ Methodological quality of an article \\ on the treatment of gastric cancer \\ adopted as protocol \\ by some Chilean hospitals
}

\begin{abstract}
Background: Surgery is a curative treatment for gastric cancer (GC). As relapse is frequent, adjuvant therapies such as postoperative chemo radiotherapy have been tried. In Chile, some hospitals adopted Macdonald's study as a protocol for the treatment of GC. Aim: To determine methodological quality and internal and external validity of the Macdonald study. Material and method: Three instruments were applied that assess methodological quality. A critical appraisal was done and the internal and external validity of the methodological quality was analyzed with two scales: MINCIR (Methodology and Research in Surgery), valid for therapy studies and CONSORT (Consolidated Standards of Reporting Trials), valid for randomized controlled trials (RCT). Guides and scales were applied by 5 researchers with training in clinical epidemiology. Results: The reader's guide verified that the Macdonald study was not directed to answer a clearly defined question. There was random assignment, but the method used is not described and the patients were not considered until the end of the study (36\% of the group with surgery plus chemo radiotherapy did not complete treatment). MINCIR scale confirmed a multicentric RCT, not blinded, with an unclear randomized sequence, erroneous sample size estimation, vague objectives and no exclusion criteria. CONSORT system proved the lack of working hypothesis and specific objectives as well as an absence of exclusion criteria and identification of the primary variable, an imprecise estimation of sample size, ambiguities in the randomization process, no blinding, an absence of statistical adjustment and the omission of a subgroup analysis. Conclusion: The instruments applied demonstrated methodological shortcomings that compromise the internal and external validity of the study (Rev Méd Chile 2006, 134; 920-6).
\end{abstract}

(Key words: Controlled clinical trial; Methods; Stomach neoplasms, Antineoplastic Agents, Combined, Evidence-Based Medicine)

Recibido el 4 de noviembre, 2005. Aceptado el 10 de mayo, 2006.

${ }^{1}$ Departamento de Cirugía. ${ }^{2}$ CIGES. Capacitación, Investigación y Gestión para la Salud Basada en Evidencia. Universidad de La Frontera, Temuco, Chile.

Correspondencia a: Dr. Carlos Manterola. Departamento de Cinugía, Universidad de La Frontera. Casilla 54-D, Temuco, Chile. Teléfono: 45-325760. Fax: 45-325761. E mail: cmantero@ufro.cl 
L a cirugía continúa siendo el único tratamiento con pretensión curativa para pacientes con cáncer gástrico avanzado. Sin embargo, la recidiva tras la cirugía es frecuente, razón por la que en los últimos años se ha puesto énfasis, por una parte, en la identificación de factores pronósticos y, por otra, en la implementación de tratamientos adicionales tendientes a incrementar la supervivencia.

Los tratamientos adyuvantes farmacológicos utilizados en la última década, han mostrado escasa efectividad, lo que ha sido objetivado en metaanálisis, en los que se concluyó que éstos no incrementan significativamente la supervivencia $^{1,2}$. Por otra parte, existen algunos reportes con la incorporación de quimiorradioterapia adyuvante $^{3-6}$. Sin embargo, se trata de series retrospectivas de reducido número de pacientes.

No obstante ello, la propuesta de administrar quimiorradioterapia tras la resección quirúrgica, publicada por MacDonald y cols ${ }^{7}$, ha sido incorporado en algunos hospitales chilenos como protocolo de tratamiento del cáncer gástrico.

El objetivo de este estudio es determinar calidad metodológica, validez interna y externa del estudio MacDonald, mediante la aplicación de una guía de lectura crítica y dos escores de calidad metodológica.

\section{MATERIAL Y MÉTODO}

Se realizó lectura crítica del artículo de MacDonald $^{7}$, aplicando una guía para artículos de terapia $^{8}$. Posteriormente, se analizó la calidad metodológica con 2 escalas; una validada para artículos referentes a tratamiento ${ }^{9-11}$ y otra utilizada para el análisis de ensayos clínicos (EC) ${ }^{12}$.

La guía de lectura crítica es una forma rápida y concreta de conocer la validez interna y externa de un estudio. Consta de 3 ítems: el primero contiene preguntas de seliminación»y preguntas de detalle»que permiten valorar la validez interna; de tal forma que si el artículo no permite dar respuestas adecuadas a las preguntas de seliminación», no se aconseja continuar la lectura del mismo. El segundo ítem se relaciona con la calidad y cuantificación de los resultados; y el tercero, con la reproducibilidad de los mismos ${ }^{8}$.

El sistema de puntuación MINCIR (Metodología e Investigación en Cirugía), es una escala diseñada y validada para determinar calidad metodológica de estudios de terapia ${ }^{10,11}$. Está compuesta por 3 ítems: el primero, relacionado con el diseño del estudio; el segundo, con el tamaño de la población estudiada; y el tercero, con la descripción de la metodología empleada. De esta forma, se genera una puntuación que puede fluctuar entre 6 y 36 puntos, asignando 6 puntos al estudio de menor calidad metodológica y 36 puntos al de mejor calidad metodológica, con un punto de corte de 18 puntos para dicotomizar el constructo «calidad metodológica».

El sistema CONSORT, es una propuesta acerca de cómo se debe comunicar un EC. Consta de 5 dominios (título y resumen, introducción, métodos, resultados y discusión) que incluyen 22 ítems, en los que se evalúa la descripción de una serie de variables relevantes que son inherentes a un $\mathrm{EC}^{12}$.

La aplicación de guía y escala de calidad metodológica fue realizada de forma independiente por tres investigadores (RT, CM, LB), con formación en análisis crítico de la literatura biomédica (ACLB) y epidemiología clínica (EC). Con posterioridad, fueron discutidos en sesiones de trabajo, oportunidades en que las que se resolvieron, por consenso, situaciones en las que se generaron diferencias. Una vez obtenidos los documentos definitivos por parte del grupo de trabajo, y con el objeto de validar los resultados obtenidos, se solicitó evaluación externa a dos investigadores independientes (VP, MV), con formación en ACLB y EC. Los resultados de estas evaluaciones fueron contrastadas con los documentos previamente generados y las diferencias consensuadas en reuniones de trabajo.

\section{RESULTADOS}

I. Aplicación de la guía de lectura crítica. Preguntas de eliminación.

1. ¿Se orienta el artículo a una pregunta claramente definida?

No. Esta sólo se puede suponer. La población blanco es heterogénea, pues incluye cánceres gástrico y gastroesofágico. La intervención está claramente descrita como quimiorradioterapia postoperatoria (CQR), no así la variable de interés (no se explicita si es morbilidad, morta- 
lidad, supervivencia global, supervivencia libre de enfermedad o efectos tóxicos).

2. ¿Fue aleatoria la asignación de los pacientes al tratamiento?

No se puede decir. En el texto no se describe qué método de asignación fue utilizado, sólo se especifica que 281 pacientes fueron asignados a CQR y 275 pacientes a cirugía exclusiva (CE) en el postoperatorio. No se mantuvo oculta la secuencia de asignación.

3. ¿Fueron adecuadamente considerados hasta el final del estudio todos los pacientes?

No. Los pacientes fueron analizados en los grupos a los que fueron asignados, pero el seguimiento sólo se completó en el grupo de CE (35,6\% de los pacientes del grupo de CQR no completó tratamiento).

Hasta esta etapa de la lectura, se considera que el artículo no supera las preguntas de eliminación, por ende, desde el punto de vista ACLB no valdría la pena seguir adelante.

II. Aplicación del puntaje MINCIR

- Diseño. Se trata de un EC multicéntrico sin enmascaramiento (pacientes, personal que aplicó las terapias, ni observadores se encontraban enmascarados). Este hecho determina que, de una asignación inicial de 12 puntos, ésta descienda a 6 puntos.

- Población. El estudio fue conducido con una población de 556 sujetos. Se justifica la muestra utilizada, aun cuando las variables utilizadas para ello no son muy claras. Al calcular la muestra necesaria con una supervivencia de $50 \%$ para el grupo de CQR y $41 \%$ para el grupo con CE (resultados reportados en el artículo $^{7}$ ), un alfa de 0,05 y una potencia de $80 \%$, la muestra necesaria para la conducción del estudio sería de 960 sujetos (480 por grupo); por ende, por existir un error en la estimación de la muestra, en este ítem se asignan sólo 6 puntos.

- Metodología. Se plantean objetivos vagos: nosotros desarrollamos un estudio para determinar la eficacia de quimiorradioterapia en pacientes con cáncer gástrico resecado» (2 puntos); se menciona, pero no se justifica, el diseño empleado un total de 556 pacientes con adenocarcinoma del estómago o de la unión gastroesofágica resecada fueron asigna- dos en forma aleatoria a CQR o CE»(2 puntos). Sólo se describen criterios de inclusión: «se incluyeron pacientes con adenocarcinoma gástrico o de la unión esofagogástrica, en los que se hubiera practicado una resección completa de la neoplasia, con intento curativo» (2 puntos). No se justifica apropiadamente la muestra: enuestro estudio fue originalmente diseñado para incluir 350 pacientes, con un alfa de 0,05 , un poder de $80 \%$ para detectar $50 \%$ de diferencia relativa en supervivencia y $95 \%$ de poder para detectar $60 \%$ de diferencia relativa en supervivencia libre de enfermedad; sin embargo, dado que el reclutamiento fue mayor de lo esperado, el comité de datos y monitoreo aprobó la expansión de reclutamiento a 550 pacientes, lo que aseguró $90 \%$ de poder para detectar $40 \%$ de diferencia en supervivencia y $40 \%$ de diferencia en supervivencia libre de enfermedad», no obstante ello, no se especificó cuál es el valor a partir del cual se calculó la diferencia que se pretendía reducir (1 punto). Se asignaron 7 puntos.

La suma de los ítems 1, 2 y 3 totaliza 19 puntos (un punto sobre el punto de corte del constructo «calidad metodológica»definido por esta escala).

III. Aplicación de pauta de evaluación CONSORT Título y Resumen

1. ¿Se describe si los participantes fueron asignados a intervenciones?, o cpermite el título del artículo identificar al estudio como un EC?

No. Sólo en el resumen se menciona que se trata de un estudio de tipo aleatorio.

Introducción y Antecedentes

2. ¿Se describen los antecedentes científicos y el motivo principal de la investigación?

Sí. Se hace mención a aspectos relacionados con el tratamiento curativo del cáncer gástrico y el potencial impacto de aplicar terapias adyuvantes; mencionándose estudios fase 3 con quimiorradioterapia ${ }^{13,14}$ que justificarían el empleo del esquema propuesto.

Métodos

3. De los participantes. ¿Se describen criterios de elegibilidad y escenarios donde se realizó el estudio?

No. Sólo se mencionan criterios de inclusión. Respecto de los escenarios, sólo se indica que 
es un estudio multicéntrico, sin que se precise en qué escenarios se realizó y de qué forma los centros involucrados, participaron en el estudio.

4. Intervenciones. ¿Se describen las intervenciones aplicadas a cada grupo y cómo y cuándo fueron éstas empleadas?

Sí. Se precisa que es CE o CQR (combinación de fluoruracilo, leucovorin y radiación localregional).

5. Objetivos e hipótesis. ¿Se describen objetivos específicos e hipótesis?

No. No es posible establecer objetivos específicos, pregunta de investigación ni hipótesis.

6. Variable resultado. ¿Se describen variables de resultado primaria y secundaria; y si aplica, se menciona cómo se pretende realizar las mediciones correspondientes?

No. No se identifica una variable primaria (fundamental para el cálculo del tamaño de la muestra). Sólo se mencionan como variables resultado mortalidad y recurrencia.

7. Tamaño de la muestra. ¿Se describe cómo fue calculado el tamaño de la muestra empleado; y si aplica, se menciona si se realizó algún análisis interino?

Sí. Describen el cálculo de la muestra, no obstante la variable de la que depende la estimación no está claramente definida. Se realizaron 2 análisis interinos; sin embargo, no se justifica por qué fue necesario practicar dos, en qué fase del estudio se realizaron, con qué tamaño de la muestra se ejecutaron, ni la conclusión a la que éstos llegaron.

8. Aleatorización. Secuencia de generación. ¿Se describe el método utilizado para determinar la secuencia, incluyendo la aplicación de restricciones?

No. No se esclarece la secuencia de generación utilizada. Aplicaron estratificación en base a las variables $\mathrm{T}$ y N, y no al TNM.

9. Aleatorización. Asignación de ocultamiento. ¿Se describe el método utilizado para determinar la secuencia de ocultamiento, clarificando cómo se ocultó la secuencia mientras la intervención era asignada?

No. No se menciona cómo se realizó la asignación de ocultamiento ni cómo se implementó el proceso.

10. Aleatorización. Implementación. ¿Se describe quién generó la secuencia de asignación, quién enroló a los participantes, y quién asignó los participantes a cada grupo?

No. No se menciona quién generó la secuencia, quién enroló ni quién asignó.

11. Enmascaramiento. ¿Se describen el mecanismo de enmascaramiento y cómo fue evaluado? No. No hubo enmascaramiento.

12. Métodos estadísticos. ¿Se describen métodos estadísticos utilizados para la comparación de grupos en relación a la variable resultado primaria, métodos para análisis adicionales como análisis de subgrupos y ajustes?

Sí. Se utilizan curvas de supervivencia de KaplanMeier y regresión de Cox. En el modelo utilizado sólo se consignaron las variables $\mathrm{T}$ y N; pero, no se realizó ajuste por otras variables de interés como localización del tumor, invasión parietal, tipo de resección y linfadenectomía, etc.

Resultados

13. Flujo de participantes. ¿Se describe el flujo de participantes según su estado (se recomienda un diagrama)?

No. El artículo no aporta diagrama de flujos; sin embargo, se elaboró uno con los datos aportados por el estudio (Figura 1).

14. Reclutamiento ¿Se describen datos definiendo los períodos de reclutamiento y seguimiento?

Sí. El reclutamiento se realizó entre 1991 y 1998. Se deduce que el promedio de seguimiento es de 5 años, con un mínimo de 3 años.

15. Datos básicos. ¿Se describen las características demográficas y clínicas de los sujetos de cada grupo?

Sí. Estos se describen en la Tabla 17; sin embargo, no se precisan eventuales diferencias en variables de interés como la proporción de D0, D1 y D2 en los grupos en comparación.

16. Números analizados. ¿Se describe el número de participantes analizados en cada grupo, incluyendo análisis con «ntención de tratarı?

Sí. Se aplicó análisis con intención de tratar (incluyendo los pacientes en los que se constataron efectos tóxicos, en los que no queda claro qué tratamiento posterior se aplicó).

17. Resultados y estimación. ¿Se resumen los resultados obtenidos para las variables resultado, su efecto en el tamaño de la muestra y su precisión? Sí. Se estimaron hazard ratios a 36 meses con intervalos de confianza y valor de $\mathrm{p}$. No se 


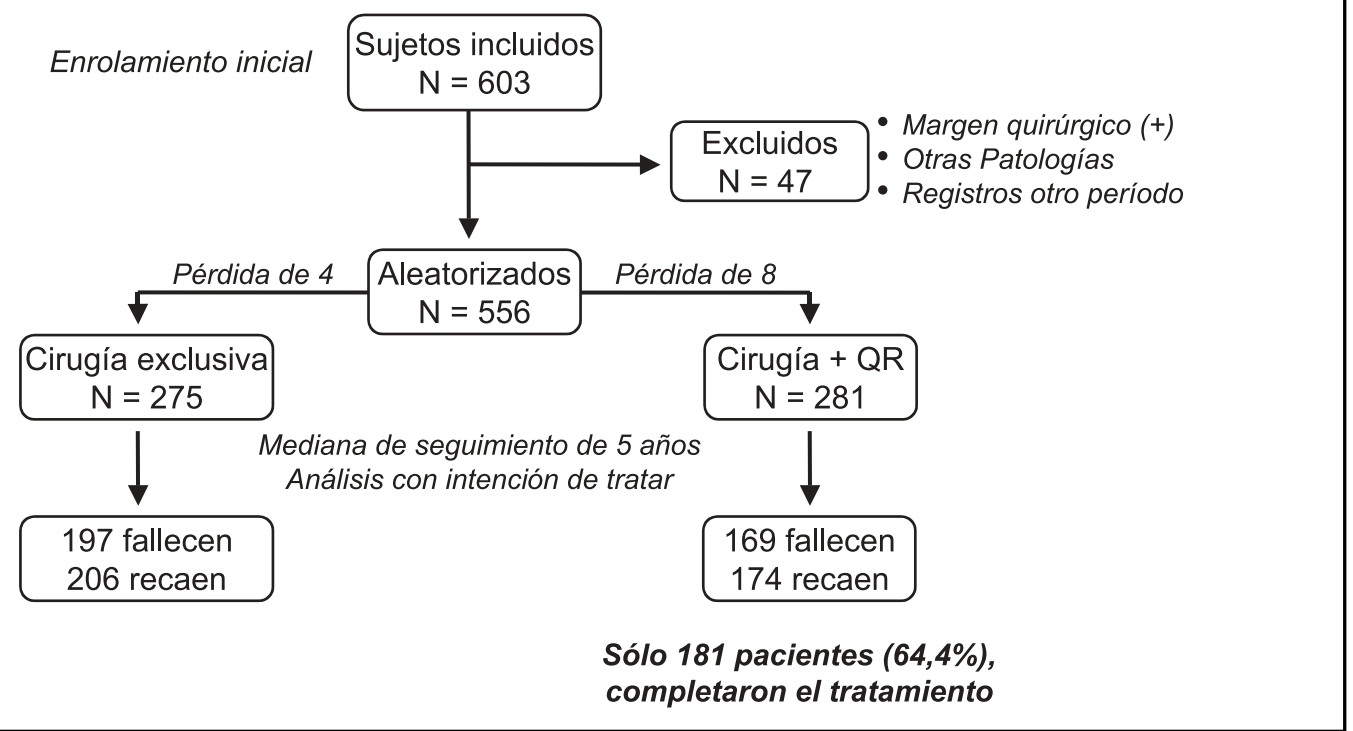

Figura 1. Diagrama de flujo de los participantes del estudio. Las razones por las que 35,6\% de los sujetos del grupo de quimiorradioterapia postoperatoria (100 pacientes), no continuaron el protocolo preestablecido fueron: 49 pacientes presentaron con efectos tóxicos, 23 pacientes abandonaron el tratamiento, 13 pacientes presentaron progresión de la enfermedad, 3 pacientes fallecieron y 12 pacientes fueron catalogados como «tros», sin otra explicación.

calcularon riesgos relativos, reducción absoluta de riesgos, número necesario a tratar ni número necesario a dañar. Tampoco hay resumen de los resultados principales.

18. Análisis adicionales. ¿Se describe otro tipo de análisis realizado?

No. No hay análisis de subgrupos ni ajuste por variables clínicas ni demográficas.

19. Eventos adversos. ¿Se describen todos los efectos adversos ocurridos en ambos grupos?

No. Sólo se mencionan los efectos adversos del grupo sometido a CQR, no así los del grupo de CE.

\section{Discusión}

20. Interpretación. ¿Se realiza una interpretación de los resultados tomando en cuenta la hipótesis, fuentes de potenciales sesgos o imprecisiones y de los riesgos asociados a la multiplicidad de análisis y resultados?

No. No se considera la interpretación de una hipótesis ni fuentes de potenciales sesgos 0 imprecisiones.
21. Generalización. ¿Se considera la validez externa de los resultados obtenidos en el estudio?

No. Las variables raza (el calificativo «others», que representa al colectivo latino, constituye el $4 \%$ de la población estudiada, siendo el resto blancos, negros y asiáticos), localización del tumor (más de $50 \%$ de los tumores son antrales) y el estadio de la enfermedad (más de $30 \%$ corresponden a T1 y T2, sin quedar claro la proporción entre ellos) no son comparables a nuestra realidad nacional.

22. Evidencia global. ¿Se realiza una interpretación de los resultados obtenidos en el contexto de la evidencia disponible?

No. Sólo se realiza una escueta discusión de los resultados obtenidos y una comparación con otros estudios similares, sin una interpretación de éstos a la luz de la evidencia disponible. No se hace mención a la evidencia relacionada con las diferencias existentes desde un punto de vista pronóstico en los pacientes con cáncer gástrico según histología, localización, estadio, etc. Por otra parte, sola- 
mente a $10 \%$ de los pacientes se les practicó disección D2; sin embargo, los autores argumentan a su favor que en otros estudios se ha manifestado que este hecho no sería relevante. Por otra parte, si los autores decidieron estratificar por la variable «N $»$, entonces, parece relevante el tipo de disección que se le realice a los pacientes.

\section{DisCUSIÓN}

¿Se puede evaluar la calidad metodológica de un estudio? Desde 1970, se han utilizado varios sistemas para calificar la calidad de las publicaciones científicas. Uno de los primeros fue el propuesto por Sackett, cuyo resultado son los miveles de evidencia», herramienta útil hasta hoy para establecer la evidencia que apoya nuestra forma de actuar ${ }^{15,16}$. Sin embargo, la «calidad metodológica» se ha de entender como un concepto multidimensional, en el que es posible evaluar múltiples facetas, de las que por el momento no existe un consenso. Por esta razón, parece relevante que al evaluar metodológicamente un artículo, se apliquen diferentes herramientas que permitan valorar de una forma global su validez interna y externa.

Al continuar aplicando la guía de lectura, verificamos la siguiente información: al desarrollar las preguntas de detalle referentes a la validez de los resultados, comprobamos que no hubo enmascaramiento; que no se puede decir si fue aleatoria la asignación de los pacientes; $\mathrm{y}$, que los grupos no fueron tratados en forma similar $(10 \%$ de los pacientes fueron resecados con D2 y $36 \%$ con D1; $35 \%$ de los pacientes sufrió alguna modificación de su esquema terapéutico original y $6,5 \%$ fue desviado a otro protocolo). Al evaluar la cuantificación de resultados, verificamos que se realizó una evaluación de las variables mediana de supervivencia global, supervivencia real a 36 meses, supervivencia global libre de enfermedad, supervivencia real libre de enfermedad a 36 meses y recurrencia; que la precisión de la estimación del efecto fue realizada mediante cálculo de hazard ratios, intervalos de confianza y valor de p. Al analizar las preguntas relativas a si me ayudarán estos resultados en el cuidado de mis pacientes, comprobamos que existen diferencias biodemográficas, de localización y tamaño de las lesiones respecto de nuestra realidad. No fueron considerados todos los resultados de importancia clínica (se omitieron variables como calidad de vida, morbilidad y mortalidad quirúrgica, y costos involucrados). No creemos que los beneficios a obtener justifiquen los riesgos y costos del tratamiento.

Desde la perspectiva «calidad metodológica» aplicando el puntaje MINCIR, si bien es cierto que la sumatoria de los ítems valorados totaliza 19 puntos, hay que recordar que apenas supera el punto de corte, tiene objetivos vagos, no hay enmascaramiento, la secuencia de asignación aleatoria no es clara y la estimación de tamaño de muestra es errónea ${ }^{17}$, situación que podría estar generando un error tipo $\alpha$ o tipo 1 .

Desde el punto de vista «calidad metodológica» aplicando la propuesta CONSORT, se ponen en evidencia problemas de forma y de fondo. Los primeros tienen relación con el inapropiado reporte de una serie de hechos inherentes a un EC (título ambiguo, ausencia de diagrama de flujo de participantes, ausencia de resumen de los resultados principales). Los segundos, con la carencia de pregunta de investigación e hipótesis de trabajo, carencia de objetivos específicos, de criterios de exclusión y de descripción de la variable primaria; $\mathrm{y}$, el desconocimiento de las conclusiones de los 2 análisis interinos practicados. Tampoco, se estipulan aspectos relacionados con el proceso de asignación aleatoria; no hay enmascaramiento; no se realizó ajuste estadístico por variables de impacto pronóstico; no se precisaron eventuales diferencias de proporción de D0, D1 y D2 en los grupos; $\mathrm{y}$, no se practicaron análisis de subgrupos.

A modo de conclusión, se puede plantear que se aplicaron 3 instrumentos de evaluación de un artículo, todos ellos de diferente concepción y que valoran distintos ámbitos de la metodología de un artículo. Todos, pusieron en evidencia falencias metodológicas similares que llevan al cuestionamiento de la validez interna y externa del estudio, hecho que a su vez hace poner en duda la lógica de la aplicabilidad de este protocolo en cualquier población, pues tiene particularidades relacionadas con la generalización de los resultados que no fueron salvaguardadas por el equipo de investigación. Mirado desde la perspectiva de Sackett ${ }^{18}$, su nivel de evidencia es $2 b$. No 
obstante ello, el protocolo es factible de realizar en nuestro medio, previa aplicación de un riguroso documento de consentimiento informado a los participantes (a quienes se debe explicar no sólo los potenciales beneficios de esta alternativa terapéutica, sino también los riesgos implícitos que han sido reportados); y, una valoración de la reproducibilidad de los resultados en forma de un estudio de fase 1 ó 2, antes de tomar la decisión de aplicarlo como protocolo a nuestros pacientes con cáncer gástrico. Otra alternativa que podría considerarse es el desarrollo de guías de práctica clínica o de protocolos basados en la mejor evidencia clínica disponible, situación que se basa, entre otras, en el análisis riguroso de la calidad metodológica y técnica de cada propuesta terapéutica, antes de su implementación clínica.

\section{REFERENCIAS}

1. Hermans J, Bonenkamp JJ, Boon MC, Bunt AMC, Ohyama S, Sasko M et al. Adjuvant therapy after curative resection for gastric cancer: meta-analysis of randomized trials. J Clin Oncol 1993; 11: 1441-7.

2. Shimada K, Ajani JA. Adjuvant therapy for gastric carcinoma patients in the past 15 years. A review of Western and Oriental trials. Cancer 1999; 86: 1657-68.

3. Ventureli A, Cardemil B, díaz J, Avendaño R, Murúa A, Kuschel $C$ et al. Cirugía más quimioterapia en cáncer gástrico. Sobrevida a 5 años. Rev Chil Cir 1999; 51: 170-5.

4. Flores P, Yáñez E, Cartes R, Grájeda J, Viluaseca M, FERNÁNDEZ E ET AL. Quimiorradioterapia postoperatoria en el tratamiento del cáncer gástrico. Rev Chil Cir 2000; 52: 621-8.

5. Hundahl SA, MacDonald JS, Benedetti J, FitzsimMONS T. Surgical treatment variation in a prospective, randomized trial of chemoradiotherapy in gastric cancer: the effect of undertreatment. Ann Surg Oncol 2002; 9: 278-86.

6. Park SH, Kim DY, Heo JS, Lim DH, Park CK, Lee KW ET AL. Postoperative chemoradiotherapy for gastric cancer. Ann Oncol 2003; 14: 1373-7.

7. MacDonald JS, Smaley SR, Benedetti J, Hundahl SA, Estes NC, Stemmermann GN et al. Chemoradiotherapy after surgery compared with surgery alone for adenocarcinoma of the stomach or the gastroesophageal junction. N Engl J Med 2001; 345: 725-30.

8. Manterola C, Vial M, Pineda V, Losada H. Revisión crítica de la literatura para artículos de terapia. Rev Chil Cir 2004; 56: 604-9.

9. Manterola C, Pineda V, Vial M, Losada H, Muñoz S. Surgery for morbid obesity: selection of operation based on evidence from literature review. Obes Surg 2005; 15: 106-13.

10. Manterola C, Pineda V, Vial M. Resección abierta vs laparoscópica en cáncer de colon no complicado. Revisión sistemática. Cir Esp 2005; 78: 1722.

11. Manterola C, Busquets J, Pascual M, Grande L. ¿Cuál es la calidad metodológica de los artículos sobre procedimientos terapéuticos publicados en cirugía española? Cir Esp 2006; 79: 95-100.

12. Altman DG, Schulz KF, Moher D, EgGer M, Davidoff F, Elbourne D, Gotzsche PC, Lang T, Consort Group (Consoldated Standards of ReporTING TRIALS). The revised CONSORT statement for reporting randomized trials: explanation and elaboration. Ann Intern Med 2001; 134: 663-94.

13. Moertel CG, Childs DS Jr, ReItemeier RJ, Colby MY JR, Новвоок MA. Combined 5-fluorouracil and supervoltage radiation therapy of locally unresectable gastrointestinal cancer. Lancet 1969; 2: 865-7.

14. No Authors Listed. A comparison of combination chemotherapy and combined modality therapy for locally advanced gastric carcinoma. Gastrointestinal Tumor Study Group. Cancer 1982; 49: 1771-7.

15. SACKETT DL. Rules of evidence and clinical recommendations on use of antithrombotic agents. Chest 1986; 89 (2 suppl): 2S-3S.

16. MEAKINS JL Innovation in surgery: the rules of evidence. Am J Surg 2002; 183: 399-405.

17. ELASHotT JD. nQuery Advisor 4.0. Windows NT, version 5.15.1. Copyright 1995-2000.

18. SACKETT DL, WenNBERG JE. Choosing the best research design for each question. BMJ 1997; 315: 1636-40. 


\section{Cartas al Editor}

Se invita a los lectores a enviar cartas al Editor, con comentarios, preguntas o críticas sobre artículos que hayan sido publicados en la Revista y a las que los autores aludidos puedan responder. También serán bienvenidos los comentarios sobre problemas de actualidad biomédica, clínica, de salud pública, de ética y de educación médica. Podrá aceptarse la comunicación preliminar de datos parciales de una investigación en marcha, que no haya sido publicada ni sometida a publicación en otra revista. La extensión máxima aceptable es de 1.000 palabras, con un máximo de 6 referencias bibliográficas (incluyendo el artículo que la motivó) y 1 Tabla o Figura. Se recomienda adjuntar una copia idéntica para PC, en diskette de 3,5", un espaciado a 1,5 líneas, tamaño de letra 12 pt y justificada a la izquierda. Las cartas que se acepten podrán ser acortadas y modificadas formalmente, por los Editores.

\section{Controversias en la revisión editorial y en las publicaciones científicas}

\section{Controversies in the editorial process and in scientific publications}

$\mathrm{S}_{\mathrm{r}}^{\mathrm{r}}$ Editor: Hemos leído con interés sus reflexiohes a propósito del proceso editorial de esta Revista1. Nos ha parecido muy edificante el interés de los editores en reflexionar y hacer autocrítica para continuar aportando información de calidad a la comunidad científica. Nos parece que, además de lo expuesto por los editores, las reflexiones sobre lo publicado en ésta y otras revistas científicas han de ampliarse para ayudar a entender por qué se rechazan trabajos y los riesgos que se corren al aceptar los que se seleccionan con el sistema estándar de la revisión

Correspondencia a: Dr. I Villamil Cajoto. Servicio de Medicina Interna, Hospital Clínico Universitario de Santiago de Compostela. Choupana s/n 15706, Santiago de Compostela. Fax: 981950501. E mail: iago.villamil.cajoto@sergas.es. por pares. En los últimos meses hemos asistido a una sucesión de escándalos en relación con las publicaciones en revistas consideradas en el mundo científico de referencia.

El problema de la valoración de los manuscritos de utilidad científica es cada vez más acuciante. Se estima que el número de artículos científicos publicados supera 2 millones por año, en todo el mundo. La posibilidad de evaluar todos los artículos por los lectores potenciales (que son cada vez más, con el acceso a Internet a texto completo de muchas revistas) es, a todas luces, una tarea difícil. Surgen así otras formas de evaluar la importancia de los artículos para poder decidir cuáles leer, y se aplican los indicadores bibliométricos, a cuya cabeza está el tan mencionado "Factor de Impacto (FI)". Los análisis de citas (base del FI) son muy laboriosos, ya que para 
conocer la cuantía real de las citas es necesario analizar las referencias bibliográficas de todos los artículos publicados en las revistas científicas. Para ello se usa, desde la creación en 1965 del Institute for Scientific Information (ISI) en Filadelfia (EE.UU), el Science Citation Index, que es el repertorio de citas para la evaluación del FI. Partimos de la base de que el FI analiza exclusivamente artículos con título, resúmenes y palabras claves en inglés, con lo que se introduce un primer sesgo. Existe un consenso de que la ciencia aplicada, extendida como una explotación local de la ciencia básica, puede encontrar un buen vehículo de transmisión en las revistas de carácter nacional, estén o no escritas en inglés. Estos indicadores son, en definitiva, datos estadísticos deducidos de las publicaciones científicas. Aunque en principio se consideró que el número de citas que recibía un documento podía ser indicativo de su calidad (esencia del FI), hoy se acepta que el número de citas que mide impacto, uso o influencia de una investigación, es sólo un indicador parcial de la calidad del trabajo, y viene también determinado por muchos otros factores, distintos de la calidad ${ }^{2}$. Además, el FI tiene otras limitaciones. Se trata de un indicador relativo que no debe aplicarse para comparar distintas disciplinas, para lo que debería utilizarse el "factor de impacto ponderado". Otra limitación es que no es correcto asignar a todos los artículos de una revista el mismo impacto, al no existir correlación entre el impacto conjunto de una revista y el que tiene cada uno de sus artículos ${ }^{3}$. En definitiva, la falta de "factores de impacto" no indica necesariamente la inutilidad del trabajo. Para ayudar a la interpretación de la evidencia disponible, se realizan los denominados metaanálisis, que, a su vez, también se han puesto en entredicho en ocasiones por los procedimientos de elaboración ${ }^{4}$. Un escalón práctico que se basa en lo que está disponible en la literatura científica, se ve reflejado en las Guías Clínicas, pero un trabajo reciente pone de manifiesto cómo las Guías, en la mayoría de los casos, "no nos guían" o nos pueden llegar a guiar $\mathrm{mal}^{5}$. Se añade al lío el "impacto" de los recientes escándalos relacionados con revistas con alto FI. Al clásico caso de fraude de Stephen Breuning (evaluado por el propio ISI) ${ }^{6}$ se unen los recientes del Dr. Hwang Woo-Suck en Science, de Thereza Imanishi-Kari en Cell, de Jacques Benveniste en Nature y de Jon Sudbo en el New England Journal of Medicine, que arrojan más dudas sobre la validez de lo que se publica. Mención aparte tiene la implicación de la industria farmacéutica en la programación de los textos de las revistas. El papel de ésta en los estudios publicados, está demostrándose cada vez más y la presión parece seguir aumentando, por lo que los editores han de soportar ésta y otros condicionantes ${ }^{7,8}$. Por último, en los motivos para publicar y para editar existen también otros riesgos: el FI se está utilizando para valorar a los aspirantes a concursos y oposiciones y en la promoción profesional, mientras que son inexistentes las evaluaciones de la calidad de los trabajos realizados por expertos ${ }^{9}$. Y puede que éste sea el problema. Los concursos de méritos incluyen epígrafes como las comunicaciones a congresos y los capítulos en libros. Las guías también "cuentan" y conseguir que un texto tenga el preciado ISBN para que compute es un trámite administrativo sencillo. Por último los artículos en revistas científicas indexadas (ISI) también son objeto puntuable, con lo que no siempre lo que mueve a la publicación de textos es un afán divulgador científico y el editor no siempre logra marginarse de esto.

En definitiva, las publicaciones periódicas necesitan una actualización. Nos va en ello a todos. Marcia Angell (New England Journal of Medicine) y Richard Smith (British Medical Journal), han pasado de la Jefatura Editorial de sus revistas, a la más demoledora crítica de los procedimientos que éstas y otras aplican en los textos que publican ${ }^{10}$. No pretendemos cambiar las vías de adquisición de conocimientos y difusión del saber científico, pero son cada vez más necesarias reflexiones que cuestionen ciertos dogmas para mejorar estos instrumentos de comunicación científica, antes que dejen de ser útiles.

\footnotetext{
Iago Villamil Cajoto ${ }^{1}$, María José Villacián Vicedo $^{2}$.

${ }^{1}$ Servicio de Medicina Interna, Hospital Clínico Universitario de Santiago de Compostela, A Coruña, España.

2 Pediatría, CS Palas de Rei.
} 


\section{REFERENCIAS}

1. Reyes H, Andresen M, Palma J. El creciente desafío del proceso editorial en la Revista Médica de Chile. Rev Méd Chile 2006; 134: 7-11.

2. Garfield E, Welujams-Dorof A. Citation data: their use as quantitative indicators for science and technology evaluation and policy-making. Science and Public Policy 1992; 19: 321-7.

3. SEgLEN PO. Citation frequency and journal impact: valid indicator of scientific quality? J Intern Med 1991; 229: 109-11.

4. Navarro Puerto MA, Ruiz Romero F, Reyes Domínguez A, Gutiérrez Ibarlucea, Hermosilla Gago T, Alonso ORTiz del Río et al. iLas guías que nos guían son fiables? Evaluación de las Guías de Práctica Clínica Españolas. Rev Clin Esp 2005; 205: 533-40.
5. Puliyel JM, Vishnubhatla S. Metaanalysis can be statistically misleading. Evid Based Med 2005; 10: 130.

6. Garfield E, Wewjams-Dorof A. The impact of fraudulent research on the scientific literature. The Stephen E. Breuning case. JAMA 1990; 263: 1424-6.

7. KJaERGard LL, Als-Nielsen B. Association between competing interests and authors' conclusions: epidemiological study of randomized clinical trials published in the BMJ. BMJ 2002; 325: 249.

8. Morin $\mathrm{K}$, Rakatansky $\mathrm{H}$, Riddick FA JR, Morse LJ, O'BANNon JM 3 $3^{\mathrm{RD}}$, GoLdRICH MS et AL. Managing conflicts of interest in the conduct of clinical trials. JAMA 2002; 287: 78-84.

9. Camí J. Impactolatría: diagnóstico y tratamiento. Med Clin (Barc) 1997; 109: 515-24.

10. Sмтtн R. Medical journals are an extension of the marketing arm of pharmaceutical companies. PloS Med 2005; 2: 364-6.

\section{FE DE ERRATUM}

En el número de mayo 2006 de Revista Médica de Chile, Volumen 134; páginas 549-555, en el artículo "Inequidades sociales y diabetes en adolescentes" de los autores Rodrigo López y Vibeke Baelum, en el resumen en inglés, página 549.

Dice:

Multilevel analyses indicate that paternal achieved education is the most influential variable.

Debe decir:

Multivariable analyses indicate that paternal achieved education is the most influential variable. 


\section{CrónICA}

Revisión por pares en la Revista Médica de Chile, AÑO 2005

\section{Peer-Reviewers in Revista Médica de Chile, YEAR 2005}

Siguiendo la tendencia mostrada en la Figura 1, de la Editorial de enero de 2006 (Rev Méd Chile 2006; 134: 7-11), el aumento en el número de manuscritos recibidos en la Revista Médica de Chile ha requerido solicitar la colaboración de un número mayor de expertos externos que opinen sobre la calidad de dichos manuscritos, que recomienden a sus autores cómo pueden mejorarlos, o que den a los Editores razones válidas para rechazarlos. La contribución de los revisores externos es un pilar inapreciable en la calidad de las revistas científicas y se ha hecho cada día más importante al aumentar la complejidad metodológica de los trabajos, en el área científica y en las especialidades clínicas. La presentación de datos recopilados retrospectivamente como "nuestra experiencia clínica", ya no puede hacerse con la simpleza de antaño porque el análisis retrospectivo de casuísti- ca requiere seguir métodos que permiten darle validez general. Un ejemplo común es la obligación de explicitar los criterios con los cuales se incluyeron o excluyeron casos con una misma patología.

La colaboración de los revisores externos es voluntaria, desinteresada y anónima (para los autores). Pero no debe ser anónima para los lectores ni para las instituciones en que trabajan dichos revisores. Por ese motivo, una vez al año $\mathrm{y}$ en el número de julio de la Revista, se identifican las personas que durante el año precedente (enero a diciembre de 2005, en esta oportunidad) revisaron al menos un manuscrito. Durante 2005 fueron 444 revisores, mientras en 2004 fueron 419. La mayoría de ellos revisaron dos o tres manuscritos en el año y quienes figuran en la nómina de Miembros del Comité Editorial Asesor de la Revista, revisaron generalmente un número aún mayor. Esta es la oportunidad de agradecer su colaboración y la nómina que se publica a continuación es un documento que acredita su inapreciable participación en el proceso de "revisión por pares".

\section{A}

$\begin{array}{lll}\text { Abarca } & \text { V } & \text { Jaime } \\ \text { Abarca } & \text { V } & \text { Katia } \\ \text { Abumohor } & \text { G } & \text { Patricia } \\ \text { Acevedo } & \text { B } & \text { Juan Carlos } \\ \text { Acuña } & \text { L } & \text { Guillermo } \\ \text { Acuña } & \text { M } & \text { Raúl } \\ \text { Acuña } & \text { P } & \text { Mónica } \\ \text { Acuña } & \text { R } & \text { Julia } \\ \text { Afani } & \text { S } & \text { Alejandro } \\ \text { Aguayo } & \text { N } & \text { Rubén } \\ \text { Ajenjo } & \text { H } & \text { María Cristina } \\ \text { Albala } & \text { B } & \text { Cecilia } \\ \text { Alcaíno } & \text { C } & \text { Héctor } \\ \text { Alegría } & \text { Q } & \text { Silvia } \\ \text { Altschiller } & \text { G } & \text { Herbert } \\ \text { Alvarez } & \text { A } & \text { Hernán } \\ \text { Alvarez } & \text { U } & \text { Gonzalo }\end{array}$

$\begin{array}{lll}\text { Alvo } & \text { A } & \text { Miriam } \\ \text { Aller } & \text { R } & \text { Felipe } \\ \text { Amigo } & \text { C } & \text { Hugo } \\ \text { Anabalón } & \text { S } & \text { Patricio } \\ \text { Ancic } & \text { C } & \text { Patricia } \\ \text { Apt } & \text { B } & \text { Werner } \\ \text { Araos } & \text { H } & \text { Daniel } \\ \text { Araya } & \text { D } & \text { Fernando } \\ \text { Araya } & \text { H } & \text { Iván } \\ \text { Araya } & \text { O } & \text { Juan Carlos } \\ \text { Araya } & \text { Q } & \text { Verónica } \\ \text { Arellano } & \text { H } & \text { Leonardo } \\ \text { Arteaga } & \text { H } & \text { Oscar } \\ \text { Arteaga } & \text { U } & \text { Eugenio } \\ \text { Asenjo } & \text { G } & \text { René } \\ \text { Atalah } & \text { S } & \text { Eduardo } \\ \text { Avendaño } & \text { B } & \text { Isabel } \\ \text { Ayala } & \text { R } & \text { Francisco }\end{array}$


B

$\begin{array}{lll}\text { Badilla } & \text { O } & \text { Lautaro } \\ \text { Baeza } & \text { B } & \text { Ramón } \\ \text { Bannura } & \text { C } & \text { Guillermo } \\ \text { Barría } & \text { S } & \text { Manuel } \\ \text { Barriga } & \text { C } & \text { Francisco } \\ \text { Becker } & \text { C } & \text { Pedro } \\ \text { Bedregal } & \text { G } & \text { Paula } \\ \text { Behn } & \text { T } & \text { Claus } \\ \text { Beltrán } & \text { B } & \text { Carlos } \\ \text { Bello } & \text { S } & \text { Sergio } \\ \text { Berger } & \text { F } & \text { Zoltan } \\ \text { Berríos } & \text { C } & \text { Ximena } \\ \text { Bertín } & \text { C } & \text { Pablo } \\ \text { Biagini } & \text { A } & \text { Leandro } \\ \text { Bianchi } & \text { Sch } & \text { Víctor } \\ \text { Blanco } & \text { R } & \text { Antonieta } \\ \text { Blümel } & \text { M } & \text { Juan Enrique } \\ \text { Boehme } & \text { K } & \text { Cecilia } \\ \text { Brahm } & \text { B } & \text { Javier } \\ \text { Bronfman } & \text { F } & \text { Lucía } \\ \text { Bunout } & \text { B } & \text { Daniel } \\ \text { Bustamante } & \text { Z } & \text { Marco } \\ & & \end{array}$

C

$\begin{array}{lll}\text { Cabello } & \text { A } & \text { Hernán } \\ \text { Cabello } & \text { C } & \text { Felipe } \\ \text { Cabrera } & \text { C } & \text { María Elena } \\ \text { Cáceres } & \text { O } & \text { Texia } \\ \text { Campusano } & \text { M } & \text { Claudia } \\ \text { Camus } & \text { A } & \text { Mauricio } \\ \text { Canals } & \text { L } & \text { Claudio } \\ \text { Canals } & \text { L } & \text { Mauricio } \\ \text { Cano } & \text { Sch } & \text { Francisco } \\ \text { Capetillo } & \text { F } & \text { María Cecilia } \\ \text { Carrasco } & \text { N } & \text { Fernando } \\ \text { Carvajal } & \text { C } & \text { Sergio } \\ \text { Carvajal } & \text { H } & \text { Carlos } \\ \text { Casar } & \text { C } & \text { Carlos } \\ \text { Cassorla } & \text { G } & \text { Fernando } \\ \text { Castillo } & \text { C } & \text { José Luis } \\ \text { Castillo } & \text { T } & \text { Silvia } \\ \text { Castro } & \text { O } & \text { José } \\ \text { Cattani } & \text { O } & \text { Andreína } \\ \text { Celedón } & \text { L } & \text { Carlos } \\ \text { Cerda } & \text { S } & \text { Sergio } \\ \text { Cifuentes } & \text { O } & \text { Lucía } \\ \text { Codner } & \text { D } & \text { Ethel } \\ \text { Codoceo } & \text { R } & \text { Verner } \\ \text { Concha } & \text { G } & \text { Selim } \\ \text { Conte } & \text { L } & \text { Guillermo } \\ \text { Contreras } & \text { P } & \text { Juan Eduardo } \\ \text { Contreras } & \text { T } & \text { Gustavo } \\ \text { Corbalán } & \text { H } & \text { Ramón } \\ \text { Cortés } & \text { M } & \text { Fanny } \\ \text { Croxatto } & \text { A } & \text { Horacio } \\ & & \end{array}$

$\begin{array}{lll}\text { Cruz Coke } & \text { M } & \text { Ricardo } \\ \text { Cuchacovich } & \text { T } & \text { Miguel } \\ \text { Cuevas } & \text { M } & \text { Ada } \\ \text { Cumsille } & \text { G } & \text { Francisco }\end{array}$

\section{CH}

$\begin{array}{lll}\text { Chamorro } & \text { B } & \text { Hernán } \\ \text { Chamorro } & \text { S } & \text { Gastón } \\ \text { Chernilo } & \text { T } & \text { Sara } \\ \text { Chianale } & \text { B } & \text { José }\end{array}$

D

De Aretxabala U Xabier

De la Fuente H María

De la Maza C María Pía

Defilippi C Carlos

Delucchi B Angela

Descouvieres C Carlos

Díaz A Patricia

Díaz C Jaime

Díaz $\quad \mathrm{T}$ Violeta

Dighero $\quad \mathrm{T}$ Humberto

Domenech L Raúl

Domínguez A Raúl

Donoso G Verónica

Donoso M Juan

Donoso S Archibaldo

Donoso S Mario

Dörr Z Otto

Dougnac L Alberto

Duffau T Gastón

Durruty V Guillermo

E

Echeverría B Carlos

Elgueta M Susana

Enríquez L Octavio

Espinoza G Ricardo

Eterovic M Ivo

F

Fajuri N Alejandro

Fardella B Carlos

Fardella B Patricia

Fasce $\mathrm{H}$ Eduardo

Feijoo $\quad S$ Rosa María

Felmer A Antonio

Fernández A Manuel

Fernández $\quad \mathrm{V} \quad$ Alejandra

Ferreccio $\mathrm{R}$ Catterine

Fica $\quad \mathrm{C}$ Alberto

Fielbaum C Oscar

Figueroa C Gustavo

Figueroa $\mathrm{E}$ Fernando

Figueroa G Guillermo

Figueroa M Claudia

Florenzano U Fernando 


\begin{tabular}{|c|c|c|c|c|c|}
\hline Florenzano & $\mathrm{U}$ & Ramón & Honeyman & M & Juan \\
\hline Flores & $\mathrm{N}$ & Nelson & Hoppe & W & Arnold \\
\hline Fruns & $\mathrm{Q}$ & Manuel & Horwitz & $\mathrm{C}$ & Nina \\
\hline Fuentealba & $\mathrm{P}$ & Carlos & Hoyl & M & Trinidad \\
\hline Fullerton & $\mathrm{U}$ & Claudio & I & & \\
\hline Fuster & $\mathrm{F}$ & Francisco & Ibáñez & $\mathrm{A}$ & Luis \\
\hline G & & & Ibáñez & $\mathrm{C}$ & Fernando \\
\hline Gaete & $\mathrm{V}$ & Ximena & Ibáñez & $\mathrm{G}$ & Pilar \\
\hline Gai & $\mathrm{H}$ & María Nella & Icaza & $\mathrm{N}$ & Gloria \\
\hline Gajardo & $\mathrm{N}$ & Jorge & Infante & $\mathrm{L}$ & José Ignacio \\
\hline Gálvez & $\mathrm{G}$ & Serqio & Iturriaga & $\mathrm{R}$ & Hernán \\
\hline García & $\mathrm{C}$ & Patricia & $\mathbf{J}$ & & \\
\hline García-Huidobro & $\mathrm{T}$ & Juan Pablo & Jadresic & $\mathrm{M}$ & Enrique \\
\hline Garrido & $\mathrm{N}$ & Jorge & Jadue & $\mathrm{H}$ & Liliana \\
\hline Gasic & B & Miguel & Jalil & $\mathrm{M}$ & Jorge \\
\hline Gatica & $\mathrm{R}$ & Héctor & Jalil & $\mathrm{M}$ & Roberto \\
\hline Gayán & B & Patricio & Jara & B & Lilian \\
\hline Germain & $\mathrm{M}$ & Alfredo & Jara & G & Alejandra \\
\hline Giaconi & G & Juan & Jarufe & $\mathrm{C}$ & Nicolás \\
\hline Gil & $\mathrm{D}$ & Rodrigo & Jiménez & $\mathrm{D}$ & Jorge \\
\hline Giordano & B & José & Jiménez & $\mathrm{P}$ & Patricio \\
\hline Glasinovic & $\mathrm{R}$ & Juan Carlos & Juez & G & Gabriela \\
\hline Gloger & $\mathrm{K}$ & Sergio & Juliet & $\mathrm{L}$ & Chrystal \\
\hline Goic & G & Alejandro & $\mathbf{K}$ & & \\
\hline Gómez & $\mathrm{H}$ & Orietta & Kakarieka & W & Elena \\
\hline Gómez & $\mathrm{M}$ & Patricia & Karmelic & $\mathrm{S}$ & Christian \\
\hline González & $\mathrm{A}$ & Patricia & Katz & B & Ricardo \\
\hline González & A & Rolando & Kauffmann & $\mathrm{Q}$ & Ronald \\
\hline González & B & Sergio & Kehr & S & Juan \\
\hline González & $\mathrm{C}$ & Carlos & $\mathbf{L}$ & & \\
\hline González & $\mathrm{D}$ & Robinson & Labarca & B & Rodrigo \\
\hline González & $\mathrm{H}$ & Jorge & Labarca & $\mathrm{L}$ & Jaime \\
\hline González & $\begin{array}{l}\mathrm{R} \\
\mathrm{Y}\end{array}$ & Gerardo & Lama & $\mathrm{T}$ & Alexis \\
\hline $\begin{array}{l}\text { González } \\
\text { Gromeona }\end{array}$ & $\begin{array}{l}\mathrm{Y} \\
\mathrm{S}\end{array}$ & Monica & Lara & G & Joaquín \\
\hline $\begin{array}{l}\text { Gramegna } \\
\text { Guarda }\end{array}$ & $\mathrm{S}^{\mathrm{S}}$ & $\begin{array}{l}\text { Glona } \\
\text { Fduando }\end{array}$ & Larraín & B & Francisco \\
\hline Guardia & $\begin{array}{l}\mathrm{S} \\
\mathrm{B}\end{array}$ & $\begin{array}{l}\text { Euuaruo } \\
\text { Svlvia }\end{array}$ & Larraín & $\mathrm{R}$ & Ernesto \\
\hline Guiraldes & $\mathrm{C}$ & Ernesto & Lavados & G & Pablo \\
\hline Guivernau & $\mathrm{B}$ & Mauricio & Lavados & $\mathrm{M}$ & Manuel \\
\hline Gutiérrez & $\mathrm{C}$ & Jorge & Lavandero & G & Sergio \\
\hline Guzmán & $\mathrm{B}$ & Leonardo & Ledermann & $\mathrm{D}$ & Walter \\
\hline Guzmán & $\mathrm{B}$ & Serqio & Leiva & $\mathrm{R}$ & Isabel \\
\hline Guzmán & $\mathrm{D}$ & Ana María & Letelier & $\mathrm{S}$ & Luz María \\
\hline & & Alla lvialla & Liberman & G & Claudio \\
\hline H & & & Liendo & $\mathrm{P}$ & Federico \\
\hline Hering & A & Enrique & Lioi & $\mathrm{C}$ & Ximena \\
\hline Hermansen & $\mathrm{T}$ & Carlos & Lisboa & B & Carmen \\
\hline Herrera & $\mathrm{G}$ & Oscar & Lizana & $\mathrm{S}$ & Carlos \\
\hline Herrera & $\mathrm{L}$ & Patricio & Lolas & $\mathrm{S}$ & Fernando \\
\hline Herrera & $\mathrm{L}$ & Renato & López & $\mathrm{K}$ & Francisco \\
\hline Herrera & $\mathrm{P}$ & Adela & López & $\mathrm{M}$ & José Manuel \\
\hline Hervé & $\mathrm{E}$ & Beatriz & López & St & Gloria \\
\hline Heusser & $\mathrm{R}$ & Felipe & Lubascher & $\mathrm{C}$ & Jaime \\
\hline Himmel & $\mathrm{K}$ & Erika & Llanos & $\mathrm{L}$ & Osvaldo \\
\hline Hirsch & B & Sandra & Llanos & $\mathrm{M}$ & Aníbal \\
\hline Hodgson & B & María Isabel & Llorens & S & Pedro \\
\hline
\end{tabular}


M

Madrid

Madrid

Maggi

Maggiolo

Majlis

Maquilón

Marcone

Marchant

Mardones

Marín

Mariné

Martínez

Martínez

Martínez

Martínez

Massardo

Matus

Mazzei

Medina

Mella

Mellado

Mellado

Mena

Mezzano

Millar

Miquel

Molina

Molinari

Montaña

Moreno

Moreno

Moreno

Morris

Mullins

Munizaga

Muñoz

Muñoz

Muñoz

Muñoz

N

Navarrete

Nazer

Neira

Nervi

Nogales

Norero

o

$\begin{array}{lll}\text { O'Ryan } & \text { G } & \text { Miguel } \\ \text { Ojeda } & \text { F } & \text { José Manuel } \\ \text { Ojeda } & \text { S } & \text { Dagoberto } \\ \text { Olivares } & \text { G } & \text { Manuel } \\ \text { Olivi } & \text { R } & \text { Henry } \\ \text { Olmos } & \text { C } & \text { Alfonso } \\ \text { Ortiz } & \text { O } & \text { Mario }\end{array}$

$\begin{array}{lll}\text { Osorio } & \text { A } & \text { Gonzalo } \\ \text { Osorio } & \text { S } & \text { Guido } \\ \text { Ovalle } & \text { A } & \text { Loreto } \\ \text { Oviedo } & \text { G } & \text { Sofía } \\ \text { Oyarzún } & \text { E } & \text { Enrique } \\ \text { Oyarzún } & \text { F } & \text { Rodulfo } \\ \text { Oyarzún } & \text { G } & \text { Manuel } \\ \text { Oyonarte } & \text { G } & \text { Miguel } \\ \text { P } & & \\ \text { Palavecino } & \text { S } & \text { Ricardo } \\ \text { Palma } & \text { C } & \text { Renato } \\ \text { Papapietro } & \text { V } & \text { Karin } \\ \text { Parada } & \text { C } & \text { María Teresa } \\ \text { Pardo } & \text { G } & \text { José } \\ \text { Paredes } & \text { V } & \text { Axel } \\ \text { Parra } & \text { R } & \text { Claudio } \\ \text { Peirano } & \text { C } & \text { Patricio } \\ \text { Pereira } & \text { G } & \text { Jaime } \\ \text { Pérez } & \text { H } & \text { María Angélica } \\ \text { Pérez } & \text { P } & \text { Gilberto } \\ \text { Pérez-Alzola } & \text { L } & \text { Patricia } \\ \text { Perret } & \text { P } & \text { Cecilia } \\ \text { Pertuzé } & \text { R } & \text { Julio } \\ \text { Pino } & \text { Z } & \text { Paulina } \\ \text { Pinto } & \text { C } & \text { Juan } \\ \text { Pinto } & \text { Q } & \text { Juan Ignacio } \\ \text { Plubins } & \text { M } & \text { Luis } \\ \text { Prado } & \text { J } & \text { Valeria } \\ \text { Prat } & \text { A } & \text { Gabriel } \\ \text { Prat } & \text { M } & \text { Hernán } \\ \text { Prieto } & \text { D } & \text { Juan Carlos } \\ \text { Puelma } & \text { P } & \text { Alvaro } \\ \text { Puga } & \text { P } & \text { Julio } \\ \text { Püschel } & \text { I } & \text { Klaus } \\ \text { Q } & & \\ \text { Quera } & \text { P } & \text { Rodrigo } \\ \text { Quezada } & \text { L } & \text { Arnoldo } \\ \text { Quezada } & \text { S } & \text { Katty } \\ \text { Quintana } & \text { F } & \text { Juan Carlos } \\ \text { Quiroga } & \text { G } & \text { Teresa } \\ \text { R } & & \\ \text { Rabagliati } & \text { B } & \text { Ricardo } \\ \text { Raggio } & \text { M } & \text { Ximena } \\ \text { Ramírez } & \text { N } & \text { Alfredo } \\ \text { Rappoport } & \text { S } & \text { Jaime } \\ \text { Repetto } & \text { L } & \text { Gabriela } \\ \text { Reyes } & \text { F } & \text { Juan } \\ \text { Reyes } & \text { G } & \text { María Loreto } \\ \text { Reyes } & \text { O } & \text { Viviana } \\ \text { Reynolds } & \text { H } & \text { Enrique } \\ \text { Rigotti } & \text { R } & \text { Attilio } \\ \text { Ríos } & \text { S } & \text { Rafael } \\ \text { Rivero } & \text { D } & \text { Santiago } \\ \text { Roa } & \text { E } & \text { Iván } \\ & & \end{array}$




\begin{tabular}{|c|c|c|c|c|c|}
\hline Roa & St & Juan Carlos & Trucco & $\mathrm{A}$ & Olivia \\
\hline Rodríguez & $\mathrm{P}$ & José Adolfo & Trucco & B & Marcelo \\
\hline Rodríguez & $\mathrm{T}$ & Jorge & Trujillo & V & Sergio \\
\hline Rodríguez & V & José Antonio & Turner & G & Eduardo \\
\hline Rojas & D & Alicia & & & \\
\hline Rojas & $\mathrm{P}$ & David & $\mathbf{U}$ & & \\
\hline Rojas & $\mathrm{S}$ & Nina & Ugarte & $\mathrm{P}$ & Francisca \\
\hline Román & A & Oscar & Undurraga & $\mathrm{P}$ & Alvaro \\
\hline Rosati & $\mathrm{M}$ & Pía María & Uribe & $\mathrm{J}$ & Pedro \\
\hline Rosselot & J & Eduardo & Uribe & $\mathrm{M}$ & Mario \\
\hline Rossi & $\mathrm{F}$ & Ricardo & Urzúa & $\mathrm{U}$ & Jorge \\
\hline Rozowski & $\mathrm{N}$ & Jaime & $\mathrm{V}$ & & \\
\hline Rugiero & $\mathrm{P}$ & Elsa & $\begin{array}{l}\text { V } \\
\text { Vaisman }\end{array}$ & & \\
\hline Ruiz & A & Inés & $\begin{array}{l}\text { Vaisman } \\
\text { Valderrama }\end{array}$ & $\begin{array}{l}\text { W } \\
\mathrm{L}\end{array}$ & $\begin{array}{l}\text { Sergio } \\
\text { Rodrigo }\end{array}$ \\
\hline $\mathbf{S}$ & & & Valdés & E & Francisco \\
\hline Sáenz & $\mathrm{F}$ & Roque & Valdés & $\mathrm{S}$ & Gloria \\
\hline Sáez & $\mathrm{H}$ & Enzo & Valdivia & C & Gonzalo \\
\hline Saieh & A & Carlos & Valdivieso & $\mathrm{D}$ & Vicente \\
\hline Salamanca & $\mathrm{F}$ & Lucía & Valdivieso & $\mathrm{F}$ & Sergio \\
\hline Salas & $\mathrm{D}$ & Cristián & Valenzuela & B & Alfonso \\
\hline Saldías & $\mathrm{P}$ & Fernando & Valenzuela & $\mathrm{E}$ & Jorge \\
\hline Salvo & $\mathrm{C}$ & Karen & Valenzuela & M & Raúl \\
\hline Sánchez & $\mathrm{D}$ & Ignacio & Vantman & B & David \\
\hline Santos & A & Manuel & Vargas & $\mathrm{C}$ & Nelson \\
\hline Sanz & $\mathrm{C}$ & Patricia & Vásquez & $\mathrm{M}$ & Alicia \\
\hline Sapunar & $\mathrm{Z}$ & Jorge & Véjar & $\mathrm{P}$ & Claudia \\
\hline Scharager & $\mathrm{G}$ & Judith & Velasco & $\mathrm{F}$ & Nicolás \\
\hline Schiattino & $\mathrm{L}$ & Irene & Véliz & $\mathrm{L}$ & Jesús \\
\hline Sedano & $\mathrm{L}$ & Manuel & Verdaguer & $\mathrm{T}$ & Juan \\
\hline Segovia & $\mathrm{D}$ & Isabel & Vergara & $\mathrm{E}$ & Fernando \\
\hline Segovia & M & Roberto & Vergara & I & Marcos \\
\hline Segovia & $\mathrm{R}$ & Erico & Vicente & $\mathrm{P}$ & Benjamín \\
\hline Seijas & $\mathrm{B}$ & Daniel & Villarroel & $\mathrm{D}$ & Luis \\
\hline Seitz & $\mathrm{C}$ & Juan & Vogel & $\mathrm{S}$ & Andrea \\
\hline Sepúlveda & $\mathrm{N}$ & Andrea & Vukasovic & $\mathrm{R}$ & José Luis \\
\hline Serani & $\mathrm{M}$ & Alejandro & $\mathbf{W}$ & & \\
\hline Serón & $\mathrm{F}$ & María & Wainstein & G & Eduardo \\
\hline Silva & I & Hernán & Weitz & $\mathrm{V}$ & Juan Carlos \\
\hline Silva & $\mathrm{S}$ & Juan Jorge & Wistuba & 0 & Iván \\
\hline Silva & Z & Claudio & Wohllk & G & Nelson \\
\hline Soffia & S & Pablo & Wolff & $\mathrm{R}$ & Marcelo \\
\hline Soza & $\mathrm{R}$ & Alejandro & Wurgaft & $\mathrm{D}$ & Rosita \\
\hline Spencer & $\mathrm{O}$ & Eugenio & & & \\
\hline Srur & $\mathrm{A}$ & Eliana & $\mathbf{Y}$ & & \\
\hline Stuardo & $\mathrm{L}$ & Andrés & Yáñez & $\mathrm{S}$ & Paulina \\
\hline $\begin{array}{l}\mathbf{T} \\
\text { Talesnik }\end{array}$ & S & Fdu & Yazigi & G & Raúl \\
\hline Tapia & I & Jorge & $\mathbf{Z}$ & & \\
\hline Thambo & B & Sergio & Zamorano & G & Jaime \\
\hline Thompson & M & Luis & Zapata & $\mathrm{L}$ & Rodrigo \\
\hline Toledo & C & Ximena & Zapata & 0 & Patricio \\
\hline Toro & U & Cecilia & Zárate & B & Víctor \\
\hline Torres & $\mathrm{H}$ & Marisa & Zilleruelo & B & Gastón \\
\hline Trejo & M & Carlos & Zilleruelo & B & Raúl \\
\hline Triviño & B & Ximena & Zúñiga & $\mathrm{D}$ & Alvaro \\
\hline
\end{tabular}




\title{
INSTRUCCIONES A LOS AUTORES
}

\author{
(ACTUALZADAS EN JULIO DE 2006)
}

Los trabajos enviados a la Revista Médica de Chile deberán ajustarse a las siguientes instrucciones, preparadas considerando el estilo y naturaleza de la Revista y los «equisitos Uniformes para los Manuscritos Sometidos a Revistas Biomédicas», establecidos por el International Committee of Medical Journal Editors, actualizados en febrero de 2006 en el sitio WEB www.icmje.org. Se dispone de la traducción al castellano de una versión previa en www.wame.org.

1. El trabajo debe ser escrito en papel tamaño carta $(21,5 \mathrm{x}$ $27,5 \mathrm{~cm}$ ), dejando un margen de al menos $3 \mathrm{~cm}$ en los 4 bordes. Todas las páginas deben ser numeradas en el ángulo superior derecho, empezando por la página del título. Debe entregarse en Bernarda Morín 488, Providencia, Santiago, tres ejemplares idénticos de todo el texto, con las Referencias, Tablas y Figuras, acompañados por una copia idéntica para $\mathrm{PC}$, en diskette de $3,5^{\prime \prime}$ o $\mathrm{CD}$, con espaciado a 1,5 líneas; con tamaño de letra 12 pt y justificado a la izquierda. Las Figuras que muestren imágenes (radiografías, histología, etc.) deben entregarse en copias de calidad fotográfica (ver además 3.10)

Al pié de la página del título debe mostrarse un recuento computacional de palabras, contadas desde el comienzo de la Introducción hasta el término de la Discusión (se excluyen para el recuento, la página de título, el Resumen, los Agradecimientos, las Referencias, Tablas y Figuras).

Se solicita que los «Artículos de Investigación» no sobrepasen 2.500 palabras. Los «Artículos de Revisión»y los «Especiales» pueden extenderse hasta 3.000 palabras. Los «Casos Clínicos»no deben exceder 1.500 palabras, pudiendo agregárseles hasta 2 Tablas y Figuras y no más de 20 referencias. Las «Cartas al Editor» no deben exceder 1.000 palabras, pudiendo agregárseles hasta 6 referencias y 1 Tabla o Figura.

2. Los «Artículos de Investigación» deben dividirse en secciones tituladas «ntroducción», «Material y Método», «Resultados»y «iscusión». Otros tipos de artículos, tales como los «Casos Clínicos»y «Artículos de Revisión», pueden acomodarse mejor a otros formatos pero deben ser aprobados por los Editores.

\section{El ordenamiento de cada trabajo será el siguiente:}

\subsection{Página del Título}

La primera página del manuscrito debe contener: 1) El título del trabajo, que debe ser conciso pero informativo sobre el contenido central de la publicación; 2) El o los autores identificándolos con su nombre de pila y apellido paterno. El uso del apellido materno o su inicial es del arbitrio de cada autor. Se recomienda a los autores escribir su nombre con un formato constante, en todas sus publicaciones en revistas indexadas en el Index Medicus y otros índices internacionales; al término de cada nombre de autor debe identificarse con número en «superíndice», el 3) Nombre de la o las Secciones, Departamentos, Servicios e Instituciones a las que perteneció dicho autor durante la ejecución del trabajo; 4) Nombre y dirección del autor con quien establecer correspondencia o solicitarle separatas. Debe incluir su número de fax y correo electrónico; 5) Fuente de apoyo financiero, si lo hubo, en forma de subsidio de investigación (grants), equipos, drogas, o todos ellos. Debe declararse toda ayuda financiera recibida, especificando si la organización que la proporcionó tuvo o no tuvo influencia en el diseño del estudio; en la recolección, análisis o interpretación de los datos; en la preparación, revisión o aprobación del manuscrito (ver la Editorial y el Artículo Especial en Rev Med Chile, enero de 2003 y la actualización de los "Requisitos Uniformes" en www.icmje.org).

Señale con letras minúsculas en «superíndices» a los autores que no sean médicos y use dichos superíndices para identificar su título profesional o su calidad de alumno o becario de una determinada escuela universitaria.

Al pie de la página del título coloque el recuento computacional de palabras, según explicitado previamente en 1.

Cada una de las secciones siguientes (3.2 a 3.8) debe iniciarse en nuevas páginas:

\section{2. Resumen}

La segunda página debe contener un resumen, de no más de 250 palabras, que describa los propósitos del estudio 0 investigación, el material y métodos empleados, los resultados principales y las conclusiones más importantes. Se recomienda utilizar el modelo de resumen estructurado». No emplee abreviaturas no estandarizadas.

Se recomienda a los autores que proporcionen su propia traducción del resumen al inglés, con la respectiva traducción del título del trabajo. La Revista hará dicha traducción para quienes no estén en condiciones de proporcionarla. Los Editores podrán modificar la redacción del resumen entregado por los autores si estiman que ello beneficiará su difusión internacional, pero solicitarán su aprobación a los autores. Los autores pueden proponer 3 a 10 palabras clave», las cuales deben ser elegidas en la lista del Index Medicus (Medical Subjects Headings), accesible en www.nlm.nih.gov/mesh/.

3. 3. Introducción

Resuma la racionalidad del estudio y exprese claramente su propósito. Cuando sea pertinente, haga explícita la hipótesis cuya validez pretendió analizar. No revise extensamente el tema y cite sólo las referencias bibliográficas que sean estrictamente atingentes a su propio estudio.

3. 4. Material y Método (o «Pacientes y Método»)

Describa la selección de los sujetos estudiados: pacientes 0 animales de experimentación, órganos, tejidos, células, etc., y sus respectivos controles. Identifique los métodos, instrumentos o aparatos y procedimientos empleados, con la precisión adecuada para permitir a otros observadores que 
reproduzcan sus resultados. Si se emplearon métodos bien establecidos y de uso frecuente (incluso métodos estadísticos), limítese a nombrarlos y cite las referencias respectivas. Cuando los métodos han sido publicados pero no son bien conocidos, proporcione las referencias y agregue una breve descripción. Si los métodos son nuevos o aplicó modificaciones a métodos establecidos, descríbalas con precisión, justifique su empleo y enuncie sus limitaciones.

Cuando se efectuaron experimentos en seres humanos, explicite si los procedimientos respetaron normas éticas concordantes con la Declaración de Helsinki (actualizada en 2000) y si fueron revisados y aprobados por un comité ad hoc de la institución en que se efectuó el estudio; cuando lo soliciten los editores, los autores deberán adjuntar el documento de aprobación respectivo. Los estudios en animales de experimentación deben acompañarse de la aprobación por el comité de ética respectivo.

Identifique los fármacos y compuestos químicos empleados, con su nombre genérico, sus dosis y vías de administración. Identifique a los pacientes mediante números correlativos, pero no use sus iniciales ni los números de fichas clínicas de su hospital.

Indique siempre el número de pacientes o de observaciones, los métodos estadísticos empleados y el nivel de significación elegido previamente para juzgar los resultados.

\subsection{Resultados}

Presente sus resultados siguiendo una secuencia lógica y concordante, en el texto, las Tablas y Figuras. Los datos se pueden mostrar en Tablas o Figuras, pero no simultáneamente en ambas.

En el texto, destaque las observaciones importantes, sin repetir todos los datos que se presentan en las Tablas 0 Figuras. No mezcle la presentación de los resultados con su discusión, la cual debe incluirse en la sección:

3.6. Discusión

Se trata de una discusión de los resultados obtenidos en este trabajo y no de una revisión del tema en general. Discuta únicamente los aspectos nuevos e importantes que aporta su trabajo y las conclusiones que Ud. propone a partir de ellos. No repita detalladamente datos que aparecen en «Resultados». Haga explícitas las concordancias o discordancias de sus hallazgos y sus limitaciones, comparándolas con otros estudios relevantes, identificados mediante las citas bibliográficas respectivas. Conecte sus conclusiones con los propósitos del estudio, que destacó en la «ntroducción». Evite formular conclusiones que no estén respaldadas por sus hallazgos, así como apoyarse en otros trabajos aún no terminados. Plantee nuevas hipótesis cuando le parezca adecuado, pero califíquelas claramente como tales. Cuando sea apropiado, proponga sus recomendaciones.

\subsection{Agradecimientos}

Exprese su agradecimiento sólo a personas e instituciones que hicieron contribuciones substantivas a su trabajo. Los autores son responsables por la mención de personas o instituciones a quienes los lectores podrían atribuir un apoyo a los resultados del trabajo y sus conclusiones (lea la Editorial y el Artículo Especial en Rev Med Chile, enero de 2003).

\subsection{Referencias}

Limite las referencias (citas bibliográficas) idealmente a 40. Prefiera las que correspondan a trabajos originales publicados en revistas incluidas en el Index Medicus (lea la Editorial publicada en Rev Med Chile 2001;129:343-5). Numere las referencias en el orden en que se las menciona por primera vez en el texto. Identifíquelas mediante numerales arábigos, colocados (entre paréntesis) al final de la frase o párrafo en que se las alude. Las referencias que sean citadas únicamente en las Tablas o en las leyendas de las Figuras, deben numerarse en la secuencia que corresponda a la primera vez que se citen dichas Tablas o Figuras en el texto.

Los resúmenes de presentaciones a Congresos pueden ser citados como referencias sólo cuando fueron publicados en revistas de circulación común. Si se publicaron en «ibros de Resúmenes», pueden citarse en el texto (entre paréntesis), al final del párrafo pertinente. Se puede incluir como referencias a trabajos que están aceptados por una revista pero aún en trámite de publicación; en este caso, se debe anotar la referencia completa, agregando a continuación del nombre abreviado de la revista la expresión «en prensa)». Los trabajos enviados a publicación pero todavía no aceptados oficialmente, pueden ser citados en el texto (entre paréntesis) como «observaciones no publicadas» 0 «sometidas a publicación», pero no deben alistarse entre las referencias.

Al alistar las referencias, su formato debe ser el siguiente:

a) Para Artículos en Revistas. Apellido e inicial del nombre del o los autores, en mayúsculas. Mencione todos los autores cuando sean seis o menos; si son siete o más, incluya los seis primeros y agregue et al». Limite la puntuación a comas que separen los autores entre sí. Sigue el título completo del artículo, en su idioma original. Luego, el nombre de la revista en que apareció, abreviado según el estilo usado por el Index Medicus: año de publicación; volumen de la revista: página inicial y final del artículo. Ejemplo: 16. GONZÁLEZ A, NICOVANI S, MASSARDO L, AGUIRRE V, CERVILLA V, LANCHBURY JS, et al. Influence of the HLA-DR beta shared epitope on susceptibility to and clinical expression of rheumatoid arthritis in Chilean patients. Ann Rheum Dis 1997;56:191-193.

b) Para Capítulos en Libros.

Ejemplo: 18. CROXATTO H. Prostaglandinas. Funciones endocrinas del riñón. En: Pumarino H, ed. Endocrinología y Metabolismo. Santiago: Editorial Andrés Bello, 1984; 823-840.

c) Para artículos en formato electrónico: citar autores, título del artículo y revista de origen tal como para su publicación en papel, indicando a continuación el sitio electrónico donde se obtuvo la cita y la fecha en que se hizo la consulta. Ej: Rev Méd Chile 2003; 131: 473-482. Disponible en: www.scielo.cl [Consultado el 14 de mayo de 2006].

Para otros tipos de publicaciones, aténgase a los ejemplos dados en los «Requisitos Uniformes para los Manuscritos Sometidos a Revistas Biomédicas».

Los autores son responsables de la exactitud de sus referencias. 


\subsection{Tablas}

Presente cada Tabla en hojas aparte, separando sus celdas con doble espacio (1,5 líneas). Numere las Tablas en orden consecutivo y asígneles un título que explique su contenido sin necesidad de buscarlo en el texto del manuscrito (Título de la Tabla). Sobre cada columna coloque un encabezamiento corto o abreviado. Separe con líneas horizontales solamente los encabezamientos de las columnas y los títulos generales. Las columnas de datos deben separarse por espacios y no por líneas verticales. Cuando se requieran notas aclaratorias, agréguelas al pie de la Tabla. Use notas aclaratorias para todas las abreviaturas no estándar. Cite cada Tabla en su orden consecutivo de mención en el texto del trabajo.

\subsection{Figuras}

Denomine «Figura» a toda ilustración que no sea Tabla (Ejs: gráficos, radiografías, electrocardiogramas, ecografías, etc.). Los gráficos deben ser dibujados por un profesional, 0 empleando un programa computacional adecuado. Envíe 3 reproducciones de cada Figura, en blanco y negro, en tamaño $9 \times 12 \mathrm{~cm}$. Las letras, números, flechas o símbolos deben verse claros y nítidos y deben tener un tamaño suficiente como para seguir siendo legibles cuando la Figura se reduzca de tamaño en la publicación. Sus títulos y leyendas no deben aparecer en la Figura sino que se incluirán en hoja aparte, para ser compuestos por la imprenta. En el respaldo de cada Figura debe anotarse, con lápiz de carbón o en una etiqueta pegada, el número de la Figura, el nombre del autor principal, y una flecha indicando su orientación espacial. Los símbolos, flechas o letras empleadas en las fotografías de preparaciones microscópicas, deben tener un tamaño y contraste suficientes para distinguirlas de su entorno. Cite cada Figura en el texto, en orden consecutivo. Si una Figura reproduce material ya publicado, indique su fuente de origen y obtenga permiso escrito del autor y del editor original para reproducirla en su trabajo.
Las fotografías de pacientes deben cubrir parte(s) de su rostro para proteger su anonimato.

La publicación de Figuras en colores debe ser consultada con la Revista, su costo es fijado por los Impresores y deberá ser financiado por los autores.

3. 11. Leyendas para las Figuras

Presente los títulos y leyendas de las Figuras en una página separada. Identifique y explique todo símbolo, flecha, número o letra que haya empleado para señalar alguna parte de las ilustraciones. En la reproducción de preparaciones microscópicas, explicite la ampliación y los métodos de tinción empleados.

3.12. Unidades de medida

Use unidades correspondientes al sistema métrico decimal. Las abreviaturas o símbolos que se emplean con mayor frecuencia, aparecen listadas periódicamente en la Revista.

4. Las separatas deben ser solicitadas por escrito a la Revista, después de recibir la comunicación oficial de aceptación del trabajo. Su costo debe ser cancelado por el autor.

5. Guía de Exigencias para los Manuscritos y Declaración de Responsabilidad de Autoría

Ambos documentos deben ser entregados junto con el manuscrito, cualquiera sea su naturaleza: artículo de investigación, caso clínico, artículo de revisión, carta al editor, u otra, proporcionando los datos solicitados y la identificación y firmas de todos los autores. En la Revista se publican facsímiles para este propósito, pudiendo agregarse fotocopias si fuera necesario. Cuando la revisión editorial exija una nueva versión del trabajo, con cambios sustantivos, los Editores podrán pedir que los autores renueven la Declaración de Responsabilidad de Autoría para indicar su acuerdo con la versión que se publicará. 


\section{INSTRUCTIONS FOR AUTHORS WHO SUBMIT MANUSCRIPTS IN ENGLISH}

1. Revista Médica de Chile accepts manuscripts to be published in English when:

a) The work was done in an English-speaking country, by authors resident in that country, or

b) The authors reside in a non-Spanish-speaking country and they feel themselves unable to prepare a manuscript in Spanish.

In both circumstances, the authors must submit a text in which English has been revised/improved by individuals familiarized with scientific/medical writing in English.

2. Manuscripts are considered with the understanding that they have not been published in print or electronic format and are not under consideration by another publication or electronic medium. The manuscript's eligibility for publication is decided by the editors after external peer-review.

3. The manuscript format should be adapted to the style shown by recent publications in Revista Médica de Chile, that can be accessed at the website www.scielo.cl. All manuscripts should follow the recommendations established in the «niform Requirements for Manuscripts Submitted to Biomedical Journals» by the International Committee of Medical Journal Editors, updated in February 2006 and accessible in the website www.icmje.org.

4. The manuscript should be submitted electronically to revmedchile@smschile.cl. All submissions should include a cover letter, and the manuscript, Tables and Figures, all in the same file if possible.

5. The manuscript should be prepared in PDF format, preferably in WORD, in letter-size pages numbered consecutively in the upper right comer. Double-space all the text, using font size 12, with justification to the left margin only. At the bottom of the Title Page provide a word count for text only, from the Introduction to the end of Discussion (excluding Title Page, Abstract, Acknowledgements, References, Tables, Figures). The typical length is up to 2,500 words in Research Articles or 3,000 words in Reviews. Case Reports should not exceed 1,500 words, they can add up to 2 Tables or Figures and 20 References. Letters to the Editor can be extended up to 1,000 words, adding up to 6 references and 1 Table or Figure.

6. Title page with: 1) The manuscript title and a short title; 2) Authors' first name and last name (Middle initial can be added at authors' discretion), identifying with roman numerals at the end of each authors' last name: 3) Work site (Division, Department, Institution); 4) Identification of the corresponding author, including e-mail, print mail address and telephone and fax numbers; 5) Financial support for this work (including research or project support/funding).

6) Word count (see above in 5.). Each following Section must begin in a new page.
7. Abstract, with a structured format when pertinent and a recommended maximum length of 250 words. The editors will prepare a translation into Spanish and the Abstract will be published both in English and Spanish. For indexing purposes, the authors should provide 3 to 5 key words selected from Index Medicus, Medical Subjects Headings, accessible at www.nlm.nih.gov/mesh/.

\section{Introduction.}

9. Material and Methods (or Patients and Methods). When the study was done in humans, the protocol's approval by an institutional Ethics Committee must be identified.

\section{Results.}

\section{Discussion and conclusions.}

\section{Acknowledgements.}

13. References. Numbered in the order they appear in the text, with the format according to Index Medicus and exemplified in the above mentioned Uniform Requirements». List all authors up to 7; if more than 7, list the first 6 followed by et al.

14. Tables and Figures. Include each of them in a separate and numbered page. When material already published is reproduced in a Table or Figure, its original source should be identified and written permission from publishers (or other copyright owner) must be provided. The cost of publication of color Figures must be consulted to the editors and covered by be authors when the article is accepted.

15. Include statements signed by each author for authorship responsibility and contributions; financial disclosure; and copyright transfer to Revista Médica de Chile.

16. Include a statement signed by corresponding author that written permission has been obtained from all persons named in the Acknowledgements.

17. Authors should identify potential conflicts of interest, including specific financial interests relevant to their manuscript, in their cover letter. Authors without financial interests in the manuscript should indicate no such interest.

18. Accepted manuscripts are edited in accordance with the above mentioned «niform Requirements»and the journal's style. A first galley proof is sent to the corresponding author electronically for approval. Authors are responsible for all statements made in their work, including the accuracy of the references and changes made by the editors, authorized by the corresponding author. 